Um estudo sobre o espaço de trabalho informativo e o acompanhamento em equipes ágeis de desenvolvimento de software

Renan de Melo Oliveira

\author{
DisSERTAÇÃO APRESENTADA \\ AO \\ Instituto DE MATEMÁticA E EstatísticA \\ DA \\ Universidade DE SÃo PAUlo \\ PARA \\ OBTENÇÃO DO TÍTULO \\ $\mathrm{DE}$ \\ Mestre em CiÊnCIAS \\ Programa: Ciência da Computação \\ Orientador: Prof. Dr. Alfredo Goldman
}

São Paulo, janeiro de 2012 
Um estudo sobre o espaço de trabalho informativo e o acompanhamento em equipes ágeis de desenvolvimento de software

Esta dissertação trata-se da versão original do aluno Renan de Melo Oliveira. 


\title{
Um estudo sobre o espaço de trabalho informativo e o acompanhamento em equipes ágeis de desenvolvimento de software
}

\author{
Esta dissertação contém as correções e alterações \\ sugeridas pela Comissão Julgadora durante a defesa \\ realizada por Renan de Melo Oliveira em 24/01/2012. \\ O original encontra-se disponível no Instituto de \\ Matemática e Estatística da Universidade de São Paulo.
}

Comissão Julgadora:

- Prof. Dr. Alfredo Goldman (orientador) - IME-USP

- Prof. Dr. Marco Aurélio Gerosa - IME-USP

- Prof. Dr. Cleidson Ronald Botelho de Souza - UFPA 


\section{Agradecimentos}

Primeiramente, gostaria de agradecer a Deus, pela vida, por meu motivo de existência. Sem Ele, este trabalho não faria sentido. Toda a honra e glória a Ele - Soli Deo Gloria.

Agradeço também a minha família, minha mãe Paulette por toda a orientação que me deu durante a vida, por ser meu exemplo de luta e vida cristã - sendo minha referência de vida. Minha tia Lúcia, por todo o auxílio dado neste período e por todo o cuidado. Minha avó Dirce, por todo o carinho que sempre me demonstrou, e por ter me dado a infraestrutura humana necessária para a realização deste trabalho. Pela minha noiva Stephanie, por ser paciente e me apoiar em todo o percurso deste trabalho, por entender e por me motivar neste período.

Ao meu orientador Prof. Dr. Alfredo Goldman, que sempre foi paciente com minhas entregas deste trabalho durante madrugadas, sempre realizou revisões atenciosas, sempre esteve engajado em me apontar o caminho a seguir, tanto neste trabalho, quanto durante a escrita de artigos e apresentações em conferências. Também por me mostrar que é possível realizar um trabalho significativo na academia sem perder a conexão e a dinamicidade da indústria. Resumidamente, por ter me orientado de verdade, não por obrigação, mas com honestidade e clareza. 


\section{Resumo}

Podemos encontrar em métodos ágeis como no Extreme Programming [Beck, 1999, Beck e Andres, 2006], no Scrum [Schwaber, 2008], no Crystal Clear [Cockburn, 2005], e no Lean Software Development [Poppendieck e Poppendieck, 2007] referências relacionadas à manipulação e disponibilização de métricas e outras informações no ambiente de desenvolvimento. Neste trabalho, estas atividades são consideradas como tarefas de acompanhamento ágil.

Observamos em métodos ágeis a importância de se realizar ações (práticas) baseadas em alguns princípios como guidelines [Poppendieck e Poppendieck, 2007]. Por isto, realizamos uma análise bibliográfica na literatura disponível para compreender princípios ágeis que possam afetar na execução deste tipo de tarefa, além de descrever sobre métricas no contexto de métodos ágeis e engenharia de software.

Apesar da bibliografia, não encontramos pesquisas experimentais com o objetivo de levantar e (ou) compreender aspectos relacionados ao sucesso na aplicação deste tipo de tarefa em ambientes de desenvolvimento. Para isto, realizamos neste trabalho uma pesquisa experimental com este objetivo, utilizando uma abordagem de métodos mistos sequenciais de pesquisa [Creswell, 2009]. Escolhemos aplicar esta pesquisa em um conjunto de quinze equipes de desenvolvimento ágil, reunidas em realizações da disciplina "Laboratório de Programação Extrema" do IME-USP nos anos de 2010 e 2011.

Esta pesquisa foi realizada em quatro fases sequenciais. Na primeira fase, realizamos sugestões para as equipes de desenvolvimento vinculadas ao acompanhamento ágil a fim de levantar aspectos valiosos em sua aplicação utilizando uma abordagem baseada em pesquisa-ação [Thiollent, 2004]. Baseado nestes resultados, agrupamos alguns destes aspectos como "heurísticas para o acompanhamento ágil", modelo similar ao de Hartmann e Dymond [2006]. Na segunda fase, aplicamos um questionário para verificar a validade das heurísticas levantadas. Na terceira fase, realizamos entrevistas semi-estruturadas com alguns integrantes destas equipes para compreender o "por quê" da validade das heurísticas levantadas, sendo analisadas com técnicas de teoria fundamentada em dados (grounded theory) [Strauss e Corbin, 2008]. Na quarta fase, reaplicamos o questionário da fase 2 em outro ambiente para triangulação da validade das heurísticas.

Como resultado final da pesquisa, estabelecemos um conjunto de heurísticas para o acompanhamento ágil, além de avaliações quantitativas de seus aspectos em dois ambientes, juntamente a diversas considerações qualitativas sobre sua utilização. Realizamos um mapeamento tanto das heurísticas como de seus conceitos relacionados à literatura disponível, identificando aspectos já existentes porém expandidos pela realização da pesquisa, e aspectos ainda não discutidos que podem ser considerados como novos na área.

Palavras-chave: espaço de trabalho informativo, big visible charts, métricas, acompanhamento ágil. 


\section{Abstract}

It is possible to find on the agile methods several references related to managing and displaying relevant information in a software development worplace. These references are available in agile methods such as Extreme Programming [Beck, 1999, Beck e Andres, 2006], Scrum [Schwaber, 2008], Crystal Clear [Cockburn, 2005], Lean Software Development [Poppendieck e Poppendieck, 2007], etc. In our work, we name this kind of activity as agile tracking, relating it to the tracker role defined by Beck [1999].

We noticed the importance of performing actions (practices) based on a set of principles as guidelines [Poppendieck e Poppendieck, 2007], which is deeply associated with agile methods. Taking this matter into account, we performed a literature review in order to discuss a few agile principles that could affect the execution of agile tracking related tasks. We also describe a few works directly related to metrics, both on the agile methods and on the software engineering area in general.

Even with related references in the literature, we could not find empirical researches with the goal of raising/understanding aspects related to successfully performing this kind of task on agile environments, which could be helpful on managing informations and informative workspaces. In order to accomplish this goal, we performed a research using a sequential mixed research methods approach [Creswell, 2009]. We chose to apply our research on a set of fifteen agile teams gathered on the IME-USP's "Laboratory of Extreme Programming" course in 2010 and 2011.

This research was performed in four sequential phases. In the first phase, we made several suggestions to the agile teams, regarding agile tracking, using and approach based on action research [Thiollent, 2004]. We used this initial approach in order to gather relevant aspects of their use of agile tracking. Based on these results, we clustered some aspects as "heuristics for agile tracking", the same model used by Hartmann e Dymond [2006]. In phase two, we applied a survey to evaluate the validity of the proposed heuristics. In phase three, we gathered data from a few semi-structured interviews performed on team members in order to understand the reasons behind the proposed heuristics, in which we used grounded theory [Strauss e Corbin, 2008] coding techniques for analysis. In phase four, we reapplied phase two survey on a different environment in order to triangulate the heuristics evaluation data gathered on phase 2 .

As the result of this empirical research, a set of heuristics were established with quantitative evaluation data and several related qualitative concepts. We also relate the set of heuristics and associated concepts with other works in agile methods, highlighting aspects expanded by this research and some others that we could not directly find in the literature, which could be considered as new in the area.

Keywords: informative workspace, big visible charts, metrics, tracking. 


\section{Sumário}

$\begin{array}{ll}\text { Lista de Figuras } & \text { ix }\end{array}$

Lista de Tabelas $\quad$ xi

1 Introdução $\quad \mathbf{1}$

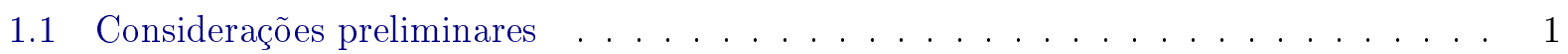

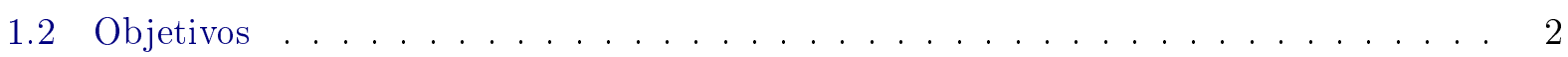

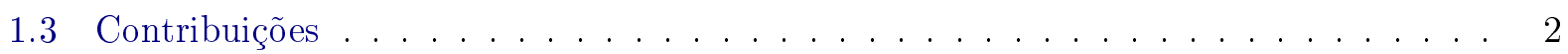

1.4 Organização do trabalho . . . . . . . . . . . . . . . . . . 3

2 Conceitos básicos $\quad 5$

2.1 Métodos ágeis de desenvolvimento de software . . . . . . . . . . . . . 5

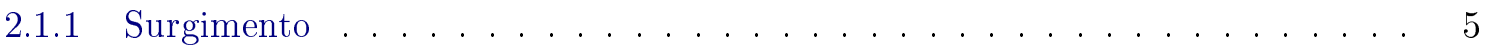

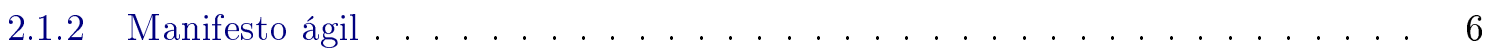

2.2 Acompanhamento ágil . . . . . . . . . . . . . . . . . . 7

2.2 .1 Programação Extrema . . . . . . . . . . . . . . . . 7

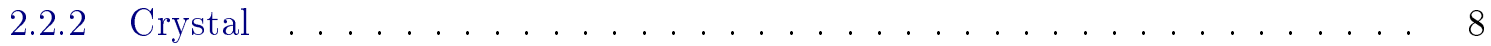

2.2 .3 Lean Software Development . . . . . . . . . . . . . . . . . . 8

2.2 .4 Scrum . . . . . . . . . . . . . . . . . . . . . 10

2.3 Métricas de acompanhamento . . . . . . . . . . . . . . . . . 11

2.3 .1 Definições . . . . . . . . . . . . . . . . . . . . 11

2.3.2 Métricas em métodos Ágeis . . . . . . . . . . . . . . . . . 11

2.3 .3 Escolha de métricas . . . . . . . . . . . . . . . . . . . . 12

3 Princípios ágeis no acompanhamento $\quad 17$

3.1 Feedback . . . . . . . . . . . . . . . . . . . . . 17

3.2 Adaptabilidade . . . . . . . . . . . . . . . . . . . . 18

3.3 Humanidade . . . . . . . . . . . . . . . . . . . . . . . 20

3.4 Foco e fluxo de trabalho . . . . . . . . . . . . . . . . . . . 21

3.5 Comunicação, reflexão e aprendizado . . . . . . . . . . . . . . . . . 23

3.6 Interação com o cliente . . . . . . . . . . . . . . . . . . . . . . 24

4 Métodos de pesquisa $\quad 25$

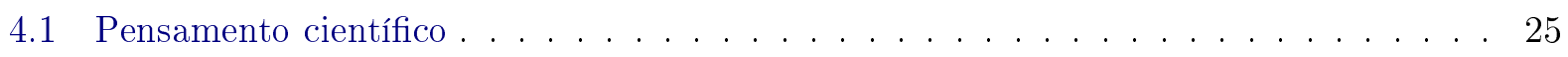

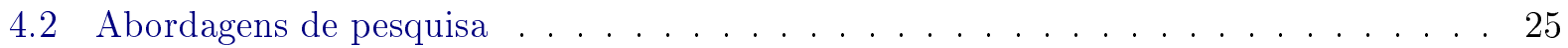

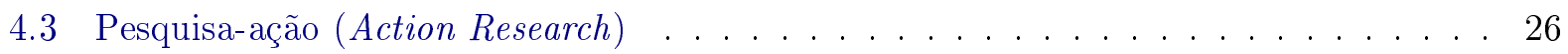


4.4 Pesquisa fundamentada em dados (Grounded Theory) . . . . . . . . . . . . 27

4.5 Métodos mistos de pesquisa . . . . . . . . . . . . . . . . . . . . 29

5 Pesquisa experimental $\quad 31$

5.1 Proposta de contribuição . . . . . . . . . . . . . . . . . . . . . . . 31

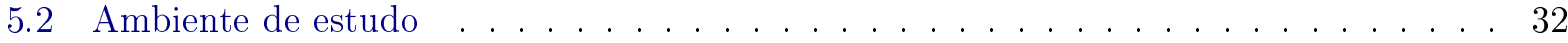

5.3 Método utilizado . . . . . . . . . . . . . . . . . . . . . 35

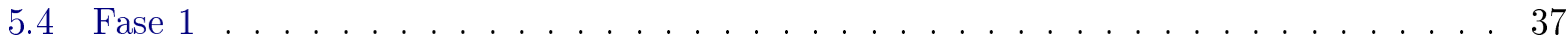

5.4 .1 Dados coletados . . . . . . . . . . . . . . . . . . . 38

5.4 .2 Análise e proposta de heurísticas . . . . . . . . . . . . . . . . 45

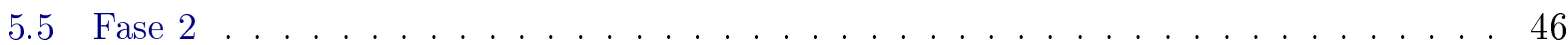

5.5.1 Formulação do questionário de validação . . . . . . . . . . . . . . . . 46

5.5 .2 Resultados . . . . . . . . . . . . . . . . . . . . . 48

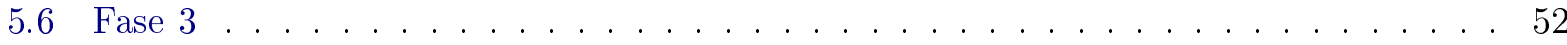

5.6 .1 Formulação da entrevista exploratória . . . . . . . . . . . . . . . . 52

5.6 .2 Codificação . . . . . . . . . . . . . . . . . . . . 53

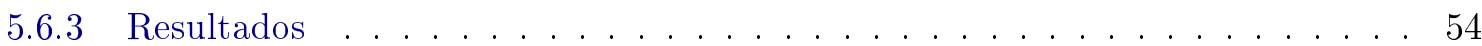

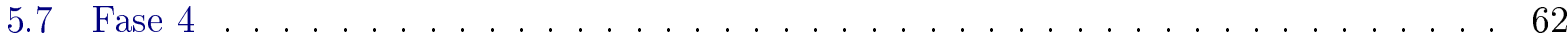

5.7 .1 Aplicação do questionário . . . . . . . . . . . . . . . . . . . . . 62

5.7 .2 Resultados . . . . . . . . . . . . . . . . 63

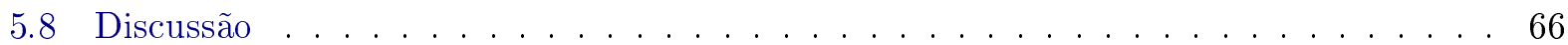

5.8 .1 Heurísticas levantadas . . . . . . . . . . . . . . . . 66

5.8 .2 Avaliação das heurísticas . . . . . . . . . . . . . . . . . . . . 67

5.8 .3 Conceitos relacionados às heurísticas . . . . . . . . . . . . . . . . 69

5.8 .4 Limitações e ameaças a validade . . . . . . . . . . . . . . . . . . 70

6 Conclusões $\quad 73$

6.1 Considerações Finais . . . . . . . . . . . . . . . . . . . . . . . 74

6.2 Sugestões para Pesquisas Futuras ． . . . . . . . . . . . . . . . 75

A Transcrição e análise das entrevistas da fase 3 da pesquisa $\quad 77$

A.1 Coach - Equipe: Archimedes . . . . . . . . . . . . . . . . . . . . 77

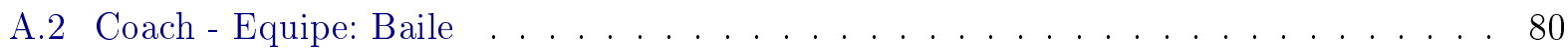

A.3 Integrante - Equipe: Calopsita . . . . . . . . . . . . . . . . . 83

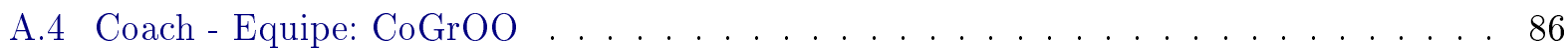

A.5 Coach 1 - Equipe: Mezuro _ . . . . . . . . . . . . . . . . . . . 9 90

A.6 Coach 2 - Equipe: Mezuro . . . . . . . . . . . . . . . . . . . . 93

$\begin{array}{ll}\text { Referências Bibliográficas } & 97\end{array}$ 


\section{Lista de Figuras}

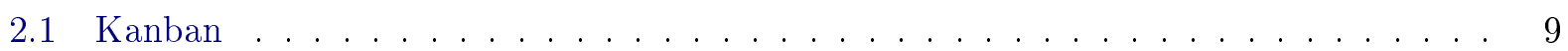

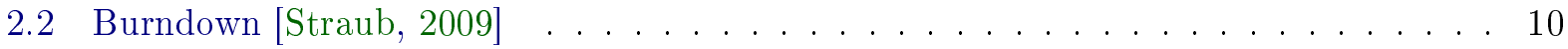

3.1 Pontos da Retrospectiva $[$ Kua, 2007] . . . . . . . . . . . . . . . . . 23

4.1 Ciclo de vida da pesquisa-ação[O'Brien, 2001] . . . . . . . . . . . . . . . 27

5.1 Foto do espaço de trabalho da equipe Atletismo . . . . . . . . . . . . . . . . . 34

5.2 Foto do espaço de trabalho da equipe Baile . . . . . . . . . . . . . . . 35

5.3 Foto do espaço de trabalho da equipe Ingresso na Pós . . . . . . . . . . . . . 35

5.4 Método misto sequencial: Fases da pesquisa experimental . . . . . . . . . . . . 36

5.5 Filtro: Proximidade da reunião diária. . . . . . . . . . . . . . . . 48

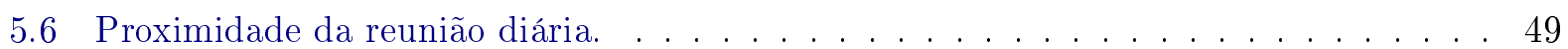

5.7 Filtro: Acompanhamento coletivo. . . . . . . . . . . . . . . . . . . . 49

5.8 Acompanhamento coletivo. . . . . . . . . . . . . . . . . . . . . . 49

5.9 Filtro: Tratamento de problemas específicos . . . . . . . . . . . . . . . . . 49

5.10 Tratamento de problemas específicos . . . . . . . . . . . . . . . . . 50

5.11 Filtro: Facilidade de assimilação. . . . . . . . . . . . . . . . . . . . 50

5.12 Facilidade de assimilação. . . . . . . . . . . . . . . . . . . . . . 50

5.13 Filtro: Pareamento no acompanhamento. . . . . . . . . . . . . . . 50

5.14 Pareamento no acompanhamento. . . . . . . . . . . . . . . . . . 51

5.15 Praticidade na manipulação. . . . . . . . . . . . . . . . . . . 51

5.16 Filtro: Remoção de informações de menor valor. . . . . . . . . . . . . . . . . . . 51

5.17 Remoção de informações de menor valor. . . . . . . . . . . . . . . . . . . . 52

5.18 Filtro: Proximidade da reunião diária - 2011. . . . . . . . . . . . . . . . 63

5.19 Proximidade da reunião diária $-2011 \ldots$. . . . . . . . . . . . . . 63

5.20 Filtro: Acompanhamento coletivo - 2011 . . . . . . . . . . . . . . . . 63

5.21 Acompanhamento coletivo - 2011. . . . . . . . . . . . . . . . . . . 64

5.22 Filtro: Tratamento de problemas específicos - 2011 . . . . . . . . . . . . . . . 64

5.23 Tratamento de problemas específicos - 2011. . . . . . . . . . . . . . . 64

5.24 Filtro: Facilidade de assimilação - 2011. . . . . . . . . . . . . . . . . . 65

5.25 Facilidade de assimilação - 2011. . . . . . . . . . . . . . . . . 65

5.26 Filtro: Pareamento no acompanhamento - 2011 . . . . . . . . . . . . . 65

5.27 Pareamento no acompanhamento - 2011 . . . . . . . . . . . . . . . 65

5.28 Praticidade na manipulação - 2011 . . . . . . . . . . . . . . . . . 66 
5.29 Filtro: Remoção de informações de menor valor - 2011 . . . . . . . . . . . . . . . . 66

5.30 Remoção de informações de menor valor $-2011 \ldots \ldots$. . . . . . . . . . . . 66 


\section{Lista de Tabelas}

5.1 Projetos de software analisados $-2010 \ldots \ldots$. . . . . . . . . . . 32

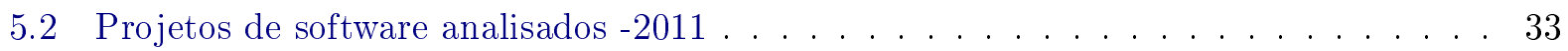

5.3 Baile - Intervenções . . . . . . . . . . . . . . . . . . . . . . . . 39

5.4 Calopsita - Intervenções . . . . . . . . . . . . . . . . . . . . 39

5.5 Atletismo - Intervenções . . . . . . . . . . . . . . . . . . . . . . 40

5.6 Mezuro - Intervenções . . . . . . . . . . . . . . . . . . . 41

5.7 Dojo Online - Intervenções . . . . . . . . . . . . . . . . . . . . . . . . . . 42

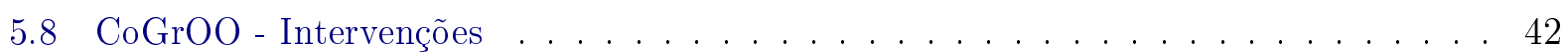

5.9 Ingresso na Pós - Intervenções . . . . . . . . . . . . . . . . . . . . . 43

5.10 Archimedes - Intervenções . . . . . . . . . . . . . . . . . . . . 44

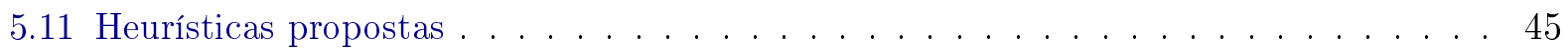

5.12 Questionários - Dados de 2010 e $2011 \ldots \ldots$. . . . . . . . . . . 68 


\section{Capítulo 1}

\section{Introdução}

\subsection{Considerações preliminares}

A engenharia de software é a área dentro da computação que busca melhores formas de se especificar, desenvolver, e manter software. Um dos assuntos tratados nesta área do conhecimento são processos de desenvolvimento de software. Existe diversidade nos modelos de desenvolvimento e podemos encontrar diferentes linhas de pensamento ao analisarmos cada uma destas abordagens.

Em meados de 1990, algumas abordagens de desenvolvimento com características similares se popularizaram como um movimento contrário à forma com que software estava sendo desenvolvido no mercado. Posteriormente, algumas destas abordagens vieram a ser conhecidas como métodos ágeis de desenvolvimento de software.

Os métodos ágeis de desenvolvimento de software possuem diversas características em comum, e normalmente tratam o modelo de desenvolvimento com base na aplicação de uma série de princípios no ambiente por meio da realização de um conjunto de práticas - conceito que é abordado neste trabalho. Dentre as principais características desta lista de métodos, está a capacidade de propor um processo de desenvolvimento considerado por alguns como leve, porém suficiente [Cockburn, 2005]. Apesar do vínculo com princípios e práticas, alguns autores como Shore e Warden [2008] afirmam que desenvolvimento ágil não é um processo específico, e sim uma filosofia, uma forma de pensar sobre o desenvolvimento de software.

Juntamente com diversos trabalhos relacionados aos métodos ágeis, uma das contribuições mais importantes dentre as encontradas na área é o Manifesto Ágil [Beck et al., 2001a]. O Manifesto Ágil foi o resultado de uma reunião entre adeptos de diferentes métodos ágeis e pretende demonstrar pontos em comum encontrados nas abordagens descritas nestes métodos. Shore e Warden [2008] afirmam que o manifesto ágil, com seus 4 valores e 12 princípios, é a descrição abrangente da forma de pensamento do desenvolvimento ágil de software.

Em diversos métodos ágeis diferentes tarefas relacionadas com a manipulação de informações úteis para a equipe de desenvolvimento podem ser encontradas, bem como a disponibilização destas informações no ambiente de trabalho desta equipe, muitas vezes conceituadas como práticas para serem realizadas pela equipe. Tarefas e práticas relacionadas a este tipo de recurso podem ser encontradas em diversos métodos ágeis como no Extreme Programming [Beck, 1999, Beck e Andres, 2006], no Scrum [Schwaber, 2008], no Crystal Clear [Cockburn, 2005] e no Lean Software Development [Poppendieck e Poppendieck, 2007]. Neste trabalho, consideramos tarefas relacionadas com a manipulação e disponibilização de informações úteis para a equipe de desenvolvimento como tarefas de acompanhamento ágil - similar a definição do papel do tracker no Extreme Programming [Beck, 1999].

O papel do tracker trata diretamente a coleta e acompanhamento de métricas em um ambiente de desenvolvimento ágil [Beck, 1999]. Neste mesmo contexto de métricas, Beck [1999] menciona a importância da forma de disponibilização destas métricas por meio do conceito Big Visible Charts. Consideramos então que o tema do acompanhamento ágil envolve o que normalmente é tratado utilizando-se termos como: Espaço de trabalho informativo [Beck e Andres, 2006], XP Card Wall 
[Sharp et al., 2006], radiadores de informação [Cockburn, 2005], métricas no desenvolvimento ágil [Beck, 1999], etc. A análise do que pode ser considerado como práticas de acompanhamento ágil, de acordo com a definição estabelecida neste trabalho, analisando a literatura base de métodos ágeis, é um dos objetivos secundários deste trabalho.

\subsection{Objetivos}

Este trabalho possui como objetivo primário ajudar a responder a seguinte pergunta de pesquisa:

- Como melhor usar as técnicas de acompanhamento ágil para auxiliar equipes ágeis de desenvolvimento de software?

Para auxiliar a responder esta pergunta, estabelecemos os seguintes objetivos:

1. Pesquisar na literatura quais práticas podem ser associadas ao acompanhamento ágil, auxiliando em sua abrangência e definição para este trabalho;

2. Analisar e discutir como o acompanhamento ágil deve ser executado em relação a princípios encontrados em métodos ágeis;

3. Realizar uma pesquisa experimental em ambientes de desenvolvimento para identificar e compreender alguns aspectos relevantes na utilização do acompanhamento ágil em ambientes reais. Com esta pesquisa experimental pretendemos:

(a) Levantar aspectos úteis para o acompanhamento ágil a partir das experiências das equipes;

(b) Compreender as razões por detrás da utilidade de cada um dos aspectos levantados.

\subsection{Contribuições}

Consideramos que a própria análise da literatura de métodos ágeis, identificando práticas de diferentes métodos que possam ser consideradas como manipulação e disponibilização de informações, seja uma contribuição inicial, pois permite uma visão geral deste assunto no contexto de métodos ágeis.

A adaptabilidade é um dos conceitos mais importantes encontrados em métodos ágeis, e é uma das principais idéias que justificam a utilização do acompanhamento ágil em equipes de desenvolvimento de software. A adaptabilidade em métodos ágeis presume que a efetividade de uma ação pode variar de acordo com o contexto em que esta ação é realizada. Por isso, sugere-se que equipes de desenvolvimento de software adaptem práticas encontradas em métodos ágeis levando em consideração seu contexto [Poppendieck e Poppendieck, 2007]. Apesar disto, é indicado que práticas sejam adaptadas baseando-se em um conjunto de princípios, também encontrados em métodos ágeis [Poppendieck e Poppendieck, 2007]. Devido à esta característica peculiar, consideramos importante uma reflexão sobre quais princípios podem influenciar na realização do acompanhamento ágil em uma equipe de desenvolvimento. Esta análise e reflexão pode ser útil, pois permite a compreensão de alguns princípios encontrados em métodos ágeis, além de como o acompanhamento ágil deve se posicionar em relação a estes princípios. Esta discussão também é considerada como contribuição relevante deste trabalho.

Planejamos a realização de uma pesquisa experimental. Para isto, realizamos uma descrição e análise de alguns métodos de pesquisa que foram aplicados neste estudo, bem como a descrição de alguns conceitos nesta assunto.

Realizamos uma pesquisa experimental buscando compreender alguns aspectos úteis na realização do acompanhamento ágil em equipes ágeis de desenvolvimento. Nesta pesquisa, visamos 
inicialmente levantar estes aspectos em 8 projetos de software-livre utilizando uma abordagem baseada em pesquisa-ação [Thiollent, 2004]. Tendo alguns aspectos levantados, tratamos estes aspectos como heurísticas para o acompanhamento ágil. Após esse levantamento, realizamos um questionário com questões fechadas para reforçar a validade das heurísticas levantadas no ambiente estudado, de forma que pudéssemos analisar estes dados de forma quantitativa. Também realizamos um conjunto de seis entrevistas semi-estruturadas neste ambiente para identificar as razões por detrás da utilidade de cada heurística, utilizando técnicas da teoria fundamentada em dados [Strauss e Corbin, 2008] para codificar as informações coletadas e extrair significado das mesmas.

\subsection{Organização do trabalho}

Este trabalho está estruturado em seis capítulos e um apêndice.

O capítulo 1 introduz alguns conceitos básicos sobre o trabalho, define seus objetivos, descreve a proposta de algumas contribuições propostas e detalha seu conteúdo e forma de organização.

No capítulo 2 realizamos uma revisão bibliográfica a respeito do tema tratado. Na seção 2.1 apresentamos brevemente o tema de métodos ágeis para o leitor - afim de que este possua ao menos uma compreensão básica sobre o assunto. Na seção 2.2 definimos o conceito de acompanhamento ágil e descrevemos na literatura básica de métodos ágeis algumas práticas que podem ser associadas à este termo. Além disto, realizamos uma descrição a respeito de alguns trabalhos diretamente relacionados a métricas no contexto de métodos ágeis e de engenharia de software na seção 2.3.

No capítulo 3 realizamos uma discussão sobre o acompanhamento ágil, tendo-se em vista um conjunto de princípios encontrados na literatura de métodos ágeis que podem afetar em como o acompanhamento ágil é realizado.

No capítulo 4 descrevemos algumas referências bibliográficas no tema de métodos de pesquisa. Na seção 4.1 descrevemos brevemente o pensamento científico e conceitos que permeiam este tema. Indicamos também algumas diferenças entre abordagens quantitativas e qualitativas na seção 4.2 e descrevemos alguns métodos de pesquisa relevantes para o posicionamento e realização deste trabalho nas seções $4.3,4.4$ e 4.5 .

A pesquisa experimental que realizamos está descrita no capítulo 5. A definição da proposta de contribuição, o ambiente estudado e o método de pesquisa adotado são descritos nas seções 5.1, 5.2 e 5.3 respectivamente. Realizamos esta pesquisa experimental em quatro fases distintas, cada uma delas possui uma seção reservada para descrever a abordagem metodológica utilizada, os instrumentos utilizados, os dados coletados e a análise realizada. Os detalhes das fases da pesquisa experimental estão disponíveis nas seções 5.8.2, 5.8.2, 5.6 e 5.7. Também realizamos uma discussão sobre os resultados obtidos e associando-os com trabalhos presentes na literatura na seção 5.8.

Descrevemos as conclusões deste trabalho, demonstrando os resultados da análise da bibliografia, a discussão sobre os princípios ágeis e os resultados obtidos na pesquisa experimental no capítulo 6 , em que realizamos algumas considerações finais, bem como sugestões para pesquisas futuras.

Também disponibilizamos um conjunto dos dados brutos bem como memorandos de codificação, ambos utilizados na fase 2 da pesquisa experimental, para que este tipo de informação seja de fácil acesso ao leitor. Estes itens podem ser encontrados no apêndice A. 


\section{Capítulo 2}

\section{Conceitos básicos}

\subsection{Métodos ágeis de desenvolvimento de software}

Conhecemos como Engenharia de Software a área de conhecimento dentro da Ciência da Computação que estuda aspectos relacionados ao desenvolvimento de software. Esta área possui como objetivo encontrar melhores formas de se especificar, construir e se manter software.

Em meados de 1990, alguns profissionais e pensadores na área de desenvolvimento de software sugeriram métodos de desenvolvimento que partilhavam de alguns aspectos em comum [Beck et al., 2001b]. Futuramente estes métodos vieram a ser conhecidos como métodos ágeis de desenvolvimento de software.

\subsubsection{Surgimento}

Algumas razões levaram ao surgimento dos métodos ágeis de desenvolvimento de software. Algumas características deste surgimento são discutidas abaixo.

Beedle et al. [2000] criticam abordagens como a do CMM (Capability Maturity Model) para o desenvolvimento de software. Estes autores afirmam que a abordagem do CMM realiza suposições incorretas a respeito da realidade do processo de desenvolvimento. Isto ocorre pois o CMM se baseia em níveis de maturidade com nomes como "inicial", "repetível", "definido", "administrado", "otimizado". Para Beedle et al. [2000], o CMM se baseia em alguns conceitos que não estão de acordo com a natureza do processo de desenvolvimento de software ao estabelecer níveis como "definido" e "repetível". A definição destes níveis é criticada por Beedle et al. [2000], pois depende que alguns aspectos como problemas, soluções, desenvolvedores e ambiente organizacional possuam características de "definidas/repetíveis", o que requer um ambiente de desenvolvimento não caótico. Para isto, [Beedle et al., 2000] indicam a necessidade de uma abordagem mais "adaptativa" comparada a uma abordagem "definida/repetível".

Cockburn [2002] também discute a respeito da natureza do processo de desenvolvimento de software. Este autor realiza uma classificação entre diversos tipos de jogos e nesta classificação considera o desenvolvimento de software como um jogo cooperativo finito, orientado a objetivo. Ao contrário desta classificação, Cockburn [2002] afirma que muitos consideram o processo de desenvolvimento de software é como o xadrez, um jogo posicional. Cockburn [2002] considera que por esta razão muitos consideram que pode-se facilmente substituir um desenvolvedor por um outro, apenas mantendo-se uma documentação do software - caso o processo de desenvolvimento utilizado esteja baseado nesta documentação. Este autor afirma que esta estratégia não é eficiente para o processo de desenvolvimento de software.

O termo "Métodos ágeis de desenvolvimento de software" se popularizou após um encontro entre alguns programadores realizado de 11 a 13 de fevereiro de 2001 nas montanhas Wasatch, Utah, Estados Unidos [Williams e Cockburn, 2003]. Os integrantes desta reunião possuíam, em sua maioria, experiência em desenvolvimento de software e muitos deles já haviam publicado livros e trabalhos tratando de novas abordagens de desenvolvimento. Como resultado desta reunião, formou- 
se uma declaração com um conjunto de afirmações em que todos os integrantes concordavam, esta declaração ficou conhecida como Manifesto ágil [Beck et al., 2001a].

O Manifesto ágil foi fundamental para a unificação das abordagens propostas pelos integrantes da reunião de Wasatch, pois declara uma priorização comum de valores entre suas propostas de processo de desenvolvimento. Após a definição do Manifesto Ágil, diversas abordagens que partilhavam das declarações realizadas neste manifesto vieram a ser conhecidas como métodos ágeis de desenvolvimento de software.

\subsubsection{Manifesto ágil}

No Manifesto ágil são declaradas algumas priorizações [Beck et al., 2001a]. Seus autores afirmam valorizar:

1. Indivíduos e iteração entre eles mais do que processos e ferramentas;

2. Software em funcionamento mais do que documentação abrangente;

3. Colaboração com o cliente mais que negociação de contratos;

4. Responder a mudanças mais que seguir um plano.

As similaridades entre métodos ágeis não se limitam apenas às declarações realizadas no Manifesto ágil, suas similaridades também são encontradas na descrição dos princípios deste manifesto [Beck et al., 2001b]. Este princípios podem ser descritos como:

1. Satisfação do cliente com entrega de software breve e contínua;

2. Aceitação a mudanças nos requisitos;

3. Maior frequência na entrega de software;

4. Proximidade entre pessoas de negócio e desenvolvedores;

5. Motivação;

6. Comunicação face-a-face;

7. Software executável como métrica primária de sucesso;

8. Ritmo sustentável;

9. Excelência técnica;

10. Simplicidade;

11. Equipe auto organizáveis;

12. Reflexão periódica na equipe.

O conjunto de princípios acima descrito pode ser considerado como genérico por entre os métodos ágeis disponíveis, tendo em vista a generalidade implícita na definição do manifesto ágil. A valorização destes princípios pode levar à realização de uma série de diferentes práticas em um ambiente de desenvolvimento. Este trabalho irá tratar de um conjunto de práticas associadas ao acompanhamento ágil de projetos, tema que será discutido logo a seguir. 


\subsection{Acompanhamento ágil}

Um dos aspectos interessantes encontrados em diversos métodos ágeis é a disponibilização explícita de informações para a equipe de desenvolvimento. Normalmente esta disponibilização é realizada de maneira informal, utilizando diversos recursos visuais para que estas informações estejam disponíveis no espaço de trabalho de uma equipe de desenvolvimento.

Juntamente com a disponibilização de informações para a equipe de desenvolvimento, encontramse também referências em diversos métodos ágeis a respeito de como se manipular e disponibilizar métricas e outras informações úteis no contexto da equipe de desenvolvimento.

No Extreme Programming é definido um papel específico em torno deste tipo de tarefa, o tracker [Beck, 1999]. O papel do tracker será melhor explicado posteriormente, porém este pode ser resumido por ser a "consciência" da equipe [Beck, 1999] por meio da manipulação de métricas e outras informações úteis no contexto. Tratando sobre métricas, Beck [1999] enfatiza a importância da disponibilização dessas informações por meio do conceito de Big Visible Charts.

Com base nessas definições e no papel do tracker, consideramos neste trabalho como tarefas de acompanhamento ágil aquelas que envolvem análise, escolha, manipulação e disponibilização de métricas e outras informações para a equipe de desenvolvimento. Em equipes ágeis, esta disponibilização de informações normalmente ocorre utilizando-se o próprio ambiente de trabalho desta equipe, tendo em vista a prática "Espaço de trabalho informativo" definida por Beck e Andres [2006].

Para compreendermos adequadamente o que no contexto de métodos ágeis pode ser considerado como acompanhamento ágil, dada a definição realizada neste trabalho, é necessário analisar o conjunto de métodos que tratam assuntos relacionados à este conceito, como ocorre por exemplo no Extreme Programming [Beck, 1999, Beck e Andres, 2006], no Scrum [Schwaber, 2008], no Crystal Clear [Cockburn, 2005], no Lean Software Development [Poppendieck e Poppendieck, 2007], etc.

Segue abaixo um conjunto de referências de diversos métodos ágeis relacionadas ao conceito de acompanhamento ágil.

\subsubsection{Programação Extrema}

Na Programação Extrema (Extreme Programming - XP), alguns papéis distintos são definidos dentro da equipe de desenvolvimento. Um dos papéis propostos é o papel do tracker. Beck [1999] define o papel do tracker como a consciência da equipe. Ele é o responsável por coletar os dados referentes às métricas escolhidas para acompanhamento, além de garantir que a equipe está consciente do que está sendo coletado [Beck, 1999]. Também é de sua responsabilidade observar constantemente a "visão geral" da situação.

Na Programação Extrema, as funcionalidades do software a serem desenvolvidas são planejadas em iterações. O planejamento do escopo de cada iteração no XP é acordado com o cliente em uma reunião denominada Planning Game [Beck, 1999]. A quantidade de tarefas a serem alocadas para uma próxima iteração, a ser acordada no Planning Game, é definida levando em consideração o histórico das iterações anteriores. Beck [1999] considera que o acompanhamento é o componente mais importante do XP, pois se a equipe não possuir a capacidade de comparar suas estimativas anteriores com o trabalho realizado, esta não terá a capacidade de aprender.

O tracker no XP possui como tarefa fundamental a coleta e atualização das métricas utilizadas pela equipe de desenvolvimento. Para que suas tarefas ocorram sem gerar grandes distúrbios, Beck [1999] afirma que a coleta do tracker não deve gerar grandes interrupções no trabalho do desenvolvimento da equipe, e por isto as métricas utilizadas não devem ser excessivamente coletadas.

Para Beck [1999], o tracker é o historiador da equipe e responsável por registrar métricas como defeitos encontrados, testes realizados, resultados de testes funcionais, etc. Com estas atribuições, o trabalho deste indivíduo deve prover feedback para a equipe de desenvolvimento.

Beck [1999] comenta a respeito de uma habilidade necessária pelo tracker, a capacidade de coletar a informação necessária sem atrapalhar o ambiente mais que o necessário. Apesar disto, é importante que o tracker atrapalhe um pouco o processo, pois quando isto ocorre os membros 
da equipe se atentam à informação coletada, como por exemplo quanto tempo estão levando na realização de uma tarefa específica [Beck, 1999].

O Extreme Programming também possui uma prática denominada "Espaço de trabalho informativo". Nesta prática sugere-se que informações relacionadas com o projeto sejam disponibilizadas no espaço de trabalho da equipe de desenvolvimento [Beck e Andres, 2006]. Beck [1999] afirma que um observador interessado ao entrar no espaço de trabalho de uma equipe deve ser capaz de captar o andamento geral do projeto em apenas quinze segundos [Beck e Andres, 2006]. Além disto, observando este ambiente mais atentamente, este observador também deve ser capaz de captar mais informações sobre problemas reais ou problemas potenciais da equipe [Beck e Andres, 2006].

Beck e Andres [2006] afirmam na prática "Espaço de trabalho informativo" que o espaço de trabalho deve suprir algumas necessidades humanas, como água e lanches. Para estes autores, isto permite conforto e encoraja interações sociais positivas.

\subsubsection{Crystal}

Crystal é uma família de métodos que enfatizam aspectos como entrega frequente, comunicação próxima e otimização reflexiva [Cockburn, 2005]. Cockburn, criador do Crystal, considera que a realidade de equipes com poucos integrantes e outras com muitos integrantes são muito diferentes para partilharem de um mesmo método, e por isto Cockburn sugere uma família de métodos e não apenas um único. Dentro desta família, o Crystal Clear é o método proposto para equipes de desenvolvimento com até 8 integrantes [Cockburn, 2005].

Em sua descrição sobre o Crystal Clear, Cockburn [2005] propõe a utilização de radiadores de informação no ambiente de desenvolvimento. Um radiador de informação consiste em algum dispositivo presente no ambiente de trabalho que permita visualização de informações. Apesar de normalmente serem utilizados um quadro ou conjunto de quadros, um radiador de informação pode ser qualquer dispositivo que promova transmissão de uma informação importante para seus observadores [Cockburn, 2005]. Existem registros de equipes se utilizando de artefatos não usuais para disponibilizar informações importantes em seu contexto de desenvolvimento de software, alguns exemplos destes artefatos são sinais de trânsito, cubos de LED, etc [Swaine, 2008].

Para que se obtenha um melhor proveito dos radiadores de informação, Cockburn [2005] afirma que estes devem possuir algumas características específicas. Cockburn [2005] também indica algumas características desejáveis que radiadores de informação devem possuir para sejam melhor aproveitados:

1. Devem ser grandes;

2. Devem ser facilmente visíveis;

3. Devem ser plenamente compreendidos pelos integrantes;

4. Devem ser facilmente atualizáveis;

5. Devem ser periodicamente atualizados (para que um observador assíduo se sinta incentivado a visitá-los).

\subsubsection{Lean Software Development}

O Lean Development é uma denominação da abordagem de desenvolvimento de produtos utilizada por empresas como Honda e Toyota durante os anos 80. Poppendieck e Poppendieck [2007], ao observarem a possibilidade de aplicação desta abordagem para a área de desenvolvimento de software, realizaram uma adaptação do Lean para esta nova realidade. Esta adaptação foi denominada como Lean Software Development.

No Lean Software Development, Poppendieck e Poppendieck [2007] se utilizam de sete princípios presentes no Lean Development. Estes princípios são fundamentais para a distinção da abordagem do Lean perante outras abordagens, estes princípios são: "elimine desperdício", "amplifique o 
aprendizado", "decida o mais tarde possível", "entregue o mais rápido possível", "fortaleça a equipe", "construa com integridade" e "veja o todo" [Poppendieck e Poppendieck, 2007].

Um dos princípios adaptados por Poppendieck e Poppendieck [2007] é o "amplifique o aprendizado", em que sugere-se prezar por um aprendizado contínuo em relação ao contexto de trabalho. Em sua descrição sobre este princípio, Poppendieck e Poppendieck [2007] sugerem a utilização de uma demonstração visível de acompanhamento para o progresso da equipe. Para este fim, estes autores mencionam a possibilidade de utilização do gráfico de burndown, indicando também a utilização de outros gráficos para uma demonstração da convergência do software.

Poppendieck e Poppendieck [2007] classificam processos de produção em geral a partir de dois modelos, o que chamam de "sistemas empurrados" e de "sistemas puxados", termos tradicionalmente utilizados no contexto de logística. No primeiro modelo, dada uma previsão de que uma certa quantidade de um produto será necessária, o processo produtivo desta quantidade é iniciada e, a cada fase do processo, os recursos são "empurrados" por esta expectativa de necessidade. No segundo modelo, quando um cliente demanda a real necessidade de um produto, esta necessidade "puxa" apenas a quantidade demandada pelo processo produtivo.

Ao defender a abordagem dos "sistemas puxados" no contexto de desenvolvimento de software, Poppendieck e Poppendieck [2007] comentam a respeito da importância da utilização do quadro conhecido como kanban, pois este quadro demonstra muitas informações úteis para a equipe, como: 1. O que precisa ser realizado; 2. O que está realizado no momento; 3. Quem está trabalhando com o quê.

O kanban é um quadro muito utilizado em métodos ágeis para a administração do trabalho interno da equipe de desenvolvimento, muitas vezes sendo base para o direcionamento das tarefas realizado em reuniões internas. Um exemplo deste quadro pode ser visualizado na Figura 2.1.

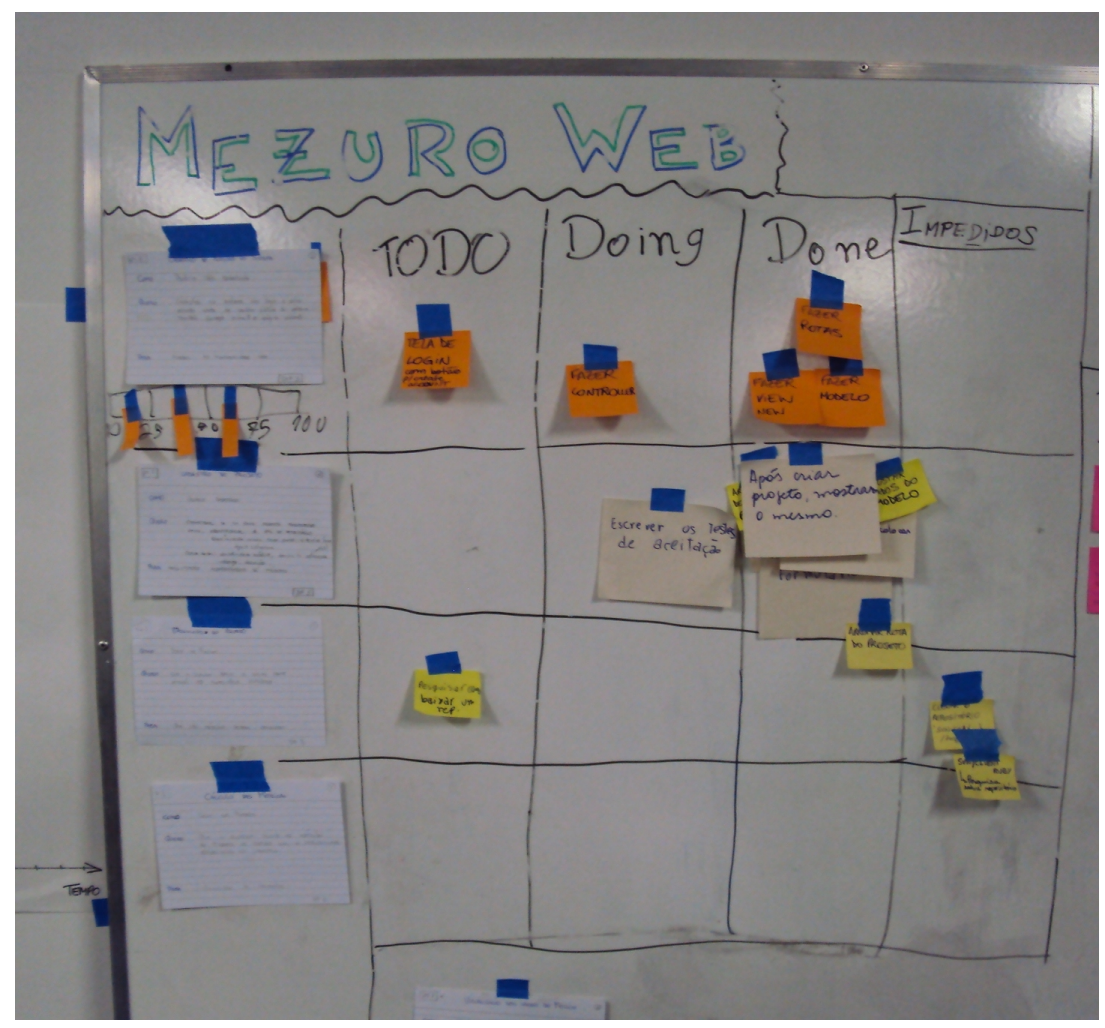

Figura 2.1: Kanban

Uma das características importantes no modelo de "sistemas puxados" é a necessidade de um controle visual para o direcionamento do trabalho a ser realizado [Poppendieck e Poppendieck, 2007]. Poppendieck e Poppendieck [2007] defendem a utilização de radiadores de informação para este fim, pois sua utilização permite que o trabalho seja auto-direcionado. Para estes autores, o trabalho auto-direcionado só se torna possível quando controles visuais simples e apropriados para 
seu domínio estejam no local, sendo atualizados, e sendo utilizados diretamente no trabalho.

Poppendieck e Poppendieck [2007] também comentam a respeito de diversos itens que podem ser disponibilizados por meio de radiadores de informação relacionados com o trabalho diário da equipe de desenvolvimento. Entre estes itens estão: listas de problemas encontrados, ideias para melhoria, candidatos para refatoração, situação da construção diária, etc.

\subsubsection{Scrum}

Beedle et al. [2000] definem o Scrum como um método de desenvolvimento de software não só iterativo e incremental, mas também adaptativo. Schwaber [2008] define o Scrum como um conjunto simples de regras e práticas que englobam a transparência, inspeção e adaptação de requisitos inerentes em um controle de processos empíricos.

O Scrum se relaciona com tarefas de acompanhamento ágil em aspectos como a utilização do gráfico de burndown. O gráfico de burndown é um quadro que resume informações importantes relativas ao escopo planejado da iteração atual e o que foi entregue até o momento, bem como a relação deste valor com uma estimativa de ideal (baseando-se em uma entrega linear das tarefas do escopo). Schwaber [2008] define o gráfico de burndown como a colisão entre o planejado e a realidade.

Para Schwaber [2008], o gráfico de burndown também é uma forma excelente de se visualizar a correlação entre a quantidade de trabalho restante em cada ponto no tempo e o progresso da equipe de desenvolvimento em reduzir seu trabalho durante esse tempo. É muito comum encontrar esse quadro em equipes de desenvolvimento ágil como um de seus principais artefatos de acompanhamento.

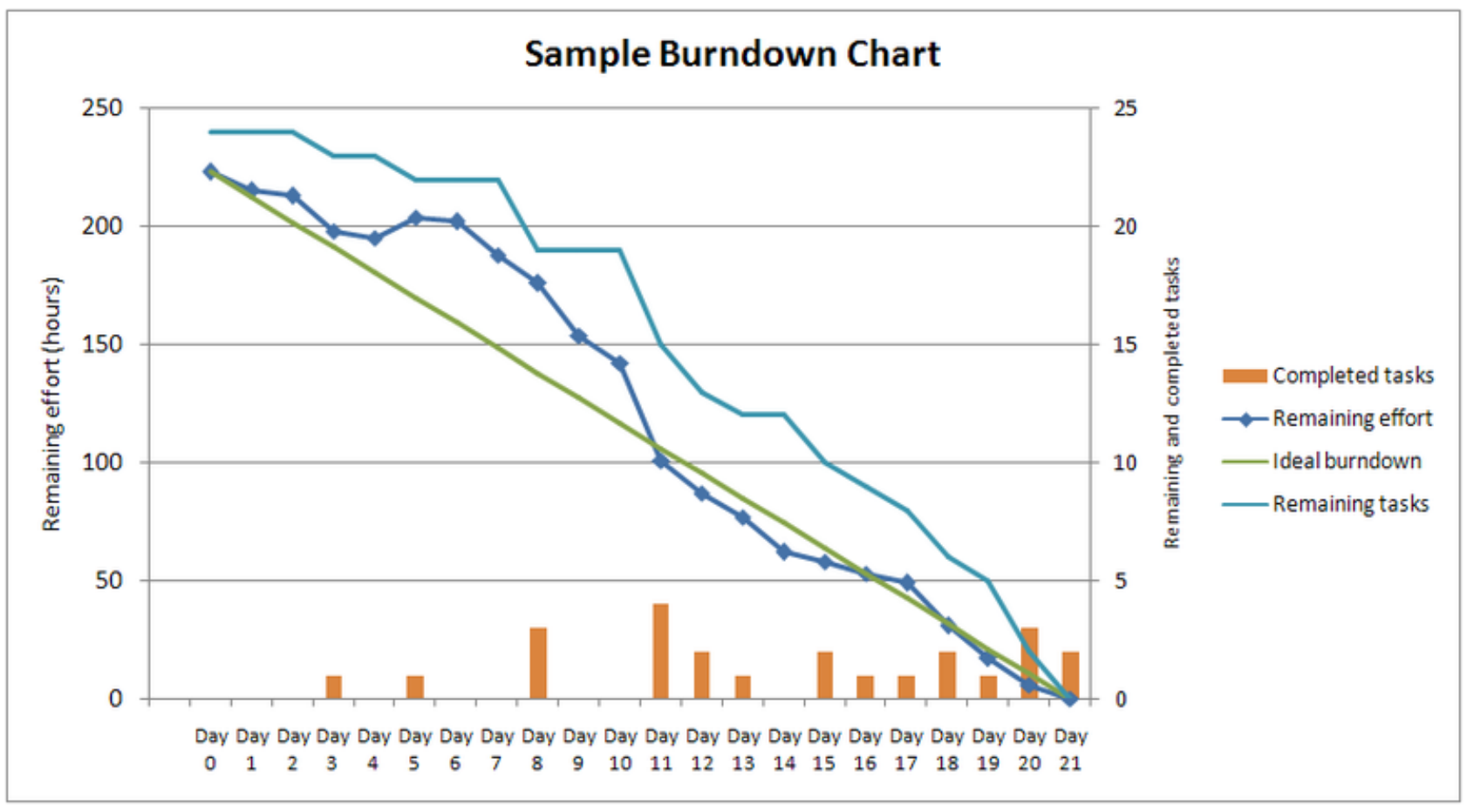

Figura 2.2: Burndown [Straub, 2009]

Dentro do contexto do Scrum, também encontram-se sugestões a respeito de tarefas de acompanhamento ágil, como a de Beedle, Devos, et al. ao afirmarem ser um erro coletar métricas demasiadamente no ambiente de desenvolvimento, pois isso consome tempo e desestimula a equipe [Beedle et al., 2000].

Podemos observar neste capítulo que os principais métodos ágeis possuem sugestões importantes ligadas ao acompanhamento. A seguir veremos alguns princípios encontrados em métodos ágeis que podem influenciar tarefas de acompanhamento ágil. 


\subsection{Métricas de acompanhamento}

Neste trabalho foram consideradas como tarefas de acompanhamento ágil as que envolvem análise, escolha, coleta e disponibilização de informações para a equipe de desenvolvimento. Muitas das informações disponibilizadas para a equipe são métricas a respeito do ambiente em que esta está inserida. Por causa desta definição é fundamental a compreensão do conceito de métrica e de assuntos relacionados com este conceito.

Para compreender a influência gerada pela escolha de métricas em projetos de desenvolvimento de software, é primeiramente necessário realizar uma contextualização sobre o que são métricas, bem como suas diferenças comparadas a outros conceitos similares, como por exemplo os indicadores e as medidas.

A escolha de métricas é um fator importante para o acompanhamento cotidiano de um projeto ágil. Autores de diversos métodos ágeis como Beck [1999], Poppendieck e Poppendieck [2007] e Cockburn [2005] mencionam a influência causada pela disponibilização de métricas em equipes de desenvolvimento. A disponibilização de uma métrica específica pode direcionar o comportamento da equipe de desenvolvimento, tanto de uma forma positiva quanto de forma negativa.

A seleção de métricas adequadas para um determinado contexto em um momento o ciclo de vida de um projeto de software pode ser uma tarefa difícil. Para auxiliar nesta tarefa encontramse algumas contribuições importantes diretamente relacionada à escolha de métricas. Basili et al. [1994] oferecem uma abordagem para o mapeamento e escolha de métricas dentro de um contexto, o Goal Question Metric (GQM). Já Hartmann e Dymond [2006] propõem um conjunto de heurísticas associadas a uma métrica imaginária ideal afim de serem utilizadas na escolha de métricas de uma forma adaptativa.

Discutimos cada um destes conceitos nas seções subsequentes deste capítulo.

\subsubsection{Definições}

O conceito de métrica é muitas vezes confundido com outros conceitos similares, como por exemplo o conceito de indicadores e de medidas. Sato, em seu trabalho a respeito de métricas, menciona algumas definições a respeito destes itens [Sato, 2007].

Pela definição de IEEE, uma medida é uma avaliação em relação a um padrão [Sato, 2007]. McGarry apud Sato define uma medida como uma avaliação de um atributo segundo um método de medição específico, funcionalmente independente de todas as outras medidas e que captura informação sobre um único atributo. Um exemplo mencionado por Sato [2007] é a medida 5cm, que neste caso possui o centímetro como padrão da medida e 5 como valor da medida.

O IEEE define uma métrica como um método para determinar se um sistema, componente ou processo possui certo atributo. Sato [2007] afirma que uma métrica geralmente é calculada por duas ou mais medidas, este autor demonstra um exemplo desta afirmação ao mencionar uma métrica de número de defeitos encontrados após a implantação de um projeto. Neste exemplo Sato afirma que a métrica é composta por duas medidas, sendo estas o número de defeitos e a data (fase) em que o defeito foi encontrado.

O IEEE também define o conceito de indicador. Para o IEEE apud [Sato, 2007], um indicador é um dispositivo ou variável que pode ser configurado para um determinado estado de base no resultado de um processo ou ocorrência de uma determinada condição. Sato [2007] também exemplifica o conceito de um indicador como um semáforo ou uma flag. Para Sato [2007], um indicador está geralmente relacionado a uma métrica e provê a interpretação desta métrica em um determinado contexto.

\subsubsection{Métricas em métodos Ágeis}

No Extreme Programming [Beck, 1999] as métricas são consideradas como as ferramentas administrativas básicas deste método . Beck [1999] considera a importância desta ferramenta ao afirmar que algumas métricas (como a relação entre o desenvolvimento estimado e o realizado) são básicas 
para a execução do Planning Game, reunião junto ao cliente definida no XP para a negociação do escopo da próxima iteração.

Para Beck [1999], métricas evidenciam circunstâncias. Por exemplo, se a diferença entre o desenvolvimento estimado e o realizado aumentar, pode ser um indício que a equipe não está trabalhando bem ou então que esta equipe está realizando outras tarefas que não se caracterizam primariamente como suprir requisitos (refatoração, programação em pares, etc). Beck [1999] considera a utilização de métricas como uma forma gentil e não coerciva de comunicar uma necessidade de mudança.

Beck [1999] sugere a disponibilização de métricas por meio de gráficos grandes e visíveis. Para este autor, esta forma de disponibilização é uma melhor opção comparada ao envio de informações por e-mail, pois a equipe de desenvolvimento aprende a ignorar ferramentas como e-mails.

Poppendieck e Poppendieck [2007] comentam sobre a utilização de medidas no processo de desenvolvimento. Ao adaptar o princípio "Veja o todo", Poppendieck e Poppendieck [2007] indicam um problema na forma com que medições de desempenho são tratadas em diversas organizações. Estes autores criticam este tipo de medição quando realizado fundamentalmente em níveis locais, pois afirmam que normalmente a maximização de medições locais é contrária à otimização da organização como um todo, mesmo que muitas vezes esta relação não esteja clara.

Poppendieck e Poppendieck [2007] definem este tipo de medida como medida de sub-otimização, o que estes autores consideram como desperdício para o desenvolvimento, gerando situações em conflito com o princípio "Elimine desperdícios". Estes autores também consideram que o foco exclusivo em medições locais gera uma tendência pela inibição da colaboração entre a área que esta sendo realizada a medição e outras áreas. Estas autores afiram isto pois consideram que este fato decorre por não existir uma recompensa para esta colaboração da área interna com a externa.

No Scrum, é proposto um gráfico denominado como burndown [Schwaber, 2008]. O gráfico de burndown é um gráfico que associa a quantidade/pontuação de histórias/tarefas desenvolvidas desde o começo da iteração até o dia atual à quantidade/pontuação estimada de histórias/tarefas desenvolvidas até o dia atual.

Dada a definição do IEEE a respeito de métricas e sua relação com a definição se um atributo está presente ou não, pode-se inferir que o gráfico de burndown é a disponibilização da métrica "Desempenho na iteração atual" de histórias/tarefas desenvolvidas propostas associada ao atributo "proximidade do desenvolvimento realizado em relação ao estimado".

Na métrica do burndown estão sendo utilizadas algumas medidas distintas, como por exemplo a quantidade de tarefas desenvolvidas em um certo dia, bem como a quantidade/pontuação ideal a ser desenvolvida por dia dada a estimativa/tempo alocado para a iteração. Indicadores relacionados à métrica do burndown podem refletir situações distintas na equipe de desenvolvimento, como por exemplo um trabalho não adequado pela equipe de desenvolvimento [Beck, 1999].

\subsubsection{Escolha de métricas}

Um dos aspectos importantes encontrados no estudo de métricas em desenvolvimento de software é a escolha das métricas a serem utilizadas. A escolha de métricas é parte importante do processo de manipulação de métricas dentro do contexto de desenvolvimento. Uma escolha adequada de métricas é fundamental para um acompanhamento adequado de uma equipe de desenvolvimento. Existem algumas contribuições relacionadas com a escolha de métricas de desenvolvimento, algumas destas são descritas abaixo.

Para Cockburn [2002], o conceito de ágil pode ser considerado como uma atitude, não apenas como uma fórmula. Esse comentário sugere que aspectos correspondentes a métodos ágeis podem variar dependendo do contexto, e sendo assim, a escolha adequada de métricas também pode variar de acordo com a situação encontrada pela equipe de desenvolvimento.

Goldrat apud [Hartmann e Dymond, 2006] indica que a avaliação de um indivíduo possui uma relação direta com o comportamento do mesmo, mas diretamente denotado pela afirmação "Me diga como serei avaliado que te direi como me comportarei".

Beck [1999] também comenta a respeito da escolha de métricas e de sua utilidade para o direcionamento da equipe de desenvolvimento. Este autor afirma que que caso exista uma situação em 
que se acredita que não estão sendo escritos testes o suficiente, deve-se disponibilizar um gráfico na parede com os número de testes escritos por dia, e atualizá-lo diariamente. Esta afirmação denota a importância da utilização e da escolha de métricas adequadas para o tratamento de necessidades específicas encontradas durante o desenvolvimento de um software.

\section{Goal Question Metric}

Basili et al. [1994] definem uma abordagem para a escolha de métricas denominada como Goal Question Metric. Estes autores descrevem o Goal Question Metric como uma forma de se identificar métricas apropriadas ao desenvolvimento de software em um ambiente organizacional.

A abordagem conhecida como Goal Question Metric (GQM) surgiu originalmente em um processo de avaliação de defeitos em um conjunto de projetos no ambiente da NASA Goddard Space Flight Center. Basili et al. [1994] informam que a aplicação deste processo envolveu um conjunto de experimentos de estudo de caso e foi expandida para incluir vários tipos de abordagens experimentais. Para estes autores, embora a abordagem tenha surgido para definir e avaliar objetivos em um projeto/ambiente específico, sua utilização foi expandida para um contexto maior.

Entre suas afirmações, Basili et al. [1994] descrevem algumas características comuns entre medições consideradas eficazes no desenvolvimento de software. Estes autores afirmam que muitos estudos realizados na aplicação de métricas e modelos em ambientes industriais apontam que as medições eficazes devem ser:

1. Focadas em objetivos específicos;

2. Aplicadas em todos os produtos, processos e recursos;

3. Interpretadas baseando-se na caracterização e compreensão do contexto, do ambiente, e de objetivos organizacionais.

Para Basili et al. [1994], medições devem ser definidas de uma forma top-down e que estas devem ser focadas em objetivos e em modelos. Estes autores afirmam que uma abordagem contrária, bottom-up, não deve funcionar para a definição de medições adequadas. Isso se dá pois existem muitas características observáveis (e consequentemente mensuráveis) a respeito do desenvolvimento de software. Devido à esta grande quantidade de características, a utilização de métricas por um indivíduo, comparada à forma como este indivíduo as interpreta, pode não se tornar clara sem os objetivos e modelos apropriados - a serem definidos dentro do contexto [Basili et al., 1994].

Basili et al. [1994] descrevem a abordagem de Goal Question Metric (GQM) afirmando que esta é baseada na seguinte suposição básica: Para que uma organização possa se utilizar de medidas de uma forma com propósito, esta primeiramente precisa especificar objetivos para si mesma e para seus projetos. Após especificação de seus objetivos, a organização deve identificar, a partir dos objetivos, os dados que permitam definir estes objetivos de forma operacional. Finalmente, após a definição dos dados, a organização deve disponibilizar um framework para a interpretação destes dados no que diz respeito aos objetivos previamente declarados.

Apesar da identificação dos objetivos, dados e da definição de um framework para interpretação destes dados, Basili et al. [1994] afirmam que é importante esclarecer quais são as necessidades de informação que a organização requer pelo menos em termos gerais. Este esclarecimento é necessário para que as necessidades de informação possam ser quantificáveis sempre que possível, permitindo então a análise da informação quantificada para a verificação do cumprimento dos objetivos estabelecidos.

Basili et al. [1994] afirmam que o resultado da aplicação da abordagem de GQM é a especificação de um sistema de medidas focado em um conjunto particular de questões/assuntos e um conjunto de regras para interpretação das medições realizadas.

O Goal Question Metric (GQM), de acordo com Basili et al. [1994], possui um modelo composto de três níveis: 
1. Nível Conceitual (Objetivo). Para Basili et al. [1994], no nível conceitual é que são definidos os objetivos a serem trabalhados. Basili et al. [1994] afirmam que um objetivo é definido para um objeto. Esta vinculação é realizada por uma série de razões, por meio de vários pontos de vista, e sendo relativa a um contexto específico. Estes autores comentam a respeito de alguns objetos que podem ser observados para a definição de métricas, estes são classificados entre produtos (entregáveis, documentação, etc.), processos (atividades no desenvolvimento normalmente temporais como especificação, testes, etc.) e recursos (itens utilizados por processos para produzir saídas como hardware, software, pessoas, etc).

2. Nível Operacional (Pergunta). Para Basili et al. [1994], no nível operacional é que são definidas as perguntas a serem utilizadas. Estas perguntas são utilizadas para caracterizar a forma com que a avaliação/realização de um objetivo específico será realizada baseando-se em um modelo de caracterização. Basili et al. [1994] afirmam que perguntas tentam caracterizar um objeto de medição (produto, processo ou recurso) no que diz respeito a um aspecto da qualidade.

3. Nível Quantitativo (Métrica). Para Basili et al. [1994], é no nível quantitativo que se define o conjunto de dados a serem utilizados. O conjunto de dados deve estar associado a cada questão levantada, de forma a tentar respondê-las de forma quantitativa. Basili et al. [1994] afirmam que os dados levantados podem ser tanto de origem objetiva (caso dependa apenas do objeto sendo medido e não do ponto de vista adotado, ex: número de versões de um documento, tamanho de um programa, etc.) quanto origem subjetiva (depende tanto do objeto medido quanto do ponto de vista adotado, ex: legibilidade, nível de satisfação do usuário, etc.).

\section{Heurísticas para a escolha de métricas}

Hartmann e Dymond [2006] discutem a respeito da escolha de métricas para projetos ágeis. Estes autores contribuem com uma lista de itens que devem ser considerados para a escolha de métricas/diagnósticos em um projeto ágil. Segue abaixo a lista com as dez características apontadas por Hartmann e Dymond [2006] e seus respectivos comentários:

1. Afirma ou reforça os princípios ágeis e do Lean. Hartmann e Dymond [2006] consideram que métricas devem afirmar/reforçar princípios ágeis e do Lean. Para estes autores, este aspecto é importante pois permite que acordos realizados durante o andamento do projeto sejam baseados primariamente na geração de valor. Para Hartmann e Dymond [2006], este item requer que pessoas que compreendam os princípios ágeis participem na definição das métricas a serem utilizadas. Hartmann \& Dymond também consideram que é um risco escolher métricas que não seguem os princípios ágeis, pois elas podem incentivar um comportamento indesejável.

2. Mede o resultado, e não a quantidade de "saída". Este item está vinculado ao conceito de se priorizar o desenvolvimento de funcionalidades com um custo/benefício elevado, relacionado inclusive com o princípio da simplicidade presente em métodos ágeis. Métricas devem priorizar a geração de valor ao invés de "saídas" do processo como apenas quantidade de funcionalidades desenvolvidas, sem levar em consideração o valor agregado pelas mesmas. Para Hartmann e Dymond [2006], o melhor resultado de um processo de desenvolvimento pode ser alcançado ao reduzir-se a quantidade de "saída" deste processo enquanto se maximiza o valor agregado.

3. Segue tendências, e não números. De acordo com Hartmann e Dymond [2006], uma métrica deve medir "um nível acima" (conceito abordado por Poppendieck e Poppendieck [2007]), para que não sejam medidas partes sub-otimizadas de um todo restringindo uma otimização global do desenvolvimento. Hartmann e Dymond [2006] também realizam afirmações a respeito da granularidade do nível das medições vinculadas ao seu público alvo. Estes autores 
indicam que a alta gerência não deve considerar métricas em níveis de resultados individuais, pois para se promover saúde em um processo de desenvolvimento não deve-se acompanhar níveis mais granulares que uma equipe/uma iteração.

4. Pertence a um conjunto pequeno de métricas e diagnósticos. Hartmann e Dymond [2006] recomendam a utilização da abordagem de "apenas o suficiente", pois afirmam que muita informação pode obscurecer tendências importantes. Hartmann e Dymond [2006] sugerem a agregação de fatores relacionados ou que competem entre si em uma única "visão geral".

5. É de fácil coleta. O esforço de coleta também deve ser analisado para a escolha de uma métrica, visto que este influencia na administração da métrica no cotidiano dos projetos de software. Hartmann e Dymond [2006] afirmam que para diagnósticos no nível de equipe o ideal é a automação de "um botão", onde informações são coletadas a partir de ferramentas operacionais. Para a utilização gerencial, Hartmann e Dymond [2006] indicam que deve-se evitar tanto retrabalho na manipulação destas métricas quanto a utilização de dados de baixo nível, casos em que deve-se utilizar agregações em cima destes dados.

6. Revela, o invés de ocultar, seu contexto e suas variáveis significativas. Hartmann e Dymond [2006] consideram que métricas sempre devem estar visualmente acompanhadas de notas a respeito de fatores de influência significativas, para desencorajar suposições falsas e facilitar a melhoria.

7. Promove "combustível" para discussões significativas. Beck et al. [2001b] indicam a comunicação face-a-face como um dos princípios por detrás do manifesto ágil. Hartmann e Dymond [2006] afirmam que conversação face-a-face é uma ferramenta muito útil para a otimização de um processo. Para Hartmann \& Dymond, qualquer medida coletada isolada de seu contexto perde seu significado, afirmando ainda que é um bom sinal quando pessoas conversam sobre o que estão aprendendo por utilizar uma métrica ou diagnóstico.

8. Promove feedback em periodicidade regular. Para Hartmann e Dymond [2006], métricas devem preferencialmente estar disponíveis em cada retrospectiva de iteração e em cada reunião chave de gerenciamento, no intuito de se amplificar o conhecimento e acelerar a melhoria do processo.

9. Pode medir o valor agregado do produto ou o processo. Hartmann e Dymond [2006] afirmam que diagnósticos devem ser capazes de medir fatores suspeitos de inibir a eficácia de um processo. Para estes autores, deve-se a audiência apropriada para cada uma destas métricas e documentar seu contexto/suposições para que permitir a utilização apropriada de seu conteúdo.

10. Encoraja o nível de qualidade "bom o suficiente". De acordo com Hartmann e Dymond [2006], a definição do que é "bom o suficiente" é dada pelo contexto do cliente de negócio ou do seu respectivo representante, não pelos desenvolvedores. Encorajar um nível de qualidade "bom o suficiente" pode ser relacionado ao princípio de simplicidade juntamente com conceito de adaptabilidade em métodos ágeis, ao se focar na geração de valor de forma rápida e adaptável.

\section{Valor como métrica chave}

Juntamente com essa lista de características de uma métrica ideal, Hartmann e Dymond [2006] comentam a respeito do conceito de métrica chave no contexto de um projeto de desenvolvimento de software.

Hartmann e Dymond [2006], ao discutirem sobre métricas a partir do ponto de vista do lean, apontam a necessidade de "definir valor aos olhos do cliente", fundamental para o princípio denominado "veja o todo" [Poppendieck e Poppendieck, 2007]. Hartmann \& Dymond relacionam a similaridade entre a necessidade da definição do que é valor com alguns princípios ágeis - como por exemplo "satisfação do cliente" e "entrega frequente de código executável". 
Para Hartmann e Dymond [2006], métodos ágeis encorajam que negócios sejam contabilizados pelo valor produzido, por meio de esforços no desenvolvimento. Tendo-se em vista esta consideração, Hartmann e Dymond [2006] afirmam que as equipes de desenvolvimento deveriam estar se otimizando tendo como base o "Valor de negócio entregue", e portanto este item deveria estar sendo acompanhado como métrica chave do projeto. 


\section{Capítulo 3}

\section{Princípios ágeis no acompanhamento}

Uma característica muito forte encontrada na abordagem de diversos métodos ágeis é que a aplicação de suas práticas devem variar de acordo com o contexto encontrado. Apesar disto, esta adaptação é direcionada através de uma série de princípios também disponíveis nestes trabalhos. Um exemplo desta característica pode ser encontrado na afirmação de Poppendieck e Poppendieck [2007], definindo princípios como guidelines e insights a respeito de disciplinas específicas, enquanto consideram que as práticas são exatamente as ações realizadas em busca destes princípios.

Poppendieck e Poppendieck [2007] afirmam que princípios são universais, porém nem sempre é fácil visualizar como aplicá-los em ambientes peculiares. Práticas, ao contrário, provém uma orientação clara, porém precisam ser adaptadas dentro de um contexto específico [Poppendieck e Poppendieck, 2007].

Beedle et al. [2000] também valoriza a adaptabilidade em um processo de desenvolvimento de software ao criticar o CMM com relação a sua abordagem "definida/repetível", considerando-a como não satisfatória para um ambiente de desenvolvimento "caótico".

Observando a relevância do conceito de adaptabilidade na aplicação de métodos ágeis, consideramos que a forma com que o acompanhamento ágil é realizado em ambientes diferentes também deve variar de acordo com o contexto encontrado. Também reconhecemos que a forma de aplicação do acompanhamento ágil, assim como qualquer aspecto encontrado na aplicação de métodos ágeis, deve estar baseada nos princípios encontrados em métodos ágeis para que seja bem fundamentada. Por isto, consideramos importante a compreensão de alguns princípios encontrados em métodos ágeis que possam influenciar na aplicação deste tipo de tarefa em contextos reais.

Dentre diversos aspectos valorizados na área de métodos ágeis, alguns princípios com maior potencial de influência em relação ao acompanhamento ágil foram selecionados para serem discutidos nesta seção.

\subsection{Feedback}

"Nenhuma direção fixa persiste por muito tempo; quando se fala em detalhes do desenvolvimento de software, os requisitos de um sistema, ou a arquitetura de um sistema" [Beck e Andres [2006], pg 19].

Feedback é um conceito muito importante para métodos ágeis. No Extreme Programming, o feedback é um de seus valores - tão importante que chega a pertencer à pequena lista de apenas cinco valores deste método [Beck e Andres, 2006].

$\mathrm{O}$ ambiente que envolve o desenvolvimento de software pode ser considerado como caótico [Beedle et al., 2000], sofrendo constantemente mudanças [Beck e Andres, 2006]. Beck e Andres [2006] acreditam que mudança é algo inevitável, e mudança cria a necessidade por feedback.

Poppendieck e Poppendieck [2007], ao adaptar o princípio "amplifique o aprendizado" para o desenvolvimento de software, comparam a diferença entre processos que se utilizam e os que não se utilizam de feedback. A importância de feedback para alguns processos chega a ser tal, de acordo com 
estes autores, que este pode ser considerado como a única forma eficaz de se tratar com projetos na área de desenvolvimento de software.

Poppendieck e Poppendieck [2007] realizam uma série de analogias referentes à importância do feedback. Estes autores comentam a respeito de um sistema de semáforos com sensores, onde os semáforos identificam a proximidade de um carro em determinado sentido, e caso não haja carros no outro sentido, este semáforo é aberto para passagem do carro. Para Poppendieck e Poppendieck [2007], sistemas baseados em feedback possuem a capacidade de ser muito mais eficientes na geração de valor a seus usuários.

Poppendieck e Poppendieck [2007] consideram o controle visual como característica importante na utilização do modelo de "sistemas puxados". Estes autores consideram que o trabalho da equipe não pode ser auto-direcionável até que controles visuais simples e apropriados para o domínio estejam no local de trabalho, sendo constantemente atualizados e utilizados para o direcionamento do trabalho [Poppendieck e Poppendieck, 2007].

Ao comentar sobre trabalho auto-direcionável, Poppendieck e Poppendieck [2007] consideram que é necessária a existência de recursos visuais para seu controle. Essa afirmação dos autores, da forma que foi tratada, denota a contínua necessidade de feedback por parte da equipe a respeito de seu trabalho cotidiano.

Poppendieck e Poppendieck [2007] indicam a utilização dos radiadores de informação, conceito defendido por Cockburn [2005] em sua família de metodologias Crystal, como uma possível implementação destes controles visuais para trabalho auto-direcionável.

O tracker, papel definido no Extreme Programming, é o indivíduo na equipe de desenvolvimento que possui o trabalho de promover feedback para o resto desta equipe [Beck, 1999].

Hunt e Hume [2007] se utilizam de um conceito similar aos radiadores de informação, os "dispositivos de feedback extremo" . Como o próprio nome indica, os dispositivos de feedback extremo são artefatos diversos que possuem a finalidade de prover feedback. A motivação por detrás dos dispositivos de feedback extremo é capturar a atenção da equipe de desenvolvimento para a situação e também em relação às métricas importantes do projeto/software tratado. Para isto, Swaine [2008] demonstram alguns exemplos de dispositivos de feedback extremo, como lâmpadas de lava, cubos de LED, etc.

Alguns dispositivos de feedback extremo são mais respeitados, afirmam Hunt e Hume [2007], como por exemplo as lâmpadas de lava. As lâmpadas de lava muitas vezes são utilizadas para indicar a aprovação ou reprovação da última execução do conjunto de testes automatizados do sistema. Para Hunt e Hume [2007], apesar de apresentarem uma quantidade baixa de informação, as lâmpadas de lava são respeitadas pois a relevância da informação transmitida é altíssima, além da sua disponibilização estar sendo realizada de forma automática e contínua.

Observamos a importância encontrada em algumas características do acompanhamento ágil para a promoção do feedback. Algumas destas características envolvem a escolha por radiadores de informação (ou dispositivos de feedback extremo) que promovam um maior e melhor feedback para a equipe de desenvolvimento de acordo com o contexto encontrado.

Também observamos que em casos como o de Hunt e Hume [2007], artefatos com características peculiares auxiliam a capturar a atenção da equipe de desenvolvimento para informações importantes. Uma possível aplicação do princípio de feedback é a utilização de artefatos adequados no ambiente de desenvolvimento para disponibilizar informações com alta relevância.

\subsection{Adaptabilidade}

"Tudo em software muda. Os requisitos mudam. O projeto muda. O negócio muda. A tecnologia muda. A equipe muda. Os membros da equipe mudam. O problema não é mudança, porque essa irá acontecer; o problema, no entanto é nossa inabilidade de acompanhar as mudanças" [Beck e Andres [2006], pg 11].

O desenvolvimento de software é considerado por diversos métodos ágeis como um processo 
caótico [Beedle et al., 2000]. O ambiente que engloba o desenvolvimento de software é conhecido por alguns autores como envolto em diversos tipos de mudanças [Beck e Andres, 2006].

Outros autores, como Highsmith [1999], chegam a considerar o ambiente de desenvolvimento de software como um ambiente extremo. Este autor também considera que em ambientes extremos, o equilíbrio é uma exceção.

"Em um ambiente complexo, seguir ao plano produz o produto que você pretendia produzir, porém não o produto que você precisa" [Highsmith, 1999].

Observamos a relação entre o princípio "elimine desperdício" do Lean Software Development e a valorização do princípio de adaptabilidade. Poppendieck e Poppendieck [2007] consideram o princípio "elimine desperdício" como o mais fundamental no Lean. Estes autores afirmam que o primeiro passo para a implantação do Lean é aprender a "enxergar" desperdício. E então, após este primeiro passo, o segundo passo que é a busca contínua por desperdícios [Poppendieck e Poppendieck, 2007].

O manifesto ágil indica uma priorização do item "responder a mudanças" em relação ao item "seguir ao plano" [Beck et al., 2001a]. Esta priorização definida no manifesto ágil indica um reconhecimento geral na abordagem encontrada em métodos ágeis pela busca por adaptabilidade.

Observa-se também que conceito de adaptabilidade está relacionado ao conceito de feedback. Highsmith [1999] considera o conceito de adaptação como sendo um padrão de mudanças contínuas existentes, em contraste a um processo de mudança periódico e discreto, como encontrado em muitas organizações.

Poppendieck e Poppendieck [2007] comentam a respeito da planta NUMMI, joint venture das empresas General Motors e Toyota. Sua administração era realizada pela Toyota, apesar de nesta planta terem sido recontratados alguns funcionários da GM. A planta NUMMI se tornou muito mais produtiva do que qualquer planta da GM, além do fato que $90 \%$ dos funcionários se descreveram como "satisfeitos" ou "muito satisfeitos". A GM tentou algumas vezes transferir funcionários para esta planta com o objetivo de transferir este modelo para suas outras plantas, porém falhou em suas tentativas [Poppendieck e Poppendieck, 2007].

Poppendieck e Poppendieck [2007] acreditam que a razão pela qual a GM falhou em transferir o modelo de trabalho da planta NUMMI para suas outras plantas é porque transferir práticas de um ambiente para outro é normalmente um engano. Ao invés disto, os autores sugerem que se entenda os princípios fundamentais pelas quais as práticas são baseadas e então transformar esses princípios em novas práticas para este novo ambiente. Esta criação de novas práticas mencionada por Poppendieck e Poppendieck [2007], tendo-se como base princípios, denota claramente a presença do conceito de adaptabilidade.

Beck e Andres [2006], definindo a prática "Espaço de Trabalho Informativo", comentam a respeito da coleta e disponibilização de métricas em gráficos na parede como uma possibilidade de implementação desta prática. Estes também indicam que ao surgimento de alguma questão que necessite de progresso constante, que esta questão passe a ser medida e disponibilizada em gráficos. Assim que esta questão for resolvida ou pare de ser atualizada, Beck e Andres [2006] sugerem que sua coleta e disponibilização sejam também interrompidas.

Observamos que o conceito de adaptabilidade pode influenciar a abordagem de tarefas de acompanhamento ágil. Uma equipe que se utiliza de uma abordagem adaptativa para o desenvolvimento de software, pode necessitar realizar mudanças diversas conforme o andamento do projeto. Questões que necessitam de progresso constante, que podem ter sido provenientes de algum processo adaptativo na equipe, requerem um maior nível de feedback. Por esta causa, estas questões devem medidas e disponibilizadas com maior eficácia [Beck e Andres, 2006].

A partir do comentário de Beck e Andres [2006], de se relacionar questões que necessitam de progresso constante e a medição desta questão, observamos também que a abordagem de tarefas de acompanhamento ágil deve ser adaptativa. Para estes autores, a medição pode fornecer o feedback necessário para a tomada de decisões [Beck, 1999], como por exemplo em momento de decisão de tarefas da próxima iteração em um Planning Game. 
Observamos então que a medição e disponibilização de informações podem ser utilizadas como ferramentas para a definição de um direcionamento para mudança, visto que o direcionamento é fundamental para a adaptação a um novo ambiente. Pode-se compreender a relação que medições e direcionamento podem possuir em uma equipe de desenvolvimento ágil ao analisar uma afirmação de Goldrat apud Sato [2007]: "Diga-me como serei avaliado e eu te direi como me comportarei".

\subsection{Humanidade}

"Pessoas desenvolvem software. Este fato simples e inescapável invalida a maioria dos conselhos metodológicos disponíveis" [Beck e Andres, 2006].

O reconhecimento e respeito da humanidade da equipe de desenvolvimento é um aspecto muito importante na formação de métodos ágeis.

Cockburn [2005] comenta a respeito de alguns exemplos de radiadores de informação em equipes de desenvolvimento, dentre eles a utilização de um semáforo de trânsito. Com relação a este radiador de informação, Cockburn [2005] afirma que semáforos foram disponibilizados em quatro equipes de desenvolivimento, porém apenas uma equipe ainda o utiliza. A interrupção de sua utilização, de acordo com Cockburn [2005], se deve ao fato de que a utilização de um recurso de reforço negativo (no caso a luz vermelha) sem o correspondente recurso visual positivo (no caso a luz verde) pode influenciar na moral da equipe.

Aspectos como o mencionado por Cockburn [2005] indicam a influência do princípio de humanidade no contexto do acompanhamento ágil, visto a inadequação do semáforo devido a seu impacto negativo na moral da equipe. As equipes escolheram interromper a utilização de um quadro, não devido à sua ausência de importância, e sim pois sua disponibilização estava afetando o bem-estar da equipe.

Cockburn [2005] também comenta que arquivos on-line e páginas Web não costumam ser bons radiadores de informação, visto que bons radiadores de informação devem estar visíveis sem um esforço significativo por parte do visualizador.

Observamos que a disponibilização possui como objetivo a visualização de informações. Também observamos que a visualização possui como objetivo que seus observadores compreendam e reflitam sobre as informações disponibilizadas.

Comunicação e a compreensão são conceitos vinculados à cognição humana, tornando pertinente o estudo desta área para este trabalho. Consideramos interessante identificar alguns vínculos do tema de cognição humana com o acompanhamento ágil. Este tipo de conteúdo poderia auxiliar na compreensão de como ocorre a interação com os radiadores de informação e a maneira em que as informações são disponibilizadas.

Blandford e Furniss [2005] comentam a respeito de uma abordagem denominada cognição distribuída. A cognição distribuída procura compreender aspectos referentes à interação entre pessoas e artefatos que compartilham de um propósito comum, tendo em vista suas relações com a cognição humana. De acordo com Blandford e Furniss [2005], partindo-se de uma perspectiva de cognição distribuída, o ambiente em que habitamos desempenha um papel central em nossa cognição, trazendo itens como artefatos e representações no centro da análise cognitiva.

"Uma forma que artefatos externos podem auxiliar a cognição é em prover uma representação explícita da relação entre o estado atual e o estado alvo" [Hutchins apud Blandford e Furniss [2005], pg 35].

A afirmação de Hutchins apud [Blandford e Furniss, 2005] pode influenciar na forma com que analisam-se e definem-se métricas de radiadores de informação. Observamos o gráfico de burndown proposto pelo Scrum [Schwaber, 2008]. Da forma que foi proposto, este artefato claramente relaciona a quantidade de tarefas alocadas para a iteração atual e a situação da equipe ao realizar estas tarefas.

De acordo com Schwaber [2008] o gráfico de burndown é a colisão entre o planejado e o realizado, além de permitir a realização de mudanças no escopo da iteração atual. As características do gráfico 
de burndown denotam sua utilização como artefato de auxílio cognitivo à equipe de desenvolvimento, representando explicitamente a relação entre o estado atual e o estado alvo, como indicado por Hutchins apud [Blandford e Furniss, 2005].

Poppendieck e Poppendieck [2007], em sua adaptação do Lean para o desenvolvimento de software, comentam a respeito de seus princípios básicos, e entre eles o princípio "fortaleça a equipe". Entre diversas características aplicáveis a respeito do princípio "fortaleça a equipe", Poppendieck e Poppendieck [2007] comentam sobre a motivação dos membros da equipe, bem como outros aspectos que influenciam neste item. Para estes autores, um dos aspectos importantes para a motivação humana é a percepção de progresso. Poppendieck e Poppendieck [2007] afirmam que mesmo uma equipe altamente motivada necessita da sensação de realização.

Poppendieck e Poppendieck [2007] acreditam que projetos deveriam possuir medidas significativas que demonstrassem o progresso em prol a um objetivo. Além disto, estes autores afirmam que estas medidas deveriam ser disponibilizadas em um local apto para que todos pudessem visualizá-las.

A partir destas afirmações observamos que existe a possibilidade de que a realização do acompanhamento ágil em projetos de software supram algumas necessidades na cognição humana dos membros da equipe de desenvolvimento, como por exemplo a percepção de progresso. Este auxílio pode ser gerado ao coletar e disponibilizar métricas adequadas para esta compreensão de progresso.

"Ao interagir com o ambiente, um indivíduo pode se utilizar do próprio corpo para suportar seus processos cognitivos" [Hutchins apud Blandford e Furniss [2005], pg 29].

Em radiadores de informação como o kanban, as tarefas a serem desenvolvidas na iteração são exibidas e conforme o andamento da equipe estas são alteradas. Observa-se que para a escolha de radiadores de informação, o caráter cognitivo se torna importante, visto o reconhecimento da humanidade da equipe de desenvolvimento. Hutchins apud [Blandford e Furniss, 2005] afirma que o próprio corpo do indivíduo pode ser utilizado para suportar seus processos cognitivos.

Tendo em vista os aspectos apresentados, observa-se que radiadores de informação em que os participantes se utilizam dos próprios corpos podem possuir uma vantagem cognitiva para a representação de informação. radiadores de informação com estas características, como por exemplo a movimentação de post-its no kanban, podem indicar um maior nível cognitivo. Também observase que este conceito pode ser estendido a outros aspectos, como valorizando a atualização dos radiadores de informação diretamente pelos membros da equipe de desenvolvimento, visando que a utilização dos próprios corpos dos desenvolvedores permita-os um maior nível cognitivo sobre as informações alteradas.

\subsection{Foco e fluxo de trabalho}

Foco e fluxo de trabalho são dois aspectos intimamente relacionados em um ambiente ágil de desenvolvimento. O fluxo em que o trabalho é realizado muitas vezes é determinado de forma diferente para cada equipe de desenvolvimento. Métodos ágeis como o Scrum [Mateos-Garcia e Sapsed, 2008] defendem a valorização por equipes multifuncionais, em que todos os membros de uma mesma equipe possuem capacidade de gerar valor para o cliente.

Beck e Andres [2006] define o conceito de fluxo em desenvolvimento de software como sendo a entrega constante de software com valor. As práticas do Extreme Programming são mais inclinadas a um fluxo contínuo de entrega de software do que comparado a fases discretas no processo de desenvolvimento. O Extreme Programming possui muitas práticas que levam em consideração o conceito de fluxo, como por exemplo a "construção diária", a "integração contínua", "entregas curtas", etc.

Uma das práticas ágeis que podem ser observada é a reunião diária, proposta no Scrum. Na reunião diária, Beedle et al. [2000] afirmam que os integrantes da equipe necessitam responder a três perguntas que indicam três aspectos a respeito do trabalho:

1. Quais itens foram completados desde a última reunião; 
2. Quais impedimentos foram encontrados que precisam ser resolvidos;

3. Quais novas tarefas a equipe deve realizar até a próxima iteração;

Observa-se como característica da adoção das três perguntas indicadas por Beedle et al. [2000] a descrição do fluxo de trabalho da equipe, visto a descrição explícita de tarefas concluídas e posteriormente tarefas a realizar. Observamos também os benefícios que esta prática pode prover ao fornecer aos membros da equipe o foco necessário para a realização das futuras tarefas.

$\mathrm{Na}$ adaptação do Lean ao desenvolvimento de software, Poppendieck e Poppendieck [2007] comentam sobre o fluxo de trabalho ao tratar sobre a diferença entre "sistemas empurrados" e "sistemas puxados". Ao defender o modelo de "sistemas puxados" no fluxo de trabalho, estes autores comentam a utilização de radiadores de informação para o chamado controle visual. No chamado controle visual, possível em "sistemas puxados", a visualização na situação atual da equipe se torna possível, aspectos como o que precisa ser feito e o que precisa ser resolvido, bem como o progresso que está sendo feito. Para Poppendieck e Poppendieck [2007], o trabalho não pode ser auto-direcionável até que controles visuais simples que sejam apropriados para o domínio estão seus locais, de forma atualizada, e sendo utilizados para direcionar o trabalho. Estes autores comentam a utilização do quadro denominado kanban como um possível radiador de informação para direcionar o fluxo de trabalho.

De acordo com Hollan et al. [2000], na teoria da cognição distribuída, um pequeno conjunto de princípios é identificado sendo amplamente aplicados na realidade. Entre os princípios comentado por estes autores está o seguinte: "pessoas descarregam esforço cognitivo no ambiente em que se encontram sempre que é prático fazê-lo." [Hollan et al. [2000], pg 181].

Observando-se do princípio citado da cognição distribuída, juntamente com a definição de controles visuais por Poppendieck e Poppendieck [2007], pode-se atribuir à tarefas de acompanhamento ágil de projetos a responsabilidade de controlar o fluxo de trabalho da equipe. Observamos que ao se utilizar de quadros/cartazes para o controle do trabalho da equipe, são disponibilizados artefatos no ambiente para descarga cognitiva dos membros da equipe de desenvolvimento, tornando mais clara a compreensão da situação atual do trabalho.

Highsmith [1999] comenta sobre membros de equipes de desenvolvimento focarem-se e desfocaremse de aspectos relacionados ao desenvolvimento. Este autor afirma que ambas as atividades são saudáveis para o andamento da equipe, tanto a necessidade de foco, pois este provê direcionamento, quanto a necessidade de desfoco, pois este permite uma análise de soluções alternativas ao problema - aspecto útil em um ambiente com alta taxa de mudanças. Highsmith [1999] também propõe a utilização de "artefatos de missão", documentos específicos que precisam responder a pelo menos três perguntas:

1. Sobre o que é o projeto?

2. O que devemos fazer neste projeto?

3. Como devemos desenvolver este projeto?

Highsmith [1999], ao mencionar sobre os "artefatos de missão", sugere a utilização do artefato denominado "visão do projeto", que tem como objetivo estabelecer o foco para com o projeto, bem como identificar a fundação para construir o comprometimento da equipe.

Ao identificar o foco do desenvolvimento como aspecto importante para o desenvolvimento de software em projetos ágeis, pode-se se utilizar de radiadores de informação para auxiliar neste fim, como por exemplo cartazes relembrando os objetivos da iteração atual e dela no projeto [Highsmith, 1999].

Em equipes que se utilizam de retrospectivas, reunião indicada entre outros autores por Schwaber [2008], a equipe possui uma lista acordada de pontos bons e ruins a respeito do desenvolvimento da última iteração, bem como pontos de mudança da equipe. Observa-se o auxílio que radiadores de informação podem prover ao se basear no princípio de foco para manter a atenção da equipe 
nos pontos de mudança levantados. Um exemplo de quadro no auxílio a retrospectivas pode ser observado na Figura 3.1.

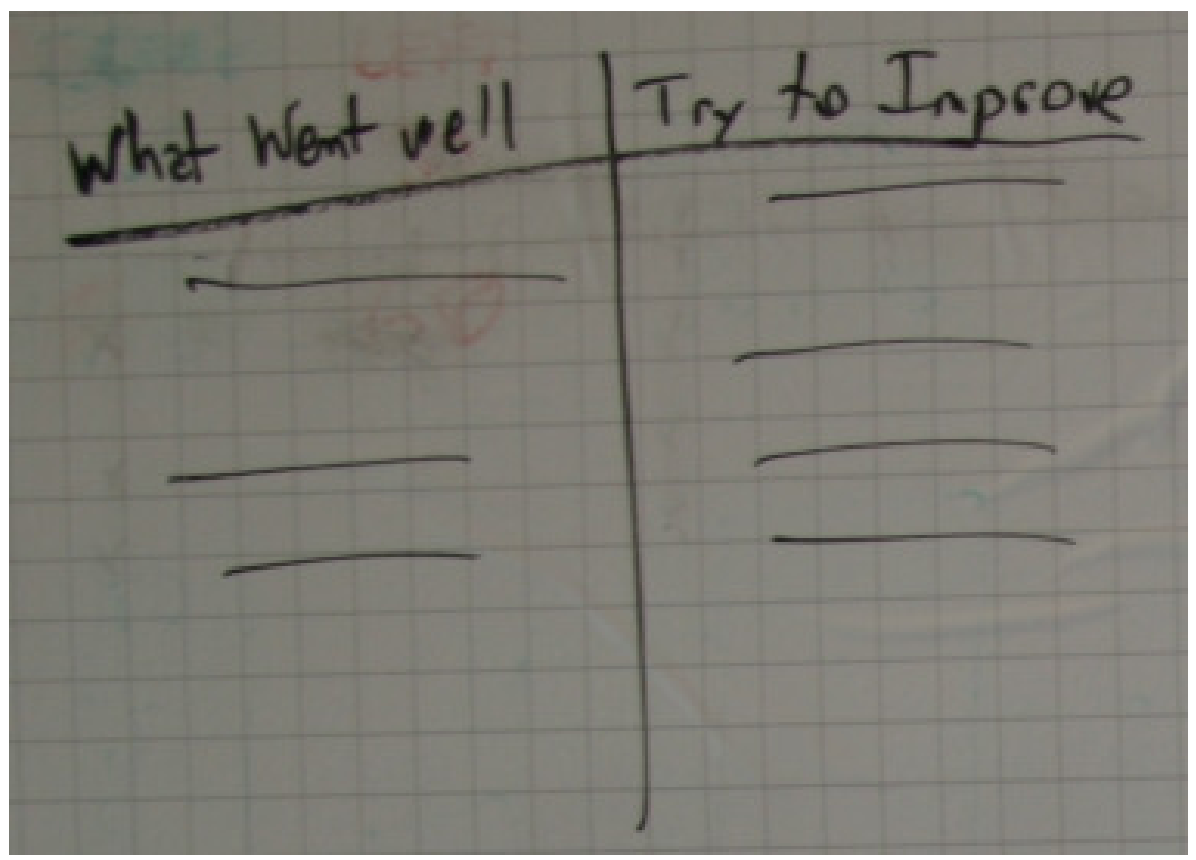

Figura 3.1: Pontos da Retrospectiva [Kua, 2007]

\subsection{Comunicação, reflexão e aprendizado}

Outro princípio vastamente encontrado na definição de diversos métodos ágeis é a comunicação.

Cockburn [2005], ao definir sete propriedades principais do Crystal Clear, define como um destes a comunicação osmótica, que para este autor significa que a informação deve fluir naturalmente dentro da equipe de desenvolvimento.

Beck e Andres [2006] consideram a comunicação como o valor mais importante para o desenvolvimento de software, e que a comunicação está além da simples transmissão de informação, ela também é importante para a sensação na equipe de cooperação eficaz. Beck e Andres [2006] também indicam a importância da reflexão no processo de desenvolvimento de software. De acordo com estes autores, boas equipes de desenvolvimento não apenas realizam seu trabalho, elas pensam como estão trabalhando e por que estão trabalhando.

Schwaber [2008] sugere que após o término de cada iteração, que a equipe de desenvolvimento se reúna para refletir a respeito de pontos positivos e negativos. Apesar disto, Beck e Andres [2006] consideram que momentos de reflexão não devem estar limitados a oportunidades "oficiais", uma conversa informal em um almoço ou cafés pode ser um ambiente para reflexão compartilhada.

O aprendizado é um elemento importante em um ambiente de desenvolvimento de software. Highsmith [1999] considera o aprendizado como uma das bases de sua abordagem proposta para ambientes complexos, o Adaptative Software Development - ASD. O ASD propõe um modelo de "Especule-Colabore-Aprenda" como abordagem a este tipo de problema. No ASD o aprendizado humano é importante pois permite a mudança de comportamento, o que sugere o conceito de adaptabilidade.

Ao analisar os princípios a pouco apresentados, observamos alguma relevância deste tema em relação à realização do acompanhamento ágil em equipes de desenvolvimento. De acordo com Hutchins apud [Blandford e Furniss, 2005], o ambiente social e físico onde indivíduos se encontram possui forte influência em seus processos cognitivos. Hutchins apud [Blandford e Furniss, 2005] afirma que comunicação face-a-face normalmente transmite mais informação do que qualquer outro meio [Blandford e Furniss, 2005]. 
Hartmann e Dymond [2006] afirmam que a comunicação face-a-face é uma ferramenta útil para o processo de melhoria da equipe. Ao discutir sobre a qualidade das métricas utilizadas em uma equipe ágil, Hartmann e Dymond [2006] afirmam que, entre outras propriedades, uma boa métrica promove "combustível" para conversação significativa. Estes consideram que é um bom sinal quando as pessoas conversam a respeito do que estas aprenderam pela observação de uma métrica.

Observa-se a importância da comunicação, reflexão e aprendizado para métodos ágeis, bem como a afirmação de Hartmann e Dymond [2006] a respeito de métricas para a promoção de comunicação e aprendizado. Denota-se que a escolha adequada das métricas a serem utilizadas influenciam a capacidade de melhoria por aprendizado da equipe. Portanto métricas que promovam discussão entre os membros da equipe devem ser levadas em consideração, dado seu benefício, indicado em diversos métodos ágeis.

\subsection{Interação com o cliente}

Um dos princípios encontrados no manifesto ágil é a proximidade da equipe de desenvolvimento com o responsável pelo negócio [Beck et al., 2001b]. Seus benefícios são essenciais para o desenvolvimento ágil.

No Extreme Programming [Beck, 1999], um dos momentos em que a interação com o cliente é mais relevante é no Planning Game, onde será analisado o resultado da entrega realizada bem como o planejamento da próxima iteração. Beck [1999] comenta a respeito da utilização de métricas para eventos como o Planning Game. Para este autor, a utilização de métricas como a diferença entre o tempo estimado e o tempo realizado é básica para a administração do evento, visto que é a partir desta métrica que consegue-se estimar a velocidade da equipe para a próxima iteração.

Em projetos que possuem o cliente presente, prática proposta no Extreme Programming, esta pessoa estará interagindo diretamente com os desenvolvedores e com o espaço de trabalho da equipe de desenvolvimento [Beck, 1999]. Observa-se então a possibilidade de se disponibilizar métricas para o cliente na forma de radiadores de informação.

Como já mencionado na prática "espaço de trabalho informativo", proposta no XP, um observador interessado deve possuir a capacidade de obter uma ideia geral do andamento do projeto em 15 segundos [Beck e Andres, 2006]. Observamos que em determinadas circunstâncias, principalmente em casos com o cliente presente, o próprio cliente pode se enquadrar como observador interessado da prática "espaço de trabalho informativo", visto que caso seja um projeto utilizando Extreme Programming, este cliente estará utilizando o sistema e possivelmente estará interessado em seu desenvolvimento. Por isto, a própria utilização de quadros e cartazes no ambiente de trabalho como forma de comunicação externa deve ser considerada. 


\section{Capítulo 4}

\section{Métodos de pesquisa}

Para a definição do método de pesquisa a ser adotado, foi necessária a compreensão de alguns conceitos relacionados à metodologia científica. Descrevemos alguns conceitos vinculados ao pensamento científico, a divisão tradicional dentre as abordagens de pesquisa, algumas abordagens utilizadas de pesquisa qualitativa, e a definição de métodos mistos de pesquisa.

\subsection{Pensamento científico}

Antes de qualquer tipo de discussão a respeito de diferentes metodologias científicas, é importante ressaltar a abordagem da geração de conhecimento científico.

"Conhecimento Científico: É aquele resultante da investigação metódica, sistemática da realidade, pela transcrição de fatos e fenômenos em si mesmos e analisando-os, a fim de descobrir suas causas e concluir sobre as leis gerais que os governam" ([de Oliveira Netto, 2005], pg 4).

Para a racionalização de premissas em conclusões utilizando-se do método científico, são geralmente utilizadas duas abordagens diferentes de argumentação. Segue abaixo uma breve descrição destas duas abordagens:

1. Dedução. Gauch [2003] afirma que em um argumento dedutivo, a validade de suas premissas garante a validade de suas conclusões. Exemplo: Premissa 1 - Todo mamífero possui um coração. Premissa 2 - Todo cavalo é um mamífero. Conclusão - Todo cavalo possui um coração.

2. Indução. Gauch [2003] afirma que ao contrário de um argumento dedutivo, em um argumento indutivo a validade de suas premissas não garante a validade das conclusões, no entanto, a validade das premissas fortalece a validade das conclusões. Exemplo: Premissa - Todo cavalo observado possui um coração. Conclusão - Todo cavalo possui um coração.

\subsection{Abordagens de pesquisa}

Uma pesquisa científica pode ser classificada, do ponto de vista de abordagem de um problema, como:

1. Pesquisa Quantitativa. De acordo com Silva e Menezes [2001], a pesquisa quantitativa considera tudo que pode ser quantificável, significando traduzir dados e opiniões em números em prol de analisá-los. Para Scott [2009], neste tipo de pesquisa a análise dos dados possui caráter desvinculado do pesquisador com relação aos dados levantados.

2. Pesquisa Qualitativa. Silva e Menezes [2001] afirmam que a pesquisa qualitativa considera uma relação dinâmica entre o mundo real e o sujeito, isto é, um vínculo que não pode ser 
desassociado com o mundo objetivo e que existe subjetividade referente ao sujeito que não permite uma tradução para números. Para identificar essa subjetividade, Silva \& Menezes Silva e Menezes [2001] afirmam que a interpretação dos fenômenos, bem como a atribuição dos significados, é básica no processo gerado por esta abordagem. Para Scott [2009], é neste tipo de pesquisa que a análise dos dados possui caráter interpretativo com os dados levantados.

\subsection{Pesquisa-ação (Action Research)}

Para a realização de pesquisas qualitativas, encontramos alguns métodos diferentes na literatura. Um dos métodos encontrados é o denominado como pesquisa-ação. De acordo com O'Brien [2001], a pesquisa-ação é um método de pesquisa no qual um grupo de pessoas identificam um problema, tomam alguma ação para tratar este problema e analisam seus resultados ao fazê-lo, realizando o processo novamente caso não estejam satisfeitos com o resultado.

Para Thiollent [2004], a pesquisa-ação não é considerada como uma metodologia, e sim um método ou uma estratégia de pesquisa agregando vários métodos ou técnicas de pesquisa social. Durante a utilização dessas técnicas se estabelece uma estrutura coletiva, participativa e ativa ao nível de captação de informação.

De acordo com Silva e Menezes [2001], o método da pesquisa-ação ocorre quando é concebida e realizada uma estreita associação de uma ação executada em um ambiente com a resolução de um problema coletivo, onde os pesquisadores e os outros participantes estão envolvidos de modo cooperativo ou participativo.

O’Brien [2001] afirma que a pesquisa-ação é utilizada em ocasiões reais ao invés de estudos experimentais artificiais, e seu foco é no tratamento de problemas reais. Para O'Brien [2001], este tipo de método também pode ser utilizado para a realização de uma pesquisa preliminar (especialmente quando a situação é muito ambígua para definir uma pergunta de pesquisa precisa).

Para O'Brien [2001], este método de pesquisa é normalmente escolhido quando as circunstâncias requerem flexibilidade, o envolvimento das pessoas na pesquisa, ou quando mudanças devem ser realizadas rapidamente ou holisticamente (observadas como todo ao invés de partes). Thiollent [2004] afirma que a pesquisa-ação encontra um contexto favorável em casos onde os pesquisadores não desejam limitar a pesquisa a aspectos acadêmicos e burocráticos, e sim em pesquisas onde as pessoas implicadas possuam algo a "dizer" e a "fazer". Portando, de acordo com Thiollent [2004], a pesquisa-ação não se trata de um simples levantamento de dados e, e sim em uma pesquisa onde os pesquisadores pretendem desempenhar um papel ativo na própria realidade dos fatos observados.

Thiollent [2004] afirma que o planejamento da pesquisa-ação é muito flexível, e ao contrário de outros tipos de pesquisa, não segue uma série de fases rigidamente ordenadas. Apesar disto, alguns autores propõem um conjunto de etapas a serem realizadas durante o processo de uma pesquisa utilizando pesquisa-ação. Um exemplo fluxo cíclico com etapas da pesquisa-ação pode ser observado na Figura 4.1.

De acordo com Thiollent [2004], na pesquisa-ação existem objetivos práticos de natureza imediata como propor soluções quando for possível e acompanhar ações correspondentes, ou pelo menos, fazer progredir a consciência dos participantes no que diz respeito à existência de soluções e de obstáculos. Este autor justifica como válido este método científico e suas principais características no seguinte trecho:

"Embora seja incompatível com a metodologia de experimentação em laboratório e com os pressupostos do experimentalismo (neutralidade e não-inferência do observador, isolamento de variáveis, etc.), a pesquisa-ação não deixa de ser uma forma de experimentação em situação real, na qual os pesquisadores intervêm conscientemente. Os participantes não são reduzidos a cobaias e desempenham um papel ativo. Além disso, na pesquisa em situação real, as variáveis não são isoláveis. Todas elas interferem no que está sendo observado. Apesar disto, trata-se de uma forma de experimentação na qual os indivíduos ou grupos mudam alguns aspectos da situação pelas ações que decidiram aplicar. Da observação e da avaliação dessas ações, e também pela evidenciação 
dos obstáculos encontrados no caminho, há um ganho de informação a ser captado e restituído como elemento de conhecimento." [Thiollent, 2004]

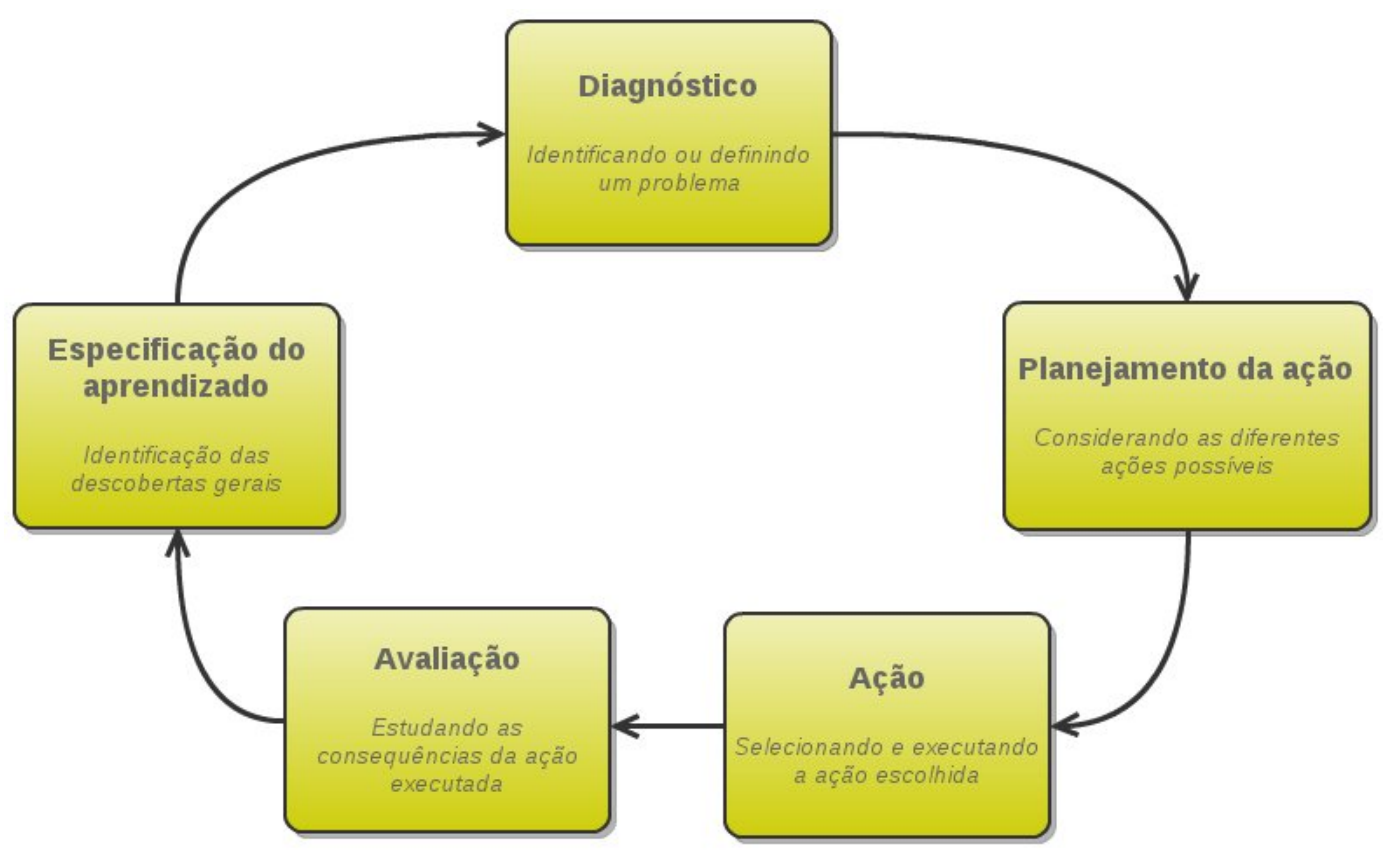

Figura 4.1: Ciclo de vida da pesquisa-ação[O'Brien, 2001].

Uma abordagem baseada em pesquisa-ação é utilizada na pesquisa experimental deste trabalho, mais precisamente em sua fase inicial. Descrevemos mais detalhes sobre esta fase, bem como questões metodológicas e contextuais desta pesquisa, na seção 5.8.2.

\subsection{Pesquisa fundamentada em dados (Grounded Theory)}

A pesquisa fundamentada em dados, ou Grounded Theory (GT), foi desenvolvida por dois sociólogos, Barney Glaser e Anselm Strauss ao final dos anos 70 e é um dos métodos de pesquisa qualitativa mas difundido na área de engenharia de software atualmente. Urquhart et al. [2009] mencionam que na última década houve um acréscimo no interesse na utilização do método de teoria fundamentada em dados em pesquisas na área de sistemas de informação.

Por divergências de pensamento, posteriormente Glaser e Strauss seguiram duas linhas diferentes em suas abordagens da teoria fundamentada em dados, gerando divergências em seus métodos. Neste trabalho seguimos a abordagem da pesquisa fundamentada em dados descrita por Strauss em Strauss e Corbin [2008].

Para Strauss e Corbin [2008], na teoria fundamentada em dados, a teoria é derivada de dados, sistematicamente analisados e reunidos por meio do processo de pesquisa. Strauss e Corbin [2008] afirmam que na utilização deste método, tradicionalmente o pesquisador não possui uma teoria preconcebida, a não ser que se deseje estender uma teoria existente. O objetivo tradicional da utilização da teoria fundamentada em dados é pesquisar uma área de estudo e deixar que teorias sujam a partir de dados sistematicamente coletados, processados e analisados.

Urquhart et al. [2009] associam quatro características que distinguem o método de teoria fundamentada em dados:

1. Possui como finalidade principal a elaboração de teorias;

2. De forma geral, o pesquisador não deve deixar que seu conhecimento de campo o leve a hipóteses pré-formuladas que a pesquisa deve verificar. Tais ideias poderiam impedir que ideias fortemente baseadas nos dados emerjam durante a análise; 
3. Análise e conceitualização devem ser geradas por meio do processo conjunto de coleta de dados e comparação constante;

4. "Pedaços de dados" de todos os tipos são selecionados por um processo de amostragem teórica, onde o pesquisador decide da onde retirar os próximos dados.

Um dos traços inerentes à utilização da teoria fundamentada em dados é o método de processamento dos dados coletados, também chamado de processo de codificação. O método de codificação dos dados é tão inerente à GT, que Urquhart et al. [2009] afirmam que muitas pesquisas têm confundido o método de pesquisa fundamentada em dados com o próprio processo de codificação. Strauss e Corbin [2008] detalham um processo de codificação de dados textuais dividido em três métodos correspondente à cada fase da codificação:

- Codificação aberta. De acordo com Strauss e Corbin [2008], a codificação aberta é um processo analítico por meio do qual os conceitos são identificados e suas propriedades e dimensões são descobertas nos dados. Na codificação aberta, o pesquisador analisa criteriosamente os dados coletados, normalmente em formato textual, tentando identificar fatos, objetos, ações, iterações. Ao identificar estes componentes, o pesquisador procura gerar conceitos que possam descrevê-los, sempre observando o contexto dos dados e informando posicionamentos não óbvios em conjuntos de anotações chamados de memorandos. Para Strauss e Corbin [2008], o ato de conceituação consiste em abstrair, dividir os dados em incidentes, ideias, eventos e atos distintos, que depois recebem um nome que os represente. Após a rotulação dos dados, o pesquisador busca conceitos similares, que representam fenômenos, procurando agrupá-los em categorias, tentando responder à pergunta: "O que está acontecendo aqui?" [Strauss e Corbin, 2008]. Juntamente com a definição de categorias, é nesta fase que se realiza a eleição de subcategorias, que representarão dimensões das categorias identificadas.

- Codificação axial. Após uma análise cuidadosa dos dados, bem como a definição e agrupamento de categorias. A análise axial consiste na identificação dos relacionamentos entre as categorias e suas subcategorias. Strauss e Corbin [2008] afirmam que o nome "axial" se deve ao fato desta associação ser realizada em torno de uma categoria, vinculando as subcategorias como propriedades e dimensões desta categoria. A identificação de subcategorias, apesar de iniciada durante a fase de codificação aberta, se torna mais útil na realização da codificação axial. Enquanto as propriedades de uma categoria descrevem características diversas sobre esta categoria, Strauss e Corbin [2008] afirmam que a definição de dimensões de uma categoria se dá ao tentar responder a perguntas relacionadas ao seu fenômeno correspondente, como por exemplo "O que?", "Quando?", "Por que?", etc.

- Codificação seletiva. Strauss e Corbin [2008] afirmam que é nesta etapa da codificação em que ocorre o processo de integração da análise realizada até o momento, buscando refinar a teoria. Durante esta etapa é que de fato se realiza a elaboração da teoria, com base na análise dos dados, tanto da codificação aberta, quanto da axial. Para realizar esta seleção afim de gerar uma teoria, Strauss e Corbin [2008] definem que nesta etapa deve ser escolhida uma categoria central, a que todas as outras categorias devem se relacionar. Nesta etapa também é realizado o refinamento da teoria, com base na categoria central, bem como a validação teórica. Uma vez que a categoria categoria central foi escolhida, Strauss e Corbin [2008] afirmam que as outras categorias devem ser vinculadas a esta por meio de um conjunto de declarações explanatórias das relações desta com as outras categorias.

Utilizamos técnicas de grounded theory na pesquisa experimental, mais precisamente na fase 3 da pesquisa. Mais detalhes do que foi realizado, bem como detalhes metodológicos da utilização destas técnicas, são descritos na seção 5.6. 


\subsection{Métodos mistos de pesquisa}

A utilização de métodos mistos de pesquisa foge da linha tradicional de pesquisa, que utilizam apenas uma abordagem quantitativa ou apenas qualitativa em seus estudos. Métodos mistos de pesquisas são definidos como uma investigação que combina ou associa tanto formas quantitativas quanto formas qualitativas de pesquisa [Creswell, 2009].

Creswell [2009] afirma que com o desenvolvimento e percepção da legitimidade de tanto a pesquisa quantitativa quanto a pesquisa qualitativa nas ciências humanas, a aplicação de uma combinação de abordagens quantitativas e qualitativas têm ganhado popularidade. Popularidade que, de acordo com Creswell [2009], entre outras razões, se deve ao fato de que problemas endereçados por pesquisadores das ciências sociais e da saúde são complexos, e a utilização de apenas uma abordagem quantitativa ou qualitativa não é suficiente para solucionar esses problemas, além do benefício de se utilizar os pontos fortes de cada uma das abordagens distintas.

Métodos mistos de pesquisa são considerados como relativamente novos nas ciências humanas e sociais como uma abordagem de pesquisa distinta [Creswell, 2009], porém já existem algumas definições básicas sobre sua forma de atuação. Creswell [2009] define alguns fatores/dimensões de correlação entre as abordagens quantitativas e qualitativas durante a realização deste tipo de pesquisa, estas são:

- Momento (Timing): Este é um ponto principal na diferenciação de pesquisas de métodos mistos, pois se refere ao fato de em que momento está sendo realizada cada uma das abordagens: Ao mesmo tempo? Em fases distintas sequenciais? Este item é chave na classificação de métodos mistos de pesquisa - pois define as categorias "concorrente" e "sequencial".

- Peso (Weighting): Este segundo fator entra no planejamento da pesquisa como o peso atribuído a cada uma das abordagens utilizadas, seja ela quantitativa ou qualitativa, ocorrendo de maneira concorrente ou sequencial. Creswell [2009] afirma que a prioridade de cada um dos tipos adotados em uma pesquisa de métodos mistos irá depender de aspectos como os interesses do pesquisador, a audiência do estudo, além do que pretende-se enfatizar nesta investigação.

- Mistura de dados (Mixing): A mistura de dados é outro item relevante em uma pesquisa que se utiliza de métodos mistos, pois se refere à como o pesquisador realiza a correlação entre dados quantitativos e qualitativos em sua pesquisa, e, de acordo Creswell [2009], como este pesquisador mistura as perguntas de pesquisa, sua filosofia, e sua interpretação.

- Teorização ou perspectiva de transformação (Theorizing or Transforming Perspectives ): Este fator se refere ao contexto teórico em que a pesquisa se encontra - se existe uma teoria que envolve o item estudado. Creswell [2009] afirma que em pesquisas de métodos mistos normalmente as teorias são encontradas nas seções iniciais como "lentes" que moldam os tipos de perguntas realizadas, quem participa do estudo, como os dados serão coletados, e as implicações causadas pelo estudo.

Creswell [2009] também descreve uma classificação entre pesquisas que utilizam métodos mistos, de acordo com o momento que as abordagens quantitativas e qualitativas são utilizadas. Esta classificação está dividida entre:

- Métodos mistos sequenciais: Nesta abordagem, a pesquisa utiliza tanto abordagens quantitativas, quanto abordagens qualitativas, de uma forma sequencial - isto é - uma abordagem seguida de outra. Creswell [2009] afirma que neste tipo de abordagem, o pesquisador deseja expandir os resultados e descobertas de um método de pesquisa com outro método. Creswell [2009] indica que uma abordagem deste tipo de pesquisa é começar com uma entrevista qualitativa com fins exploratórios e continuar com um método quantitativo como questionários, para que o pesquisador possa generalizar resultados para uma população maior. Alternativamente, o estudo também pode iniciar com um método quantitativo em que o estudo ou teoria 
é testado, seguido de um método qualitativo envolvendo uma exploração de alguns casos ou indivíduos [Creswell, 2009].

- Métodos mistos concorrentes: Já nesta abordagem, o pesquisador coleta dados de formas diferentes (tanto quantitativas quanto qualitativas) no mesmo momento, afim de integrá-las e possuir uma análise mais abrangente do problema de pesquisa.

Consideramos que a pesquisa experimental realizada neste trabalho se enquadra na classificação de Creswell [2009] como métodos mistos sequenciais. Mais detalhes sobre a abordagem utilizada podem ser observados na seção 5.3 


\section{Capítulo 5}

\section{Pesquisa experimental}

Como já mencionado, o acompanhamento ágil da forma que foi definido neste trabalho, relacionase com referências bibliográficas importantes em métodos ágeis como na descrição de métodos como o Extreme Programming [Beck, 1999, Beck e Andres, 2006], o Scrum [Schwaber, 2008], o Crystal Clear [Cockburn, 2005], o Lean Software Development [Poppendieck e Poppendieck, 2007], etc.

Com base na revisão bibliográfica realizada, encontramos uma baixa quantidade de estudos experimentais relacionados a temas que envolvem o acompanhamento ágil como o espaço de trabalho informativo e a manipulação de métricas (no contexto de métodos ágeis). Por isto, consideramos que a realização de uma pesquisa experimental seria útil para a comunidade ágil, tanto para a academia quanto para a indústria.

Este capítulo descreve a pesquisa experimental realizada, desde a sua proposta de contribuição até a análise dos resultados obtidos em relação à bibliografia existente.

\subsection{Proposta de contribuição}

De acordo com Poppendieck e Poppendieck [2007], princípios são universais, porém nem sempre é fácil visualizar como aplicá-los em ambientes peculiares, ao contrário de práticas que são melhor direcionadas porém necessitam ser adaptadas para o contextos diferentes. Consideramos que a afirmação destes autores se enquadra em diversos aspectos na implementação de métodos ágeis em uma equipe de desenvolvimento de software, devido à natureza adaptativa destes métodos. Consideramos também que a aplicação de conceitos de acompanhamento ágil em uma equipe ágil de desenvolvimento de software não é uma exceção ao aspecto adaptativo de métodos ágeis, em que ações devem ser tomadas com base em princípios.

Dentro dos temas que permeiam o conceito de acompanhamento ágil, existem trabalhos que levam em consideração o conceito de adaptabilidade. A definição de heurísticas para métricas realizada por Hartmann e Dymond [2006] se posicionam como "guia" para a definição de métricas levando em consideração o caráter adaptativo deste tipo de tarefa.

Ao analisar na literatura trabalhos, não encontramos estudos experimentais que buscassem sistematicamente levantar e compreender aspectos úteis na realização do acompanhamento ágil em equipes reais de desenvolvimento. Consideramos, portanto, que uma pesquisa experimental com este objetivo, estudando o acompanhamento ágil em casos reais de desenvolvimento, contribuiria significativamente para a comunidade.

Devido ao conceito de adaptabilidade, consideramos interessante o modelo de "heurísticas" adotado por Hartmann e Dymond [2006]. Identificar aspectos relevantes no acompanhamento ágil por meio do modelo de "heurísticas" possui ao menos duas grandes vantagens. A primeira é que este modelo sugere que diferentes ações sejam tomadas de acordo com o contexto encontrado. A segunda é que a heurística resume uma ideia abstrata, e por isto uma única heurística pode resultar em diversas ações a serem executadas dentro de um mesmo ambiente.

Ao final desta pesquisa experimental pretendemos sugerir algumas heurísticas para a manipulação e disponibilização de informações no ambiente de trabalho, no contexto de uma equipes ágeis de 
desenvolvimento co-localizadas. Além disto, pretendemos demonstrar algumas razões e condições de como aplicar estas heurísticas. Maiores detalhes de como esta pesquisa experimental foi realizada podem ser encontrados nas seguintes seções deste capítulo.

\subsection{Ambiente de estudo}

Encontramos a oportunidade de aplicar esta pesquisa experimental em um ambiente acadêmico de desenvolvimento de software. Este ambiente de desenvolvimento foi formado devido à realização de uma disciplina do departamento de Ciência da Computação do Instituto de Matemática e Estatística da Universidade de São Paulo.

A disciplina em questão denomina-se "Laboratório de Programação Extrema" e possui como objetivo que alunos de graduação e pós-graduação aprendam aspectos relacionados a métodos ágeis por meio da participação real em projetos ágeis de desenvolvimento de software. A pesquisa experimental realizada neste trabalho foi aplicada envolvendo duas turmas desta disciplina, suas realizações no primeiro semestre de 2010 e 2011.

No contexto da turma de 2010, formaram-se oito projetos de desenvolvimento de software. A descrição de cada um destes projetos, bem como o tema de seu software desenvolvido pode ser observado na Tabela 5.1, juntamente com a quantidade de indivíduos envolvidos em cada um dos projetos.

Tabela 5.1: Projetos de software analisados - 2010

\begin{tabular}{|c|c|c|}
\hline Nome do Projeto & Tipo de Projeto & $\begin{array}{l}\text { Qtde. } \\
\text { Integrantes }\end{array}$ \\
\hline Archimedes & $\begin{array}{l}\text { Plugin da plataforma eclipse para o pro- } \\
\text { cessamento de CAD. }\end{array}$ & 6 \\
\hline Atletismo & $\begin{array}{l}\text { Sistema de acompanhamento do treina- } \\
\text { mento de atletas. }\end{array}$ & 6 \\
\hline Baile & $\begin{array}{l}\text { Sistema de utilidades orientado a servi- } \\
\text { ços. }\end{array}$ & 5 \\
\hline Calopsita & $\begin{array}{l}\text { Sistema para administração de projetos } \\
\text { ágeis. }\end{array}$ & 6 \\
\hline CoGrOO & $\begin{array}{l}\text { Interface web para a integraçãa do pro- } \\
\text { jeto de correção ortográfica - CoGrOO. }\end{array}$ & 6 \\
\hline Dojo On-line & $\begin{array}{l}\text { Sistema web para a realização de confe- } \\
\text { rências Dojo com integrantes geografica- } \\
\text { mente distantes. }\end{array}$ & 7 \\
\hline Ingresso na Pós & $\begin{array}{l}\text { Sistema para administração do ingresso } \\
\text { dos estudantes na pós-graduação do } \\
\text { IME-USP. }\end{array}$ & 6 \\
\hline Mezuro & $\begin{array}{l}\text { Sistema web para a utilização de ferra- } \\
\text { menta de métricas de projetos open- } \\
\text { source. }\end{array}$ & 6 \\
\hline
\end{tabular}

Já na turma de 2011, 7 equipes foram formadas, sendo que duas estavam envolvidas no mesmo projeto, porém desenvolvendo módulos diferentes com finalidades diferentes dentro de seu contexto. Algumas informações sobre estas equipes e seus projetos podem ser observadas na tabela 5.2. Três dos projetos dos sete desenvolvidos no ano anterior foram mantidos, tendo seu desenvolvimento continuado no ano de 2011. Apesar disto, a vasta maioria dos integrantes destes projetos não havia trabalhado em nenhum destes projetos anteriormente nem tampouco participado na disciplina no ano de 2010 - o que constitui uma situação similar à encontrada no ano de 2010.

Em ambas as turmas, cada aluno da disciplina escolheu qual projeto desejaria participar de acordo com uma lista de preferências pessoais. O objetivo de cada equipe era o desenvolvimento de 
Tabela 5.2: Projetos de software analisados -2011

\begin{tabular}{lll}
\hline \hline Nome do Projeto & Tipo de Projeto & $\begin{array}{l}\text { Qtde. } \\
\text { Integrantes }\end{array}$ \\
\hline $\begin{array}{l}\text { CHOReOS - mid- } \\
\text { dleware }\end{array}$ & $\begin{array}{l}\text { Tem o objetivo de ter um protótipo do } \\
\text { Middleware para coreografia de serviços } \\
\text { web. }\end{array}$ \\
CHOReOS - V \& V & $\begin{array}{l}\text { Tem como objetivo desenvolver um fra- } \\
\text { mework para testes automatizados de } \\
\text { coreografias de serviços web. }\end{array}$ \\
& $\begin{array}{l}\text { Plugin da plataforma eclipse para o pro- } \\
\text { cessamento de CAD. }\end{array}$ \\
Arquimedes & $\begin{array}{l}\text { Sistema web para a utilização de ferra- } \\
\text { menta de métricas de projetos open- }\end{array}$ \\
Mezuro & $\begin{array}{l}\text { source. } \\
\text { Sistema para administração do ingresso }\end{array}$ & 6 \\
dos estudantes na pós-graduação do & \\
Ingresso na Pós & $\begin{array}{l}\text { IME-USP. } \\
\text { Rede social para a construção colabora- }\end{array}$ & 7 \\
tiva de um acervo digital de imagens da & \\
Arquigrafia & $\begin{array}{l}\text { arquitetura brasileira. } \\
\text { Sistema para administração de listas de }\end{array}$ & 6 \\
& $\begin{array}{l}\text { exercícios a serem preenchidas na inter- } \\
\text { net. }\end{array}$ & \\
\hline Lista de Exercícios \\
on-line
\end{tabular}

sistemas de código aberto, utilizando métodos ágeis, e assim aprender sobre estes métodos de desenvolvimento por meio de uma experiência prática. Cada um destes grupos possuía um integrante na posição de coach. Os indivíduos na posição de coach foram escolhidos para liderarem o desenvolvimento das equipes, possuindo a responsabilidade de assegurar que as equipes utilizassem e compreendessem os princípios presentes em métodos ágeis ao aplicá-los em seus projetos. A escolha destes indivíduos se deu buscando integrantes mais experientes em métodos ágeis de desenvolvimento. Esta escolha foi realizada pelo próprio professor organizador da disciplina.

Para cada equipe existiam um ou mais indivíduos interessados no desenvolvimento e utilização do software de cada projeto desenvolvido. Indivíduos com este papel foram encarados como clientes das equipes - tendo-se como base o modelo de interação e colaboração com o cliente definida em métodos ágeis como o Extreme Programming [Beck, 1999].

Durante ambos os semestres das duas turmas, foram realizadas reuniões semanais entre coaches afim de discutir problemas, sugerir melhorias, compartilhar informações e promover ideias, tanto para um melhor desenvolvimento de cada grupo envolvido, quanto para o bom andamento da disciplina e do aprendizado pelos alunos.

Para a turma de 2010, houve uma disponibilidade de dois alunos de mestrado auxiliarem o bom andamento dos projetos envolvidos, estes alunos se enquadraram em um papel denominado Meta-coach. Ambos pesquisavam temas relacionados a métodos ágeis de desenvolvimento e possuíam experiência na realização desta disciplina por diversos anos. Estes alunos também possuíam experiência em métodos ágeis, tanto academicamente quanto profissionalmente, inclusive chegaram a participar de eventos internacionais na área de desenvolvimento ágil. Parte das responsabilidades dos Meta-coaches era de acompanhar as equipes de desenvolvimento, direcionando a equipe em como lidar com o desenvolvimento dos projetos por meio da utilização de métodos ágeis e nas técnicas disponíveis, além de remover impedimentos ligados à infra-estrutura do ambiente.

A participação do pesquisador deste trabalho na turma de 2010 perante os integrantes das equipes de desenvolvimento se deu por meio de um papel denominado como Meta-tracker. O Metatracker, que era o pesquisador deste trabalho, foi a figura criada durante a realização da disciplina, 
e possuía como objetivo auxiliar e realizar sugestões às equipes com relação a tarefas de acompanhamento ágil durante o desenvolvimento dos projetos realizados. O Meta-tracker também era um aluno de mestrado, pesquisando o tema de acompanhamento e espaço de trabalho informativo em métodos ágeis. Além disto, este indivíduo possuía cerca de cinco anos de experiência na área de desenvolvimento de software, além de ter experiências passadas trabalhando com métodos ágeis.

Devido a criação da figura do Meta-tracker, bem como a oportunidade criada para o estudo do tema deste trabalho no ambiente mencionado, a utilização de uma abordagem baseada em pesquisaação durante a fase inicial/exploratória se tornou viável, e foi aplicada na turma de 2010. Detalhes desta fase inicial, bem como suas intervenções nas equipes de desenvolvimento, são melhor descritas na seção 5.8.2.

Apesar do conjunto de papéis estabelecidos para suportar as equipes de desenvolvimento, em ambas as turmas cada equipe possuía autonomia para a tomada de decisões em assuntos como o andamento de seu projeto, sua interação com o cliente, forma de trabalho, etc. Esta autonomia era válida enquanto estas decisões não impactassem negativamente no bom andamento da disciplina.

O contexto da turma de 2011 era bastante similar. A turma possuía dois alunos na figura de Meta-coach, porém neste caso uma aluna de doutorado e um aluno de mestrado - ambos estudando temas relacionados a métodos ágeis - além do mesmo professor da disciplina para auxiliar as equipes com o mesmo papel exercido em 2010.

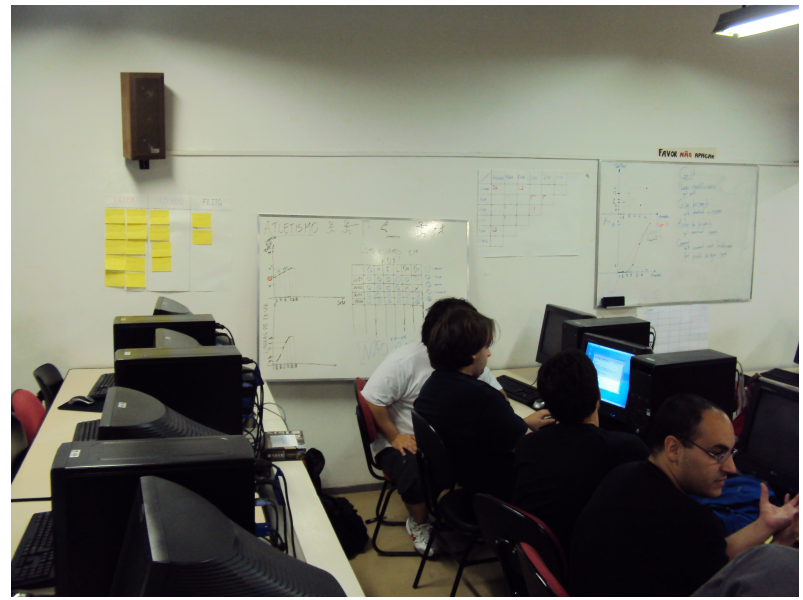

Figura 5.1: Foto do espaço de trabalho da equipe Atletismo

No contexto de 2011, não houve intervenção do pesquisador por meio de nenhum papel, o que se mostrou relevante para a aplicação com sucesso da quarta fase da pesquisa. Mais detalhes sobre esta fase específica podem ser observados na seção 5.7 .

Em ambas as turmas, o desenvolvimento de todos os projetos era realizado em um ambiente de laboratórios da universidade, mais precisamente no Centro de Ensino de Computação do IME-USP. Era requisitado para todos os integrantes das equipes a carga horária de dedicação presencial de 8 horas semanais, sendo que possuíam o hábito de partilhar o momento de almoço ao menos uma vez por semana. De forma geral, os integrantes das equipes trabalhavam no desenvolvimento de maneira presencial em ambas as turmas, com raras exceções.

Diversas fotos foram capturadas pelo pesquisador durante a realização de 2010 da disciplina que exemplificam o ambiente físico em que as equipes se encontravam. Algumas destas fotos são disponibilizadas nas figuras 5.1, 5.2 e 5.3 .

O ambiente de 2010 foi o adotado para realização das três fases iniciais desta pesquisa, enquanto no ambiente de 2011 foi aplicada a fase 4 . Mais detalhes sobre a abordagem adotada em cada uma destas fases são descritos na seção 5.3 . 


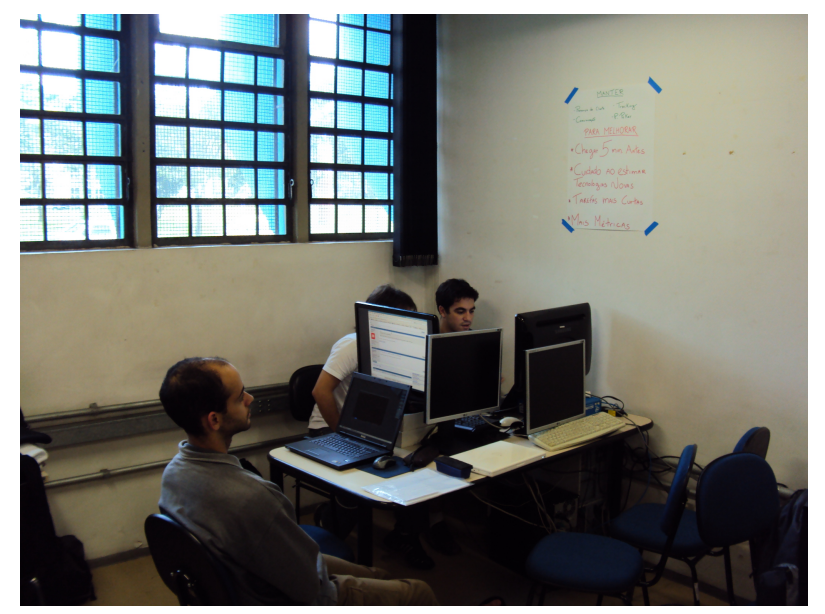

Figura 5.2: Foto do espaço de trabalho da equipe Baile

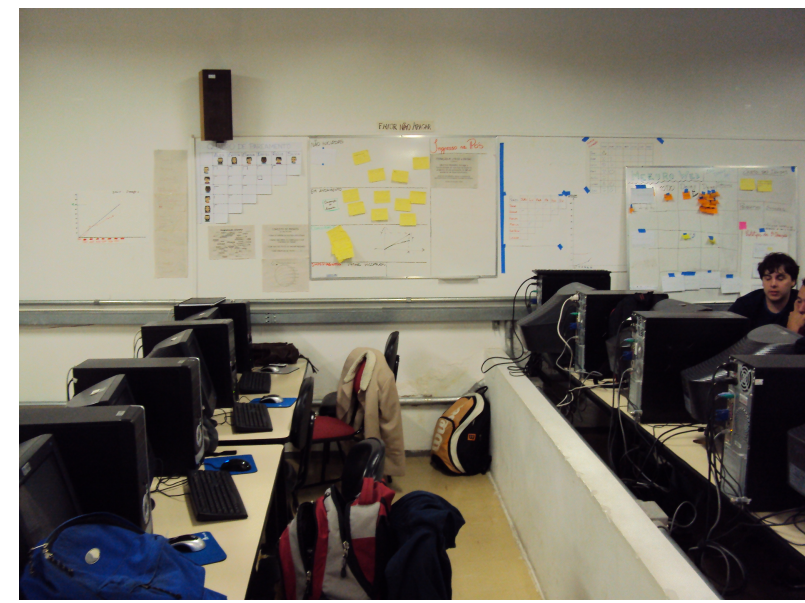

Figura 5.3: Foto do espaço de trabalho da equipe Ingresso na Pós

\subsection{Método utilizado}

Como já mencionado, propomos neste trabalho uma pesquisa experimental com os seguintes objetivos:

1. Levantar aspectos úteis para o acompanhamento ágil a partir das experiências das equipes;

2. Compreender as razões por detrás da aparente utilidade de cada um dos aspectos levantados.

Dado o ambiente estudado, bem como os objetivos deste trabalho, realizamos esta pesquisa experimental utilizando a abordagem de métodos mistos sequenciais [Creswell, 2009]. Utilizamos esta abordagem pois permite que apliquemos diferentes métodos, tanto quantitativos, quanto qualitativos, para expandir os resultados da pesquisa de maneira sequencial - e assim obter respostas mais completas sobre o problema de estudo.

Observamos que o conceito de acompanhamento ágil é muito abrangente, pois relaciona-se com diversos temas diferentes como métricas, layout e disposição do espaço de trabalho, cognição humana a respeito da disponibilização de informações, adaptabilidade da equipe por meio de informações, etc. Por isto consideramos que o levantamento inicial de aspectos úteis para o acompanhamento ágil possui caráter subjetivo. Além disto, este caráter subjetivo também se deve à adaptabilidade deste tipo de tarefa ao contexto específico de cada equipe.

Portanto, para atingir o objetivo de levantar aspectos úteis para o acompanhamento ágil, adotamos na fase inicial deste estudo uma abordagem qualitativa de pesquisa. Devido à oportunidade encontrada de interagir com os oito projetos de desenvolvimento software descrita na seção 5.2, 


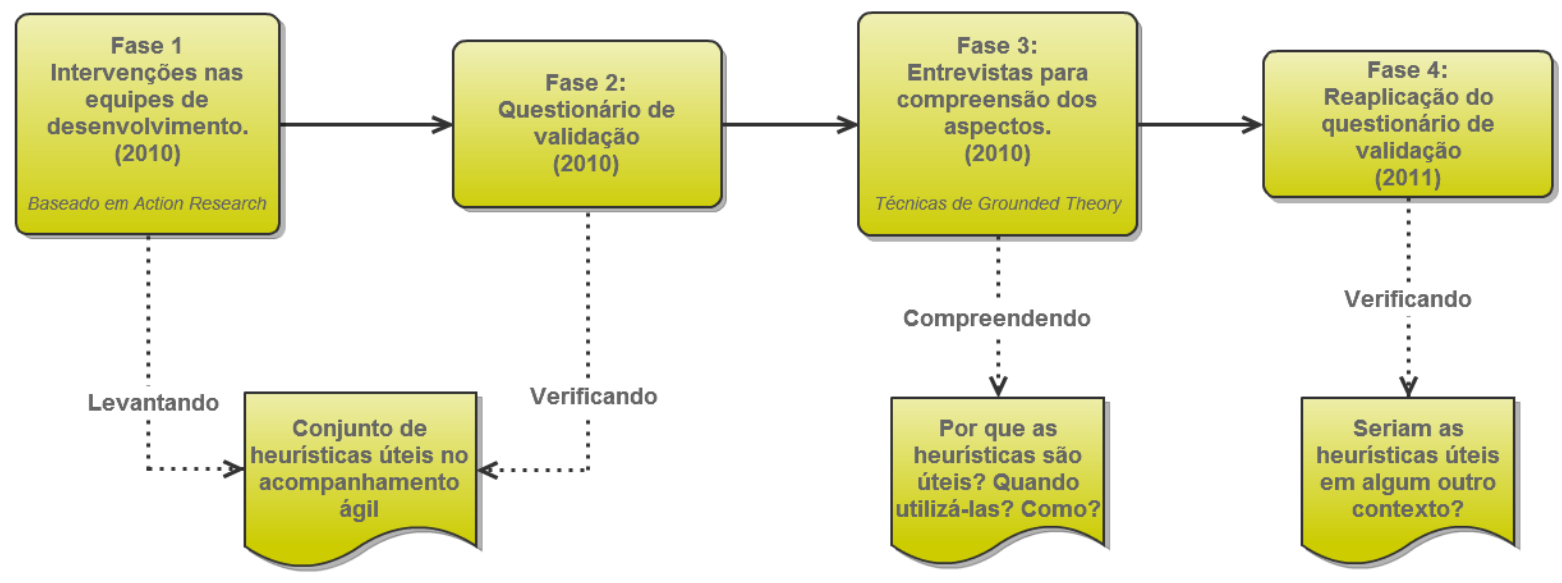

Figura 5.4: Método misto sequencial: Fases da pesquisa experimental

em que o pesquisador possuía responsabilidades de auxiliar e sugerir melhorias para as equipes de desenvolvimento por meio do papel de Meta-tracker, nesta fase realizamos uma abordagem baseada em pesquisa-ação [Thiollent, 2004].

A fase 1 consistiu de uma série de intervenções nas equipes de desenvolvimento da turma de 2010, mediante a reuniões com os integrantes de cada equipe de desenvolvimento. Nestas reuniões realizamos sugestões para a melhoria relacionadas ao acompanhamento ágil e depois avaliamos os efeitos das sugestões realizadas, seguindo uma abordagem baseada em pesquisa-ação (action research) Thiollent [2004]. Por meio dessas intervenções, juntamente com a análise da bibliografia, levantamos alguns aspectos que aparentaram ser úteis/importantes para a administração e disponibilização de informações durante o andamento dos projetos analisados. Maiores detalhes a respeito da periodicidade das reuniões com as equipes de desenvolvimento, bem como as sugestões realizadas, métodos de avaliação, resultados obtidos e análise destes resultados são melhor descritos na seção 5.8.2.

Apesar das intervenções no ambiente, realizadas durante a fase 1, a interação e análise do pesquisador levou em consideração apenas o que foi tratado nas reuniões, tanto na realização das sugestões, quanto na avaliação das mesmas. Observamos que as interações de cada equipe com tarefas de acompanhamento ágil se deu de forma mais abrangente do que o tratado nas reuniões descritas na fase 1. Além disto, a abordagem da fase 1, quando foi realizada, não previa um método avaliativo a respeito de o quão útil/importante se revelaria cada um dos aspectos levantados. Consideramos que este tipo de informação seria útil para avaliar utilidade/importância dos aspectos levantados na fase 1, auxiliando para reforçá-los como valiosos ou não, levando em consideração a experiência e avaliação pessoal de cada integrante das oito equipes de desenvolvimento.

Com o objetivo de melhor avaliar os aspectos levantados na fase 1, consideramos que uma abordagem quantitativa se aplicaria melhor, e portanto para a fase 2 deste estudo aplicamos um questionário para todos os integrantes das equipes de desenvolvimento da turma de 2010. Dados sobre a formulação deste questionário bem como a taxa de respondentes e os resultados obtidos estão descritos na seção 5.8.2.

Além de levantar aspectos úteis para o acompanhamento, realizado na fase 1, e melhor avaliar sua utilidade nos projetos analisados, realizado na fase 2 , consideramos como interessante a contribuição de compreender o "por quê?" da utilidade de cada um destes aspectos. Consideramos que para compreender as razões por detrás dos aspectos levantados, seria útil realizarmos entrevistas com alguns integrantes das equipes de desenvolvimento com esta finalidade. Para isso, realizamos uma série de entrevistas semi-estruturadas, realizando perguntas relacionadas à utilidade/importância dos aspectos levantados na fase 1. Estas entrevistas foram aplicadas para alguns membros das equipes da turma de 2010. Os dados resultantes destas entrevistas foram analisados utilizando 
técnicas da teoria fundamentada em dados (grounded theory). Mais detalhes sobre a realização das entrevistas, bem como o método de codificação utilizado, e os resultados desta análise são disponibilizados na seção 5.6.

Apesar de aplicarmos um questionário na fase 2, com características quantitativas, para avaliarmos os aspectos levantados na fase 1, ambas as fases seriam realizadas com foco na mesma turma, a de 2010. Tendo em vista que o processo de sugestões e intervenções nas equipes durante a fase 1 foram realizadas pelo pesquisador, seria útil uma avaliação dos aspectos levantados na fase $1 \mathrm{em}$ relação a uma turma em que o pesquisador não teve participação alguma. Para isto, a fase 4 desta pesquisa consistiu na aplicação deste mesmo questionário para a turma de 2011, a fim de obter dados que permitissem alguma triangulação sobre a validade dos aspectos levantados na fase 1. Mais detalhes sobre a fase 4 podem ser observadas na seção 5.7.

A Figura 5.4 exemplifica visualmente o design da pesquisa experimental realizada, tendo-se como ambiente estudado o cenário descrito na seção 5.2.

\section{$5.4 \quad$ Fase 1}

Como já mencionado, durante a fase 1 desta pesquisa, possuíamos o objetivo de levantar alguns aspectos aparentemente úteis referentes ao tema estudado, o acompanhamento ágil. Por isto, consideramos esta fase da pesquisa com um caráter exploratório no ambiente mencionado na seção 5.2, o que justificou a utilização de uma abordagem qualitativa de pesquisa.

A escolha por uma abordagem baseada em pesquisa-ação também se deu devido à oportunidade de atuar ativamente nestas equipes de desenvolvimento, auxiliando-as justamente com relação ao tema estudado neste trabalho. Como já mencionado na seção 4.3, a colaboração do pesquisador em relação ao objeto de estudo [O'Brien, 2001] para a realização de ações para a resolução de problemas coletivos [Silva e Menezes, 2001] são características da pesquisa-ação.

As intervenções realizadas nas equipes de desenvolvimento se deram por meio de entrevistas periódicas a estas equipes. As intervenções eram realizadas na média a cada 15 dias, porém sua periodicidade variava de acordo com a disponibilidade dos integrantes da equipe. A cada entrevista procurávamos interagir com indivíduos interessados das equipes de desenvolvimento, porém foi dada prioridade para a presença dos coaches das equipes, pois além de serem indivíduos mais experientes, possuíam responsabilidade sobre os outros integrantes da equipe, bem como para o bom andamento de seu projeto.

Em cada reunião realizada com cada equipe de desenvolvimento, alguns assuntos eram tratados. Dentro da realização de cada reunião, procurávamos compreender o contexto atual da equipe de desenvolvimento, situação do projeto, satisfação do cliente, entregas, situação do espaço de trabalho informativo, etc. Após contextualização da situação do projeto, identificávamos alguns problemas indicados pela própria equipe de desenvolvimento com relação a seu projeto. Muitas vezes o próprio pesquisador identificava possíveis problemas na disponibilização de informações no ambiente de trabalho da equipe.

Com a compreensão do contexto, problemas atuais e potenciais melhorias no ambiente, realizávamos sugestões para a equipe de desenvolvimento. Essas sugestões visavam a resolução de algum problema levantado pela equipe, ou alguma possível melhoria no ambiente correspondente identificado pelo pesquisador, utilizando-se de tarefas relacionadas ao acompanhamento ágil, isto é, manipulação e disponibilização de informações para a equipe de desenvolvimento.

As sugestões realizadas em uma reunião eram posteriormente avaliadas pela equipe de desenvolvimento. Para cada sugestão realizada para uma equipe de desenvolvimento em uma reunião, era requisitado um retorno avaliativo para esta equipe em alguma das reuniões posteriores. $\mathrm{O}$ resumo do retorno indicado para cada sugestão realizada foi transcrito, e posteriormente classificado da forma descrita na seção 5.4.1. Na época em que esta fase da pesquisa foi realizada, não possuíamos conhecimento suficiente sobre métodos avaliativos para serem aplicados em uma abordagem de pesquisa-ação, e por esta razão este método avaliativo foi adotado. Por isto, consideramos que a validade dos aspectos levantados por meio da análise dos dados da fase 1 deveria ser verificada por 
meio de um instrumento mais adequado para este fim, o que justifica a realização da fase 2 desta pesquisa experimental.

Como já mencionado na seção 4.3, a pesquisa-ação não é considerada como uma metodologia de pesquisa, e sim como um método [Thiollent, 2004]. Por isto, seu planejamento é flexível, e não exige fases rigidamente ordenadas durante sua realização. Apesar disto, autores como Susman apud [O’Brien, 2001] especificam fases específicas para a realização de uma pesquisa-ação.

A abordagem utilizada nesta fase 1 não foi planejada com vínculo às etapas cíclicas descritas por Susman apud [O'Brien, 2001], porém consideramos que os procedimentos adotados se assemelham a este conjunto de etapas. Estas etapas são melhor descritas na seção 4.3 e exemplificadas pela Figura 4.1. Susman apud [O'Brien, 2001] define alguns procedimentos na pesquisa-ação por meio do ciclo "diagnosticar um problema", "planejar uma ação", "realizar a ação", "avaliar as consequências de uma ação", "especificar aprendizado".

Consideramos que os mesmos procedimentos definidos no ciclo de Susman apud [O'Brien, 2001] foram realizados, apesar de procedimentos como "identificar um problema" e "planejar uma ação" terem sido realizados imediatamente em uma mesma reunião. Apesar disto, não realimentávamos o conhecimento adquirido de forma sistemática, como apontado pelo ciclo deste autor. Ao contrário, a análise do conjunto de dados coletados se deu apenas em um período próximo ao final do semestre em que esta pesquisa experimental foi realizada.

Detalhes de como os dados desta fase da pesquisa foram coletados são descritos na seção 5.4.1.

\subsubsection{Dados coletados}

Durante as entrevistas, sugestões foram realizadas com base em características identificadas no contexto da equipe. A equipe possuía total autonomia em seguir ou não seguir as sugestões realizadas.

O registro dos dados da fase 1 foi dado da seguinte forma: Para manter a dinamicidade das reuniões, porém não perder detalhes relevantes para a realização das sugestões, durante a reunião ou logo após a mesma anotávamos uma transcrição breve das sugestões realizadas e das características identificadas do contexto que justificam a realização de cada sugestão em uma planilha eletrônica. Estas sugestões eram anotadas, juntamente com seu contexto, e posteriormente (em outra reunião) requisitávamos à equipe um retorno sobre a utilidade de cada sugestão, transcrevendo na mesma planilha um resumo da opinião dos integrantes entrevistados relacionadas à sugestão.

Posteriormente, próximo ao final do período de acompanhamento das equipes, realizamos uma classificação do retorno coletado e, para facilitar a análise inicial, cada retorno foi classificado da seguinte forma:

1. Positivo - Considerado como positivo (Apenas apresenta opiniões positivas em relação à relevância da sugestão realizada);

2. Negativo - Considerado como negativo (Apenas apresenta opiniões negativas em relação à relevância da sugestão realizada);

3. Indeterminado - Não está claro se tende para positivo ou negativo (Opiniões não apresentam um direcionamento claro, ou possui opiniões tanto positivas quanto negativas por entre os integrantes da equipe presentes na reunião);

4. Não realizado - Objeto da sugestão não foi implementado, impossibilitando análise sobre o retorno;

5. Não coletado - Sugestão foi realizada, porém não houve possibilidade de coleta do retorno correspondente à sugestão.

Os dados de cada sugestão realizada, características do contexto que justificam esta sugestão e classificação do retorno obtido sobre esta sugestão estão disponíveis por equipe, nas tabelas 5.3, 5.4, 
5.5, 5.6, 5.7, 5.8, 5.9 e 5.10. Também disponibilizamos para cada sugestão um número identificador (Id), afim de facilitar referências posteriores para sugestões específicas no decorrer deste texto.

Tabela 5.3: Baile - Intervenções

\begin{tabular}{|c|c|c|c|}
\hline Id & Contexto & Intervenção (Sugestão) & Retorno \\
\hline 1 & $\begin{array}{l}\text { Equipe deseja realizar entregas nos prazos } \\
\text { e "vencer a inércia". }\end{array}$ & $\begin{array}{l}\text { Pontuar as datas importantes no } \\
\text { quadro. }\end{array}$ & Positivo \\
\hline 2 & $\begin{array}{l}\text { Quadro de histórias realizadas considerado } \\
\text { confuso. }\end{array}$ & Utilizar burndown ou burn-up. & Positivo \\
\hline 3 & $\begin{array}{l}\text { Quadro que relaciona testes não aparenta } \\
\text { clareza na relação entre testes escritos e } \\
\text { testes com falhas. }\end{array}$ & $\begin{array}{l}\text { Alterar quadro para medir quanti- } \\
\text { dade total de testes e quantidade de } \\
\text { testes com falhas. }\end{array}$ & Não realizado \\
\hline 4 & $\begin{array}{l}\text { Equipe considera alta a quantidade de bugs } \\
\text { e deseja tratá-los. }\end{array}$ & $\begin{array}{l}\text { Representar no quadro tarefas de } \\
\text { bugs com uma cor diferenciada de } \\
\text { post-it. }\end{array}$ & Positivo \\
\hline 5 & $\begin{array}{l}\text { Equipe está atrasando em suas entregas e } \\
\text { deseja identificar quais tarefas são respon- } \\
\text { sáveis por seu atraso. }\end{array}$ & $\begin{array}{l}\text { Disponibilizar diariamente a rela- } \\
\text { ção entre o gasto/estimado das ta- } \\
\text { refas atuais sendo trabalhadas. }\end{array}$ & Positivo \\
\hline
\end{tabular}

Tabela 5.4: Calopsita - Intervenções

\begin{tabular}{ll}
\hline Id & \multicolumn{1}{c}{ Contexto } \\
\hline 1 & $\begin{array}{l}\text { Equipe não está se atentando à informa- } \\
\text { ções em alguns quadros. }\end{array}$ \\
2 & $\begin{array}{l}\text { Equipe não está se atentando à informa- } \\
\text { ções em alguns quadros (mesma que su- } \\
\text { gestão 1). }\end{array}$ \\
3 & $\begin{array}{l}\text { Considera-se a representação de uma pes- } \\
\text { soa pelas iniciais de seu nome como não } \\
\text { intuitivo no kanban. } \\
\text { Alguns quadros distantes não estão sendo } \\
\text { observados pelos membros da equipe. }\end{array}$
\end{tabular}

$5 \quad$ Alguns quadros estão difíceis de visualização pela distância.

6 Considera-se poluído o visual disponibilizado no quadro principal da equipe e existe quadro de "Pontos a melhorar" ocupando parte deste espaço.

$7 \quad$ Considera-se poluído o visual disponibilizado no quadro principal da equipe e existe um lembrete para discussão ocupando parte deste espaço.

8 Considera-se poluído o visual disponibilizado no quadro principal da equipe.

9 Considera-se poluído o visual disponibilizado no quadro principal da equipe e medidas totais das iterações realizadas partilham deste espaço.

10 Integrantes da equipe não estão atualizando periodicamente os quadros.

11 Tarefas de desenvolvimento da equipe são realizadas em par e pretende-se valorizar a atenção às métricas levantadas.

\begin{tabular}{lr}
\multicolumn{1}{c}{ Intervenção (Sugestão) } & Retor \\
$\begin{array}{l}\text { Realizar a atualização dos quadros } \\
\text { durante a reunião diária da equipe. }\end{array}$ & Positivo \\
$\begin{array}{l}\text { Não acrescentar excessivamente o } \\
\text { número de quadros no ambiente. }\end{array}$ & Positivo \\
\end{tabular}

Representar as pessoas por seu nome, escrito no quadro com um pequeno tamanho de fonte.

Alterar a localização destes quadros para uma mais próxima do local da realização da reunião diária.

Aumentar o tamanho dos quadros mais distantes.

Transformar "Pontos a melhorar" em cartaz acima do quadro.

Positivo

Positivo

Não realizado

Positivo

Transformar lembrete para discussão também em cartaz acima do quadro.

Eliminar informações não mais necessárias para o contexto.

Montar um quadro com um gráfico de colunas para representar esta informação e removê-la do quadro.

Rotacionar a função do tracker entre os membros da equipe.

Delegar as tarefas de atualização dos quadros e cartazes para um par de integrantes ao invés de apenas um integrante.

Indeterminado

Positivo

Positivo

Positivo

Positivo 
Tabela 5.4 - Continuação

\begin{tabular}{|c|c|c|c|}
\hline Id & Contexto & Intervenção (Sugestão) & Retorno \\
\hline 12 & $\begin{array}{l}\text { Deseja-se valorizar a rotatividade da fun- } \\
\text { ção de tracker. }\end{array}$ & $\begin{array}{l}\text { Montar um quadro para visual- } \\
\text { mente verificar a quantidade de dias } \\
\text { que um membro específico exerceu } \\
\text { esta função. }\end{array}$ & Positivo \\
\hline 13 & $\begin{array}{l}\text { Quadro de burn-up está distante do lo- } \\
\text { cal de discussão possui difícil aproximação } \\
\text { pois compartilha cartolina com o gráfico de } \\
\text { testes. }\end{array}$ & $\begin{array}{l}\text { Separar o burn-up e o quadro de tes- } \\
\text { tes. }\end{array}$ & Positivo \\
\hline 14 & $\begin{array}{l}\text { Mesmo separado, o burn-up está distante e } \\
\text { não gera discussão na reunião diária. }\end{array}$ & $\begin{array}{l}\text { Eliminar o burn-up atual em carto- } \\
\text { lina e criar um novo baseando-se no } \\
\text { quadro branco. }\end{array}$ & Positivo \\
\hline 15 & $\begin{array}{l}\text { Burn-up não indica exatamente qual data } \\
\text { corresponde a uma situação de pontos de } \\
\text { tarefa finalizados (apenas número do dia } \\
\text { dentro da iteração), o que dificulta a com- } \\
\text { paração com a situação atual. }\end{array}$ & $\begin{array}{l}\text { Indicar data em cada dia da itera- } \\
\text { ção disponibilizada no burn-up. }\end{array}$ & Positivo \\
\hline 16 & $\begin{array}{l}\text { Lembrete de discussão das métricas não } \\
\text { está sendo observado. }\end{array}$ & Remover quadro com o lembrete. & Não coletado \\
\hline 17 & $\begin{array}{l}\text { É necessário de espaço no quadro branco e } \\
\text { Kanban está ocupando parte relevante do } \\
\text { espaço disponível. }\end{array}$ & $\begin{array}{l}\text { Redesenhar o quadro do kanban } \\
\text { redimensionando-o para um tama- } \\
\text { nho menor. }\end{array}$ & Positivo \\
\hline
\end{tabular}

Tabela 5.5: Atletismo - Intervenções

\begin{tabular}{|c|c|}
\hline Id & Contexto \\
\hline 1 & $\begin{array}{l}\text { Equipe aponta dificuldade técnica no } \\
\text { aprendizado de uma tecnologia específica. }\end{array}$ \\
\hline 2 & $\begin{array}{l}\text { Não está visivelmente clara a diferenciação } \\
\text { entre os humores dispostos relacionados ao } \\
\text { aprendizado tecnológico. }\end{array}$ \\
\hline 3 & $\begin{array}{l}\text { Equipe não realizou entrega de funciona- } \\
\text { lidade na iteração anterior e está preocu- } \\
\text { pada com o conteúdo entregue no final da } \\
\text { iteração atual }\end{array}$ \\
\hline 4 & $\begin{array}{l}\text { Existem dois quadros diferentes incenti- } \\
\text { vando a escrita de testes e considera-se que } \\
\text { este ponto não é necessidade fundamental } \\
\text { para a situação atual. }\end{array}$ \\
\hline 5 & $\begin{array}{l}\text { Equipe deseja manter sempre dois inte- } \\
\text { grantes da equipe alocados para tarefas de } \\
\text { teste de funcionalidades e refatorações ne- } \\
\text { cessárias. }\end{array}$ \\
\hline 6 & $\begin{array}{l}\text { Equipe realiza reunião diária em local afas- } \\
\text { tado do kanban. }\end{array}$ \\
\hline
\end{tabular}

7 Não está visualmente disponível o responsável por cada tarefa no kanban e considera-se que isto é importante.

8 Equipe aponta dúvidas pontuais na tecnologia Ruby on Rails e existem outras equipes fisicamente próximas que utilizam a mesma tecnologia.

Intervenção (Sugestão) Retorno

Criar um quadro para medir o humor de cada membro da equipe vinculado ao conhecimento desta tecnologia (Humorômetro).

Utilizar cores diferentes para melhorar a diferenciação visual destes itens.

Utilizar quadro de burn-up e definir Positivo uma meta mínima de sucesso,

Excluir um dos quadros e manter apenas um, o mais aplicável (no caso, o de cobertura de testes).

Manter tarefas de testes representadas por post-its de cor diferente em relação às tarefas de desenvolvimento.

Trocar o kanban de uma cartolina fixada na parede por um disponível no quadro móvel.

Criar post-its com os nomes dos integrantes e disponibilizá-los associados às tarefas diárias alocadas aos mesmos.

Montar quadro de dúvidas gerais Não realizado sobre Ruby on Rails para compartilhamento equipes distintas.
Positivo

Positivo

Positivo

Positivo

Positivo

Positivo 
Tabela 5.5 - Continuação

\begin{tabular}{|c|c|c|c|}
\hline Id & Contexto & Intervenção (Sugestão) & Retorno \\
\hline 9 & $\begin{array}{l}\text { Disponibilização de gráfico de cobertura de } \\
\text { testes se encontra com leves alterações com } \\
\text { base em } 100 \% \text {, porém informação ainda é } \\
\text { útil para o acompanhamento da equipe. }\end{array}$ & $\begin{array}{l}\text { Alterar a disponibilização desta in- } \\
\text { formação para uma discriminação } \\
\text { de dois estados, "100\%" e "Abaixo } \\
\text { de } 100 \% " \text {. }\end{array}$ & Positivo \\
\hline 10 & $\begin{array}{l}\text { Indicativo do estado da cobertura de tes- } \\
\text { tes está desenhado, o que dificulta prática } \\
\text { alteração. }\end{array}$ & $\begin{array}{l}\text { Alterar seta desenhada para post-it, } \\
\text { permitindo maior usabilidade deste } \\
\text { indicador. }\end{array}$ & Não realizado \\
\hline
\end{tabular}

Tabela 5.6: Mezuro - Intervenções

\begin{tabular}{ll}
\hline Id & \multicolumn{1}{c}{ Contexto } \\
\hline 1 & $\begin{array}{l}\text { Equipe aponta desnível técnico entre os } \\
\text { membros a respeito da tecnologia adotada. }\end{array}$ \\
2 & $\begin{array}{l}\text { Equipe aponta problemas recentes na pre- } \\
\text { paração de ambiente de desenvolvimento. }\end{array}$ \\
3 & $\begin{array}{l}\text { Não está disponibilizado no espaço de tra- } \\
\text { balho quem está alocado para cada tarefa } \\
\text { e considera-se isso como possível contribui- } \\
\text { ção visual. } \\
4\end{array}$ \\
$\begin{array}{l}\text { Equipe realiza reunião diária em um corre- } \\
\text { dor, o que dificulta a visualização dos qua- } \\
\text { dros na parede. }\end{array}$ \\
$5 \quad \begin{array}{l}\text { Corredor dificulta comunicação e discussão } \\
\text { sobre os quadros e as métrica. } \\
\text { Equipe irá realizar a reunião diária em lo- } \\
\text { cal diferente de seu espaço de trabalho. }\end{array}$
\end{tabular}

$7 \quad$ Função do tracker é realizada por diversos integrantes, porém a organização do exercício desta função não está visualmente disponibilizada, permitindo rotatividade não igualitária por entre os membros.

8 Equipe indica que deseja medir estimativas erradas, possui quadro de burn-up, porém a verificação do andamento ideal da iteração só se torna claro perto de seu final.

9 Equipe indica que deseja medir estimativas erradas.

10 Equipe deseja entender a satisfação do cliente.

11 Equipe deseja coletar satisfação de seu cliente remoto.

12 Local de manipulação do quadro não possui fácil acesso a material como caneta e post-its e considera-se que isto esteja inibindo alterações eventuais.

Intervenção (Sugestão) Retorno

Criar um quadro para medir o hu- Positivo mor de um membro com relação à tecnologia em questão.

Manter lista de impedimentos re- Positivo lacionados a ambiente e infraestrutura disponível no quadro.

Disponibilizar nomes dos integrantes associados a cada tarefa diariamente.

Mudar o local da reunião diária para uma outra localidade que promova proximidade dos integrantes do quadro.

Realizar reunião diária em semicirculo.

Escolher informações mais importantes e mantê-lo no quadro móvel, permitindo proximidade dos mesmos em uma reunião diária fisicamente longe do espaço da equipe.

Criar uma tabela indicando a quan- Não realizado tidade de dias em que cada membro da equipe exerceu função de tracker.

Vincular ao burn-up a métrica de situação esperada dado velocidade estimada e situação atual.

Criar quadro comparando pontos de tarefa planejado/realizado entre iterações distintas.

Associar ao quadro do burn-up a satisfação coletada do cliente, relacionando coleta e tarefas desenvolvidas.

Coletar por resposta de e-mail ao cliente a sua satisfação atual discretizada entre poucas possibilidades de rostos emotivos associados.

Disponibilizar um conjunto de postits dispostos ao lado do quadro bem como uma caneta de quadro nas proximidades.

\section{Positivo}

Positivo

Positivo

Não realizado

Não realizado

Não realizado

Positivo

Positivo

Não coletado 
Tabela 5.6 - Continuação

\begin{tabular}{llll} 
Id & \multicolumn{1}{c}{ Contexto } & \multicolumn{1}{c}{ Intervenção (Sugestão) } & Retorno \\
\hline 13 & $\begin{array}{l}\text { Nome dos integrantes vinculados a cada ta- } \\
\text { refa está sendo reescritos diariamente. }\end{array}$ & $\begin{array}{l}\text { Criar post-its contendo o nome de } \\
\text { cada integrante e associá-lo à tarefa } \\
\text { na reunião diária. }\end{array}$ & Positivo \\
14 & $\begin{array}{l}\text { Equipe aponta problemas anteriores com } \\
\text { o alinhamento entre uma funcionalidade } \\
\text { imaginada em relação a esperada pelo } \\
\text { usuário. }\end{array}$ & $\begin{array}{l}\text { Criar tarefa de validação com usuá- } \\
\text { rio com representação no quadro via } \\
\text { post-it. }\end{array}$ & Não colado \\
\hline
\end{tabular}

Tabela 5.7: Dojo Online - Intervenções

\begin{tabular}{|c|c|c|c|}
\hline Id & Contexto & Intervenção (Sugestão) & Retorno \\
\hline 1 & $\begin{array}{l}\text { Equipe realiza reunião diária fisicamente } \\
\text { distante de alguns cartazes importantes es- } \\
\text { tão fora da visão dos membros em suas ati- } \\
\text { vidades diárias. }\end{array}$ & $\begin{array}{l}\text { Alterar o local destes cartazes para } \\
\text { se manter próximos à reunião diá- } \\
\text { ria. }\end{array}$ & Não realizado \\
\hline 2 & $\begin{array}{l}\text { Equipe afirma não ter sido realizada troca } \\
\text { constante de pares }\end{array}$ & $\begin{array}{l}\text { Aumentar tamanho do quadro de } \\
\text { pareamento e aproximá-lo ao local } \\
\text { da reunião diária. }\end{array}$ & Positivo \\
\hline 3 & $\begin{array}{l}\text { Equipe possui integrantes com perfis téc- } \\
\text { nicos específicos e importantes para a alo- } \\
\text { cação de tarefas. }\end{array}$ & $\begin{array}{l}\text { Criar um quadro com estabeleci- } \\
\text { mento de perfis técnicos. }\end{array}$ & Não realizado \\
\hline 4 & $\begin{array}{l}\text { Equipe identificou problemas com tecnolo- } \\
\text { gias específicas. }\end{array}$ & $\begin{array}{l}\text { Criar um quadro que demonstre o } \\
\text { aprendizado de cada integrante em } \\
\text { cada tecnologia. }\end{array}$ & Não realizado \\
\hline 5 & $\begin{array}{l}\text { Equipe realizou retrospectiva e estabele- } \\
\text { ceu pontos a serem melhorados que mesmo } \\
\text { após uma iteração não foram tratados ade- } \\
\text { quadamente. }\end{array}$ & $\begin{array}{l}\text { Disponibilizar em cartaz os pontos } \\
\text { estabelecidos na última retrospec- } \\
\text { tiva para serem tratados. }\end{array}$ & Não coletado \\
\hline
\end{tabular}

Tabela 5.8: CoGrOO - Intervenções

\begin{tabular}{ll}
\hline Id & \multicolumn{1}{c}{ Contexto } \\
\hline 1 & $\begin{array}{l}\text { Tabela de pareamento possui iniciais de } \\
\text { cada nome, e considera-se esta representa- } \\
\text { ção pessoal insuficientemente clara. } \\
\text { Local onde é realizada a reunião diária não } \\
\text { permite proximidade do quadro por toda a } \\
\text { equipe. }\end{array}$ \\
3 & $\begin{array}{l}\text { Equipe realiza método rotativo de mem- } \\
\text { bros na função de tracker porém não ad- } \\
\text { ministra visualmente esta informação. } \\
\text { Equipe deseja não permitir que uma funci- } \\
\text { onalidade seja entregue sem testes. }\end{array}$
\end{tabular}

5 Equipe deseja valorizar a criação de testes automatizados em suas tarefas.

6 Equipe aponta que o tempo de suas reuniões diárias está muito alto.

\begin{tabular}{ll}
\multicolumn{1}{c}{ Intervenção (Sugestão) } & Retorno \\
rocar iniciais pela escrita completa & Positivo \\
os nomes.
\end{tabular}
dos nomes.

Alterar o local da reunião diária juntamente com o quadro kanban para um melhor local.

Disponibilizar no quadro membro atual e futuro na função de tracker.

Indicar em cada post-it de tarefa na cor vermelha uma letra "A" representando ausência de testes e em verde a letra " $\mathrm{T}$ " representando o estado de com testes.

Criar quadro indicando a quantidade de testes criados pela equipe.

Criar local no quadro branco temporário para medir tempo decorrido de reunião diária - em momento de reunião diária.
Positivo

Positivo

Positivo

Indeterminado

Positivo 
Tabela 5.8 - Continuação

\begin{tabular}{|c|c|c|c|}
\hline Id & Contexto & Intervenção (Sugestão) & Retorno \\
\hline 7 & $\begin{array}{l}\text { Equipe está mapeando problemas em meio } \\
\text { à área do quadro do burn-up e considera-se } \\
\text { que isto está poluindo o sentido do quadro. }\end{array}$ & $\begin{array}{l}\text { Criar especificamente um quadro } \\
\text { para tratamento de problemas en- } \\
\text { contrados. }\end{array}$ & Não coletado \\
\hline 8 & $\begin{array}{l}\text { Considera-se que a equipe possui área vi- } \\
\text { sual de seu espaço de trabalho poluída e } \\
\text { quadro de "commits por dia" não aparenta } \\
\text { mais possuir utilidade. }\end{array}$ & $\begin{array}{l}\text { Remover quadro de "commits por } \\
\text { dia". }\end{array}$ & Não coletado \\
\hline 9 & $\begin{array}{l}\text { Equipe mantém uma lista consideravel- } \\
\text { mente grande de itens a lembrar dispos- } \\
\text { tas visualmente, complicando a visibili- } \\
\text { dade dos itens mais importantes. }\end{array}$ & $\begin{array}{l}\text { Diminuir a quantidade de itens dis- } \\
\text { postos para apenas os poucos mais } \\
\text { importantes. }\end{array}$ & Não coletado \\
\hline 10 & $\begin{array}{l}\text { Considera-se que equipe se encontra com } \\
\text { excesso de informação visual. }\end{array}$ & $\begin{array}{l}\text { Remover/reduzir quadros desneces- } \\
\text { sários/menos importantes para li- } \\
\text { berar área visual. }\end{array}$ & Não coletado \\
\hline
\end{tabular}

Tabela 5.9: Ingresso na Pós - Intervenções

\begin{tabular}{ccccc}
\hline Id & Contexto & Intervenção (Sugestão) & Retorno \\
\hline 1 & $\begin{array}{l}\text { Equipe enfrenta problemas com equipe } \\
\text { completa durante seu horário de trabalho. }\end{array}$ & $\begin{array}{l}\text { Estabelecer uma meta de horas com } \\
\text { time completo e criar um quadro } \\
\text { para disponibilizar esta informação. }\end{array}$ \\
& $\begin{array}{l}\text { Equipe está realizando reunião diária em } \\
\text { corredor e possui quadros importantes que }\end{array}$ & $\begin{array}{l}\text { Montar no ambiente um apoio para } \\
\text { quadros com papelão ou outro ma- }\end{array}$ & Não realizado
\end{tabular}
estão de difícil acesso a 110 número derável de membros da equipe.

3 Equipe possui pontos que acabaram de ser reconhecidos para serem tratados em retrospectiva.

4 Quadro de "dedicação" encontrado na equipe não possui legenda e possui conteúdo não claro para uma pessoa de fora da equipe.

5 Para o quadro de "dedicação remota", existe um eixo falso na disponibilização deste gráfico (2 dimensões, porém a informação é em 1 dimensão).

6 Equipe possui meta de horas de trabalho com equipe completa alta ( $100 \%$ do trabalho da equipe) e está com problemas com relação a ausências e o cumprimento desta meta.

7 Não cumprimento de uma meta alta no quadro de "Dedicação" se demonstra desestimulante.

8 Considera-se que quadro branco possui excesso de informações disponibilizadas e ausência de espaço vazio para preenchimento diverso.

9 Considera-se que quadro branco possui excesso de informações disponibilizadas e ausência de espaço vazio para preenchimento quadros com papelão ou outro material disponível.

Criar quadros ou métricas para estes assuntos focando-se de uma forma coletiva ao invés da individual.

Inserir legenda dos dados dispostos Positivo no quadro.

Reconstruir o gráfico em apenas uma dimensão para clarificar a informação.

Definir uma nova meta mais baixa, visando alcançabilidade.

Positivo

Alterar o título de "Dedicação" do quadro para desvincular uma meta de quantidade de horas não atingida de uma equipe com baixa dedicação.

Utilizar post-its menores no kanban Positivo com frases curtas.

Redesenhar o quadro de kanban Não realizado com um tamanho menor. 
Tabela 5.9 - Continuação

Id

Contexto

10 Ausência de espaço vazio para preenchimento diverso e existe uma área de informações a serem realizadas em momento de "commit" que considera-se não mais com alta necessidade.

11 Considera-se que quadro branco possui excesso de informações disponibilizadas e ausência de espaço vazio para preenchimento diverso (mesma que para sugestão 8).

12 Equipe aponta que não está clara a comparação entre o planejado $\mathrm{x}$ realizado em seu quadro de burn-up.

13 Coach da equipe considera que integrantes não se demonstram interessados nas informações disponibilizadas no espaço visual da equipe.

14 Coach da equipe considera que integrantes não se demonstram interessados nas informações disponibilizadas no espaço visual da equipe (mesma que sugestão 13).

15 Coach da equipe considera que integrantes não se demonstram interessados nas informações disponibilizadas no espaço visual da equipe (mesma que sugestão 13 e 14).

16 Significado das medições no quadro de burn-up não está claro.
Intervenção (Sugestão)

Retorno

Remover área de informações em momento de "commit" do quadro branco.

Rearranjar quadros e informações para manter ao menos um quarto do quadro branco para preenchimentos eventuais.

Apontar em forma de tracejado estas duas realidades.

Rotacionar os membros na função de tracker.

Realizar o preenchimento e alterações dos quadros em pares de integrantes.

Criar um quadro demonstrando a quantidade de dias que cada integrante participou como tracker.

Disponibilizar legenda indicando as medições realizadas neste gráfico.

Positivo

Positivo

Não realizado

Positivo

Não realizado

Não realizado

Não realizado

Tabela 5.10: Archimedes - Intervenções

\begin{tabular}{|c|c|c|c|}
\hline Id & Contexto & Intervenção (Sugestão) & Retorno \\
\hline 1 & $\begin{array}{l}\text { Equipe aponta que deseja melhorar o "au- } \\
\text { xílio ao tracker". }\end{array}$ & $\begin{array}{l}\text { Realizar as atividades de tracking } \\
\text { em duplas. }\end{array}$ & Positivo \\
\hline 2 & $\begin{array}{l}\text { Equipe aponta que deseja melhorar o "au- } \\
\text { xílio ao tracker" (mesma que sugestão 1). }\end{array}$ & $\begin{array}{l}\text { Rotacionar os membros na função } \\
\text { de tracker constantemente. }\end{array}$ & Não realizado \\
\hline 3 & $\begin{array}{l}\text { Equipe aponta que deseja melhorar o "au- } \\
\text { xílio ao tracker" (mesma que sugestão } 1 \text { e } \\
\text { 2). }\end{array}$ & $\begin{array}{l}\text { Criar "coluna" para identificar } \\
\text { quantas vezes cada integrante } \\
\text { participou como tracker com o } \\
\text { intuito de igualar a rotatividade. }\end{array}$ & Positivo \\
\hline 4 & $\begin{array}{l}\text { Equipe aponta problema na compreensão } \\
\text { correta a respeito da implementação de } \\
\text { uma funcionalidade. }\end{array}$ & $\begin{array}{l}\text { Marcar separadamente com um as- } \\
\text { terisco o post-it correspondente a } \\
\text { uma funcionalidade com implemen- } \\
\text { tação já clara para a equipe. }\end{array}$ & Não realizado \\
\hline 5 & $\begin{array}{l}\text { Equipe aponta problema na compreensão } \\
\text { correta a respeito da implementação de } \\
\text { uma funcionalidade (mesma que sugestão } \\
\text { 4). }\end{array}$ & $\begin{array}{l}\text { Criar post-it de tarefa "verificar } \\
\text { com o cliente" relacionado com cada } \\
\text { funcionalidade. }\end{array}$ & Positivo \\
\hline 6 & $\begin{array}{l}\text { Equipe enfrenta problemas para a escolha } \\
\text { da sua alimentação para um dia da semana } \\
\text { específico. }\end{array}$ & $\begin{array}{l}\text { Montar quadro para a sugestão e } \\
\text { votação pelos integrantes da esco- } \\
\text { lha de estabelecimento a ser ado- } \\
\text { tado para o almoço da equipe. }\end{array}$ & Positivo \\
\hline 7 & $\begin{array}{l}\text { Equipe deseja realizar mais "commits" e } \\
\text { "updates" no versionador diariamente. }\end{array}$ & $\begin{array}{l}\text { Montar quadro indicando se "já re- } \\
\text { alizei update hoje?" e "Quantidade } \\
\text { de commits". }\end{array}$ & Não realizado \\
\hline
\end{tabular}




\subsubsection{Análise e proposta de heurísticas}

O principal objetivo da fase 1 da pesquisa foi de levantar aspectos úteis para o acompanhamento ágil com base em uma abordagem baseada em pesquisa-ação.

O método de avaliação utilizado para cada uma das sugestões realizadas foi simplesmente resumir as opiniões dos integrantes em reuniões posteriores à que a sugestão havia sido dada, anotando-as para posterior análise. Consideramos que o método de avaliação utilizado não foi muito adequado para avaliar quais sugestões haviam resultado em maior benefício para as equipes comparativamente com outras sugestões. Observamos que um mecanismo quantitativo para avaliação em que pudéssemos coletar a informação "quão útil você considera o resultado desta sugestão" seria mais apropriado, porém apenas percebemos isto próximo ao final do período de acompanhamento das equipes.

Tendo esta restrição em vista, analisamos os dados coletados e propomos alguns aspectos que aparentaram ser úteis durante as intervenções realizadas com as equipes de desenvolvimento. Para esta proposta, também levamos em consideração nossa experiência obtida ao realizar tais intervenções e ao presenciar as reuniões com as equipes, quando esta afirmava o retorno obtido por cada sugestão.

Segue a lista de heurísticas propostas, disponíveis na Tabela 5.11, relacionando-as com algumas intervenções realizadas nas equipes de desenvolvimento que obtiveram retorno positivo.

Tabela 5.11: Heurísticas propostas

\begin{tabular}{|c|c|c|}
\hline Heurística & Equipe & ID \\
\hline \multirow{6}{*}{$\begin{array}{l}\text { Mantenha quadros mais importantes próximos ao local da reu- } \\
\text { nião diária }\end{array}$} & Calopsita & 4 \\
\hline & Calopsita & 14 \\
\hline & Atletismo & 6 \\
\hline & Dojo Online & 2 \\
\hline & $\mathrm{CoGrOO}$ & 2 \\
\hline & Mezuro & 4 \\
\hline \multirow{2}{*}{$\begin{array}{l}\text { Promova a alteração dos radiadores de informação por todos os } \\
\text { integrantes da equipe }\end{array}$} & Calopsita & 10 \\
\hline & Ingresso na Pós & 13 \\
\hline \multirow{5}{*}{ Foque-se em necessidades específicas do momento } & Calopsita & 12 \\
\hline & Atletismo & 1 \\
\hline & Atletismo & 3 \\
\hline & Mezuro & 1 \\
\hline & Mezuro & 2 \\
\hline \multirow{6}{*}{$\begin{array}{l}\text { Disponibilize a informação de forma a ser facilmente assimilada } \\
\text { pelo cérebro }\end{array}$} & Calopsita & 3 \\
\hline & Calopsita & 9 \\
\hline & Calopsita & 15 \\
\hline & Atletismo & 2 \\
\hline & Atletismo & 5 \\
\hline & CoGrOO & 1 \\
\hline \multirow[b]{2}{*}{ Realize preenchimento e(ou) alterações em duplas } & Archimedes & 1 \\
\hline & Calopsita & 11 \\
\hline \multirow[t]{2}{*}{ Promova praticidade e facilidade de manutenção } & Mezuro & 13 \\
\hline & Calopsita & 2 \\
\hline Remova quadros com pouco valor & Calopsita & 16 \\
\hline
\end{tabular}

Os dados coletados na fase 1 se mostraram relevantes para o domínio estudado pois recebemos feedback relacionado a cada sugestão realizada para equipes de desenvolvimento vinculada ao tema de acompanhamento ágil. Apesar disto, os dados coletados se restrigem apenas às situações em que realizamos as sugestões acima descritas, e portanto outras situações vivenciadas pelas equipes de 
desenvolvimento não foram acompanhadas.

Para levar outras experiencias das equipes em consideração, e não apenas as relacionadas com nossas sugestões, criamos um questionário com caráter quantitativo, disposto na fase 2 , que procura avaliar se de fato as heurísticas levantadas apresentam utilidade por entre os membros das equipes. Devido a esta restrição do método avaliativo da fase 1, apenas com seus resultados não podemos afirmar que as heurísticas levantadas representam os aspectos mais importantes vinculados ao acompanhamento ágil neste ambiente, e sim uma lista de aspectos aparentemente úteis. A afirmação das heurísticas levantadas representarem aspectos úteis no ambiente estudado deverá ser concluído também com base nos dados do questionário quantitativo, como mecanismo de triangulação para reforçar esta afirmação.

\section{$5.5 \quad$ Fase 2}

Por meio dos dados coletados durante a fase 1 foi possível direcionar a pesquisa para a compreensão das sete heurísticas propostas, relacionadas com retornos positivos de sugestões realizadas nas equipes de desenvolvimento estudadas.

Apesar da identificação de um conjunto de heurísticas propostas ter sido realizada relacionandoa com retornos positivos, considera-se que os dados coletados na fase 1 não são suficientes para a real validação das mesmas. Para esta validação, foi proposta a aplicação de um questionário parcialmente fechado para os integrantes destas equipes.

\subsubsection{Formulação do questionário de validação}

O questionário formulado foi disponibilizado para todos os integrantes das equipes de desenvolvimento por meio de uma página na internet. O questionário foi formulado focando-se em perguntas fechadas seguindo a escala Likert de cinco pontos, visto seu objetivo primário de validação das heurísticas. Estas perguntas foram elaboradas buscando avaliar o valor que cada aspecto relacionado às heurísticas possuiu nas experiências dos integrantes das equipes como o valor em se possuir quadros e (ou) cartazes próximos ao local da reunião diária ou o valor em se remover quadros que perderam valor no contexto da equipe, etc. Formulamos estas perguntas requisitando que o participante avaliasse a utilidade ou importância de cada um desses aspectos ao indicar o valor adequado na escala (Muito baixa/Baixa/Média/Alta/Muito Alta). O termo utilizado para representar o valor [Utilidade ou Importância] foi escolhido de acordo com o conceito de cada aspecto para que as perguntas fizessem sentido ao respondente. Utilizamos o temo utilidade para aspectos que representem uma característica positiva aparentemente opcional no contexto do acompanhamento ágil, enquanto o termo importância foi utilizado para características que podem gerar impacto negativo caso não estejam presentes no contexto.

Apesar da maioria de suas perguntas serem diretamente relacionadas ao valor das heurísticas, consideramos útil manter perguntas de contextualização do participante, tendo em vista a anonimidade de sua participação. As perguntas de contextualização englobavam aspectos como qual a equipe do integrante em questão bem como se este participante era coach ou não desta equipe. Além dos aspectos de contextualização do participante, considerou-se interessante disponibilizar questões abertas gerais sobre o tema de acompanhamento ágil para fins exploratórios.

Segue uma representação textual do questionário disponibilizado pela internet para os integrantes das equipes analisadas:

\section{- Considerações iniciais}

1. A qual equipe você pertence?* - Múltipla escolha

2. Você é coach de sua equipe?* (Sim/Não) 
3. Como você classifica a sua interação na manipulação de quadros e(ou) cartazes durante o desenvolvimento de seu projeto?*

Interação: (Muito Baixa, Baixa, Média, Alta, Muito Alta)

\section{- Proximidade da reunião diária}

1. Você considera que, durante o desenvolvimento de seu projeto, quadros e(ou) cartazes importantes estiveram próximos ao local da reunião diária de sua equipe, ao invés de apenas presentes no ambiente de trabalho?*

(Sim/Não)

2. (Visibilidade condicional à resposta "Sim" na pergunta anterior) Quão importante você considera o fato de quadros e(ou) cartazes importantes estarem próximos ao local da reunião diária, ao invés de apenas presentes no ambiente de trabalho, dentro do contexto de seu projeto?*

Importância: (Muito Baixa, Baixa, Média, Alta, Muito Alta)

\section{- Acompanhamento coletivo}

1. Você considera que, durante o decorrer de seu projeto, a manipulação de quadros e(ou) cartazes foi bem divida por entre a maioria dos integrantes de sua equipe?* - Obs: Este aspecto inclui tanto o casos onde esta divisão ocorreu através da rotatividade dos integrantes como casos onde esta divisão ocorreu diariamente (Sim/Não)

2. (Visibilidade condicional à resposta "Sim" na pergunta anterior) Quão útil você considera o fato da manipulação de quadros e(ou) cartazes ter sido bem dividida por entre a maioria dos membros de sua equipe?*

Utilidade: (Muito Baixa, Baixa, Média, Alta, Muito Alta)

\section{- Tratamento de problemas específicos}

1. Você considera que, em algum momento durante o decorrer de seu projeto, sua equipe se utilizou de quadros e(ou) cartazes para lidar com problemas específicos encontrados durante seu desenvolvimento?*

(Sim/Não)

2. (Visibilidade condicional à resposta "Sim" na pergunta anterior) Quão útil você considera o fato da manipulação de quadros e(ou) cartazes ter sido realizada para lidar com problemas específicos encontrados durante o desenvolvimento de seu projeto?*

Utilidade: (Muito Baixa, Baixa, Média, Alta, Muito Alta)

\section{- Facilidade de assimilação}

1. Você considera que, em algum momento de seu projeto, houve a disponibilização de informações contidas em quadros e(ou) cartazes de forma que estas se encontraram fáceis de serem assimiladas?* Obs: Isto inclui a utilização de imagens, cores, post-its com cores diferentes, e outras formas de disponibilização levando-se em consideração a facilidade de assimilação da informação dentro do ambiente do projeto.

(Sim/Não)

2. (Visibilidade condicional à resposta "Sim" na pergunta anterior) Quão importante você considera o fato das informações contidas em quadros e(ou) cartazes terem sido disponibilizadas de forma fácil de serem assimiladas, dentro do contexto de seu projeto?* Importância: (Muito Baixa, Baixa, Média, Alta, Muito Alta)

\section{- Pareamento no tracking}


1. Houve, em algum momento de seu projeto, a manipulação de quadros e(ou) cartazes em duplas, entre os integrantes da equipe?*

(Sim/Não)

2. (Visibilidade condicional à resposta "Sim" na pergunta anterior) Quão útil você considera o fato da manipulação de quadros e(ou) cartazes ter sido realizada em duplas, dentro do contexto de seu projeto?*

Utilidade: (Muito Baixa, Baixa, Média, Alta, Muito Alta)

\section{- Praticidade na manipulação}

1. Como você classifica a importância da praticidade na manipulação de quadros e cartazes utilizados no contexto de seu projeto?* Obs: Isto inclui tanto aspectos referentes ao preenchimento cotidiano, quanto a alteração/substituição de quadros e(ou) cartazes já existentes

Importância: (Muito Baixa, Baixa, Média, Alta, Muito Alta)

\section{- Remoção de informações com pouco valor}

1. Você considera que houve, em algum momento de seu projeto, a remoção de quadros, cartazes ou informações que, com o passar do tempo, perderam valor dentro do contexto de seu projeto?*

(Sim/Não)

2. (Visibilidade condicional à resposta "Sim" na pergunta anterior) Como você classifica a importância na remoção de quadros, cartazes ou informações que, com o passar do tempo, perderam valor dentro do contexto de seu projeto?*

Importância: (Muito Baixa, Baixa, Média, Alta, Muito Alta)

\section{- Considerações finais}

1. Quais aspectos não tratados neste questionário você considera relevantes com relação à manipulação de quadros e(ou) cartazes informativos durante o decorrer seu projeto? -

(Pergunta Aberta)

2. Comente um pouco a respeito de sua percepção com relação à utilização de quadros e cartazes informativos em um contexto de desenvolvimento ágil.

(Comentário aberto)

\subsubsection{Resultados}

A pesquisa foi disponibilizada para todos os 48 membros das equipes (incluindo coaches). Dentre os membros das equipes, 30 indivíduos responderam ao questionário (62,5\% de todos os integrantes).

A maioria das heurísticas propostas foram indicadas como possuindo valor pelos participantes. Esses resultados reforçam as sugestões realizadas com feedback positivo, identificados durante a fase 1 da pesquisa.

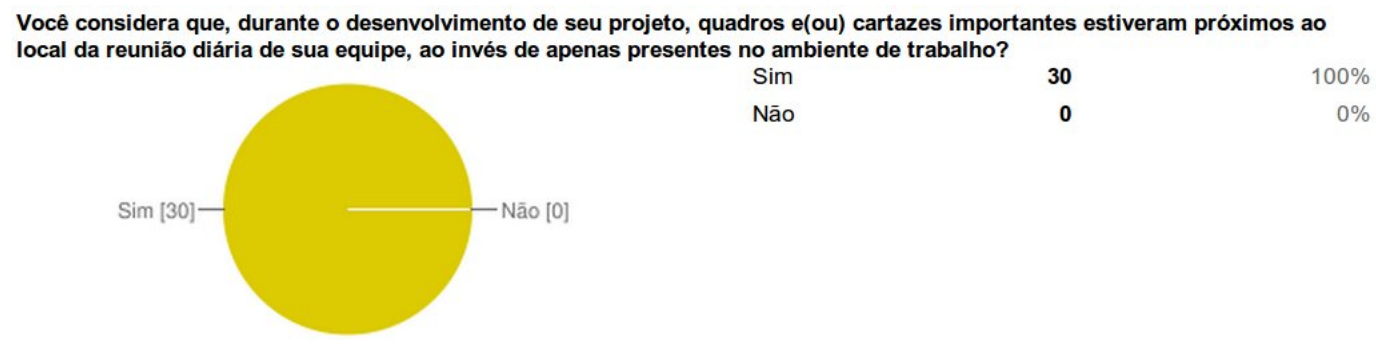

Figura 5.5: Filtro: Proximidade da reunião diária. 


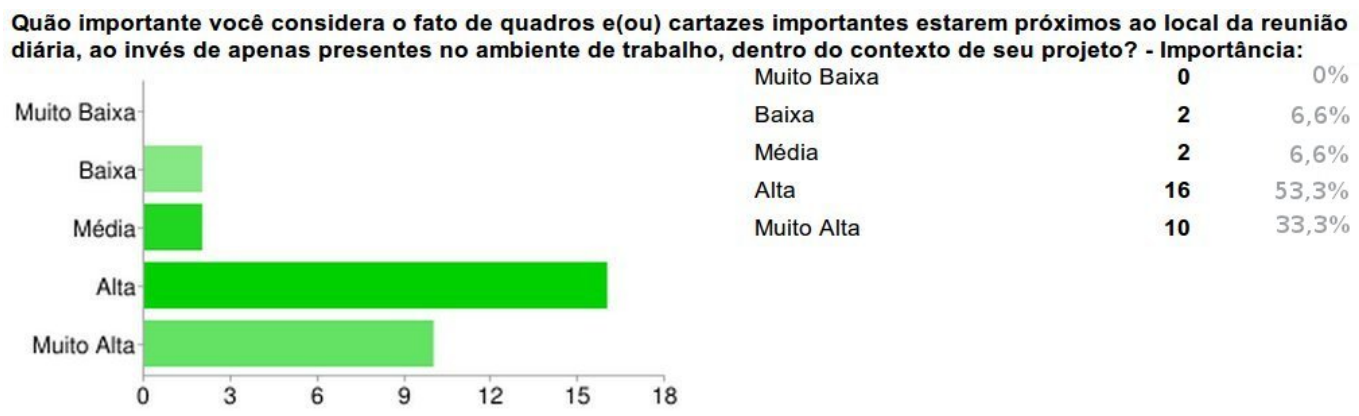

Figura 5.6: Proximidade da reunião diária.

O aspecto de proximidade de quadros importantes do local da reunião diária foi considerado com importância alta ou muito alta por $86,6 \%$ dos respondentes, o que consideramos reforçar a proposta de esta heurística como valiosa. Mais detalhes estão disponíveis na Figura 5.6. Todos os participantes do questionário responderam à esta pergunta, conforme indicado na Figura 5.5.

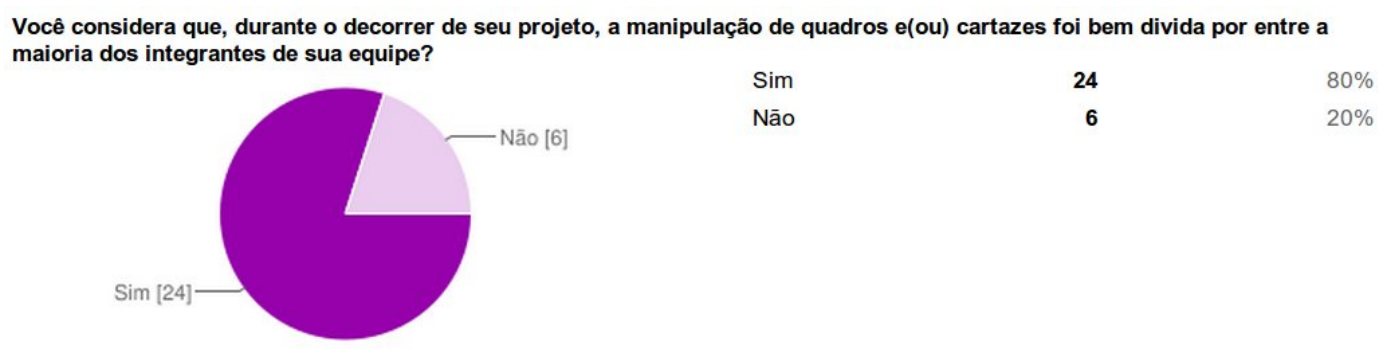

Figura 5.7: Filtro: Acompanhamento coletivo.

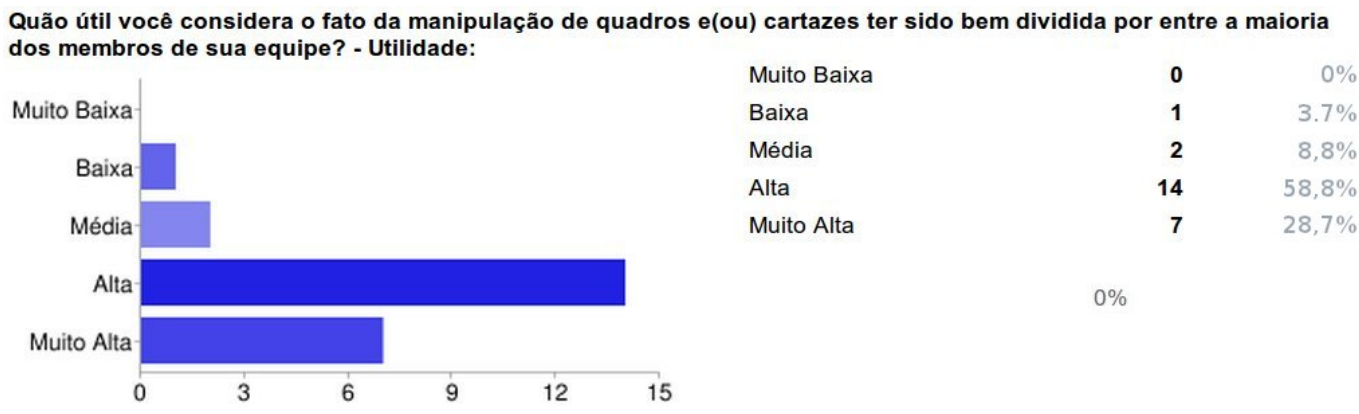

Figura 5.8: Acompanhamento coletivo.

A boa divisão de tarefas relacionadas ao acompanhamento foi considerada com utilidade alta ou muito alta por $87,5 \%$ dos respondentes, o que também reforça a heurística relacionada como valiosa. Estes dados estão disponíveis na Figura 5.8. A pergunta foi respondida por 24 participantes do questionário (80\%), conforme indicado na Figura 5.7.

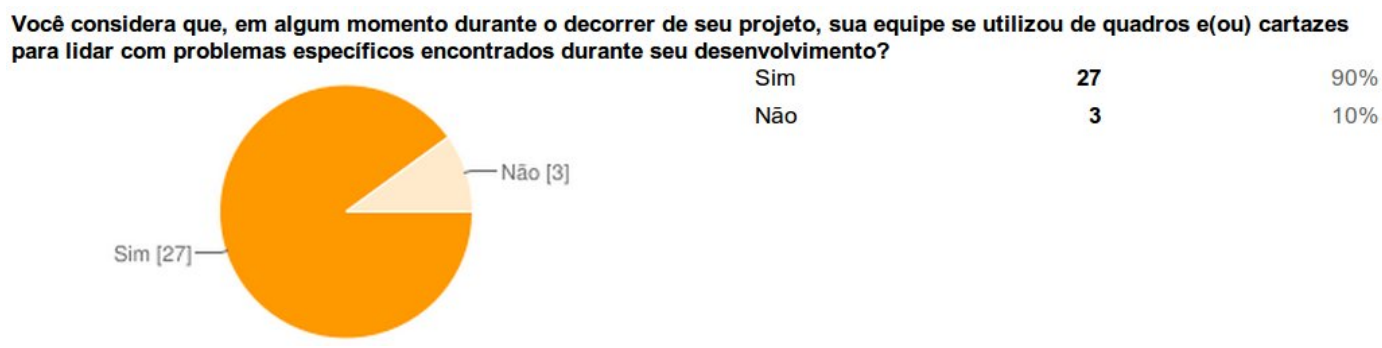

Figura 5.9: Filtro: Tratamento de problemas especificos 


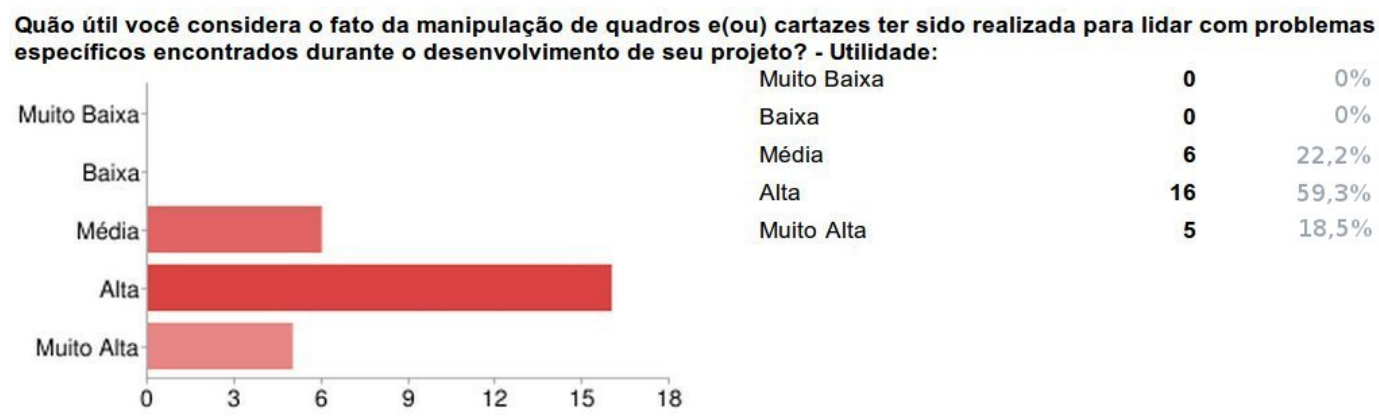

Figura 5.10: Tratamento de problemas específicos

Os resultados do aspecto "Tratamento de problemas específicos" também foram considerados como positivos, sendo apontados como alta ou muito alta por $77,8 \%$ das pessoas com relação a utilidade do acompanhamento no tratamento de problemas específicos encontrados durante o desenvolvimento. Mais informações podem ser observadas na Figura 5.10. Esta pergunta foi respondida por 27 participantes do questionário (90\% dos respondentes), conforme Figura 5.9.

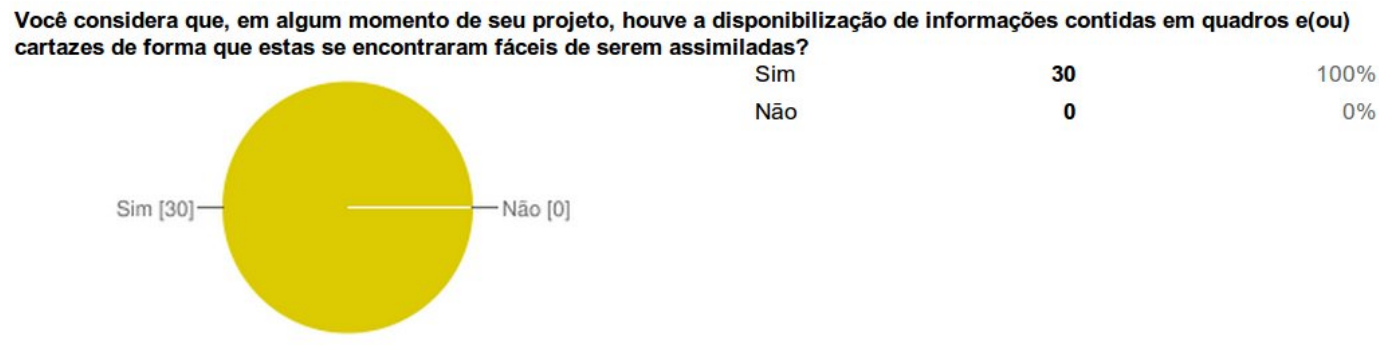

Figura 5.11: Filtro: Facilidade de assimilação.

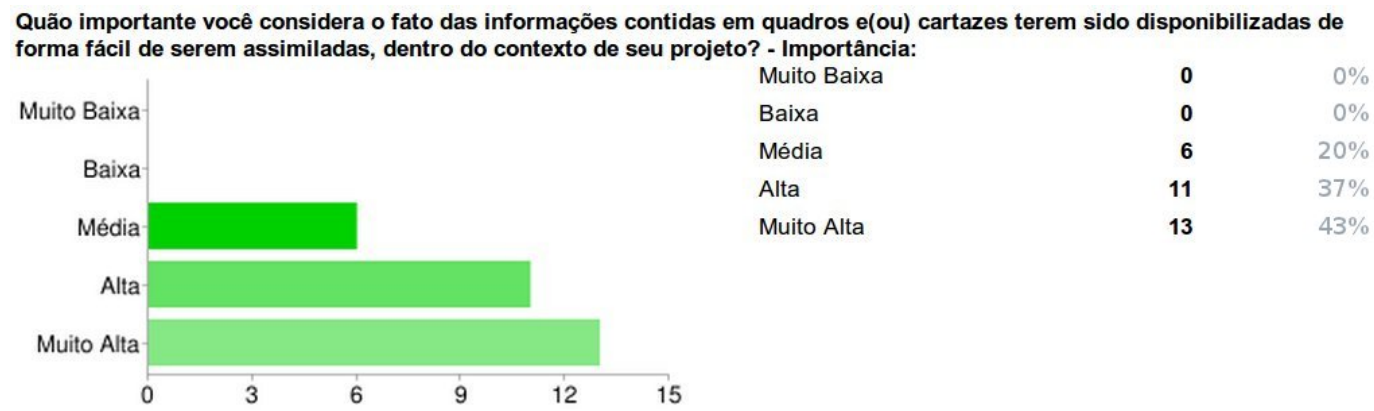

Figura 5.12: Facilidade de assimilação.

A importância da facilidade de assimilação foi avaliada como alta ou muito alta por $80 \%$ das respostas. O resumo destas respostas pode ser observado na Figura 5.12. Todos os participantes do questionário responderam à esta pergunta, conforme Figura 5.11.

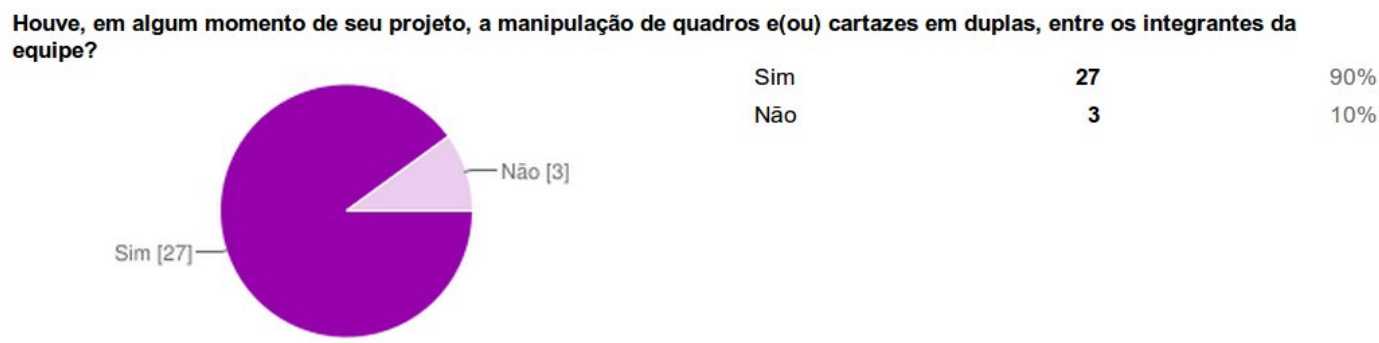

Figura 5.13: Filtro: Pareamento no acompanhamento. 


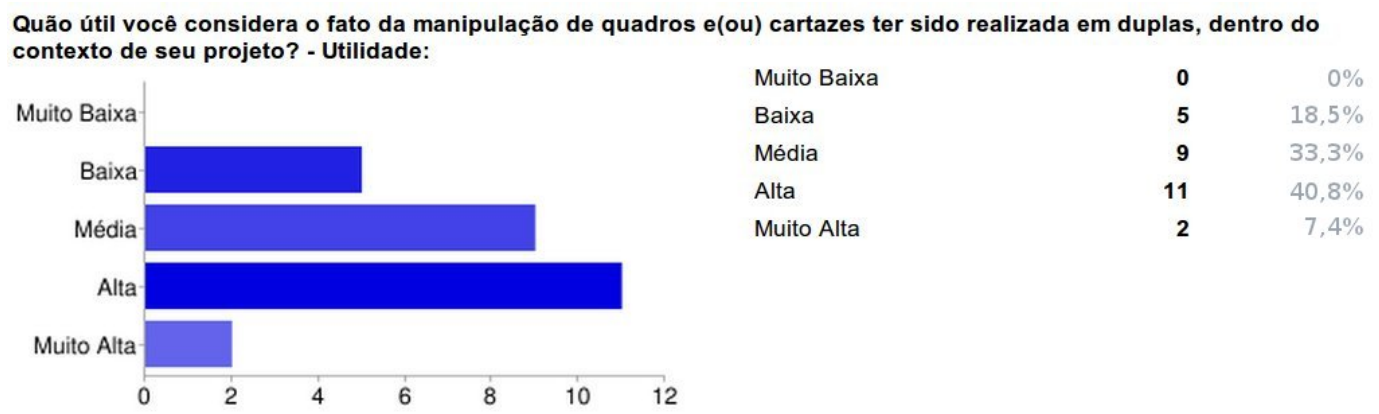

Figura 5.14: Pareamento no acompanhamento.

As respostas vinculadas com a realização de tarefas de tracking em pares mostram alguns resultados um pouco mais divergentes, sendo considerados como baixo/muito baixo com relação a sua utilidade por $17 \%$ dos respondentes e alta/muito alta por $44 \%$ dos mesmos. Esses dados não invalidam a heurística relacionada com esta pergunta como possivelmente valiosa em ambientes, sendo que $83 \%$ dos respondentes a considera com utilidade ao menos regular. No entanto, sua aplicabilidade deve ser melhor avaliada em diferentes ambientes comparada a outras heurísticas em busca de evidências mais conclusivas. A Figura 5.14 mostra o resumo destas respostas. Esta pergunta foi respondida por 27 participantes (90\% dos respondentes do questionário), conforme Figura 5.13.

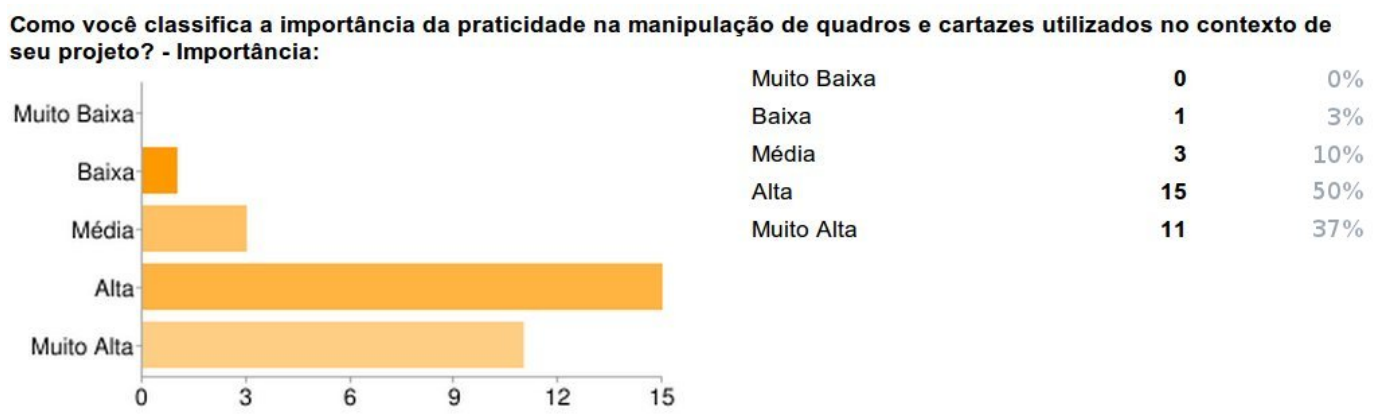

Figura 5.15: Praticidade na manipulação.

Possuir uma manutenção prática recebeu uma impressionante porcentagem de respostas positivas, com $87 \%$ destas indicando este aspecto com importância alta ou muito alta. Isto demonstra que, em alguns ambientes, promover a praticidade na manutenção de quadros ou cartazes pode ser um aspecto bem relevante em tarefas de acompanhamento, incluindo a administração do espaço de trabalho informativo. Maiores informações quanto a essas respostas podem ser observadas na Figura 5.15. Todos os participantes do questionário responderam à esta pergunta, não houve pergunta filtro correspondente, pois consideramos que o tema da praticidade na manipulação de quadros e cartazes se encontra presente em qualquer contexto de espaço de trabalho informativo.

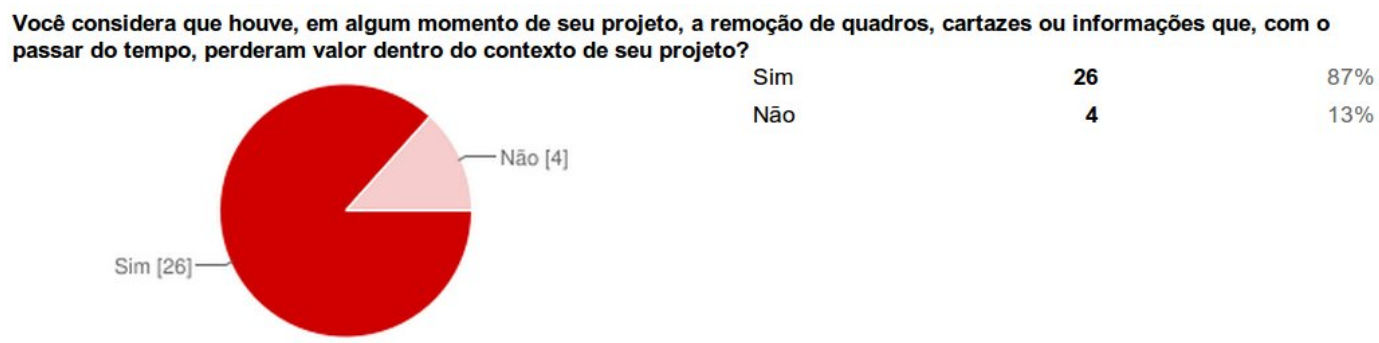

Figura 5.16: Filtro: Remoção de informações de menor valor.

O aspecto de remoção de informações foi avaliado por pelo menos média com relação a sua importância por todos os respondentes que consideram que isto ocorreu em suas equipes. Apesar 


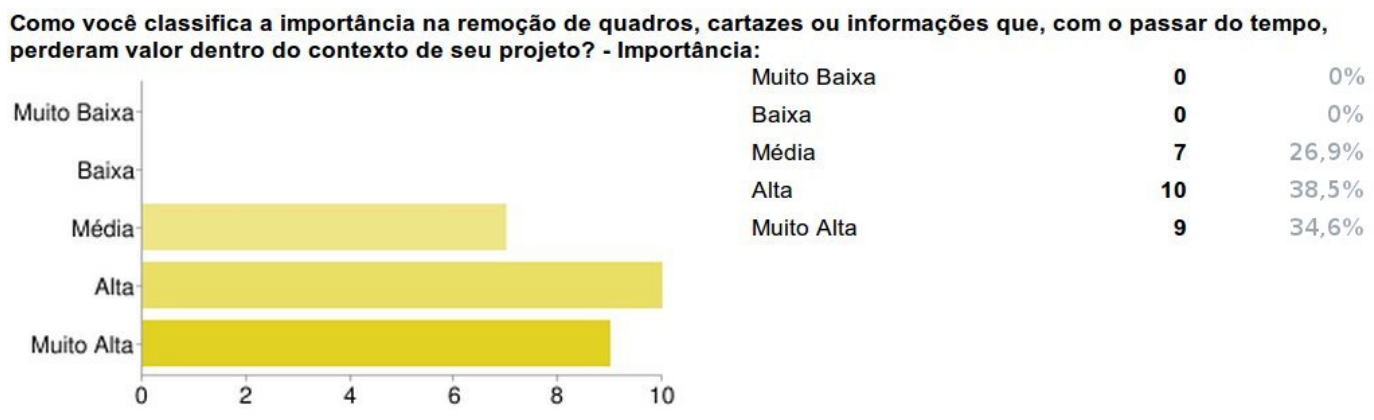

Figura 5.17: Remoção de informações de menor valor.

disto, as opiniões dos respondentes entre média, alta e muito alta foram bem dividas resultando em $23 \%, 33 \%$ e $30 \%$ das respostas respectivamente. Estes resultados, disponíveis na Figura 5.17, denotam que esta heurística pode ao menos ser considerada como importante. Nós supomos que a sua aceitação pode estar relacionada a outros assuntos do ambiente correspondente (como poluição visual por exemplo), tendo em vista que houve uma certa divergência em seus resultados. Não havendo ao menos um respondente afirmando que este aspecto possui uma importância baixa ou muito baixa, junto ao fato da importância ter sido consideravelmente bem dividida entre média/alta/muito alta pode também indicar uma característica "higiênica" desta heurística na administração de um espaço de trabalho informativo. A má administração de um espaço de trabalho informativo quanto a esse aspecto pode resultar em uma influência negativa na equipe. Esta pergunta foi respondida por 26 integrantes (87\% dos participantes do questionário), como indicado na Figura 5.16.

\subsection{Fase 3}

Juntamente com a validação das heurísticas propostas no ambiente estudado, foco da fase 2 da pesquisa, também esperávamos como resultado uma melhor compreensão destas heurísticas, caso se demonstrassem úteis.

Tendo esta finalidade em mente, realizamos na denominada fase 3 uma série de entrevistas de caráter exploratório para alguns integrantes das diferentes equipes de desenvolvimento analisadas procurando compreender a razão por detrás da aparente utilidade/importância das heurísticas propostas.

\subsubsection{Formulação da entrevista exploratória}

Para manter a dinamicidade das entrevistas, realizamos a coleta destes dados por meio da gravação de voz durante sua realização. Esta forma de coleta também foi escolhida pois possibilita uma análise mais detalhada de cada entrevista posteriormente à sua realização.

Apesar de seu caráter exploratório, o objetivo das entrevistas era de uma melhor compreensão da aparente utilidade/importância das heurísticas proposta, e portanto consideramos que estas entrevistas deveriam ser pré-direcionadas em torno de perguntas relacionadas. Por isso, estabelecemos uma série de tópicos a serem abordados durante a realização das entrevistas.

Apesar disto, esperávamos que a dinamicidade da interação de perguntas e respostas promovesse alguma reflexão sobre a aparente utilidade/importância destas heurísticas, o que poderia levar a perguntas mais direcionadas, dependendo das respostas dos entrevistados, no momento da entrevista.

Segue o conjunto de tópicos abordados durante estas entrevistas:

1. Utilidade da proximidade de quadros e cartazes no local da reunião diária e suas razões;

2. Importância da coletividade no acompanhamento ágil e suas razões;

3. Utilidade do tracking para tratamento de problemas específicos e suas razões; 
4. Importância da facilidade de assimilação dos quadros e(ou) cartazes e suas razões;

5. Utilidade do pareamento nas tarefas de acompanhamento ágil e suas razões;

6. Importância da praticidade de manipulação de quadros e(ou) cartazes e suas razões;

7. Importância da remoção de quadros e(ou) cartazes não mais necessários e suas razões.

Pessoas com o papel de coach possuíam a responsabilidade de entender/administrar sua equipe como um todo. Por esta razão consideramos que suas respostas deveriam ser mais ricas para a questão de formulação de hipóteses sobre a aparente utilidade/importância das heurísticas propostas. Por isto procuramos realizar estas entrevistas com um maior número de coaches possível. Apesar disto, a escolha dos entrevistados também sofreu influências como disponibilidade de tempo e interesse dos entrevistados.

Foram realizadas 6 entrevistas com a seguinte distribuição por entre as equipes:

- Coach da equipe Baile;

- Coach da equipe Archimedes;

- Coach 1 da equipe Mezuro;

- Coach 2 da equipe Mezuro;

- Integrante da equipe Calopsita;

- Coach da equipe CoGrOO.

As entrevistas foram gravadas com um gravador de áudio para que pudessem ser posteriormente analisadas.

\subsubsection{Codificação}

Nesta seção explicamos o processo de codificação utilizado para compreender e analisar os dados das entrevistas realizadas.

A abordagem de codificação foi inspirada no processo de codificação de dados da Teria Fundamentada em Dados (Grounded Theory - GT) exemplificada por Strauss e Corbin [2008].

Strauss e Corbin [2008] sugerem um processo de codificação baseada em três abordagens diferentes, a codificação aberta, a codificação axial e a codificação seletiva - cada uma aplicada como uma fase no momento de análise.

Apesar da base metodológica na codificação, algumas adaptações foram feitas devido ao contexto e objetivos específicos encontrados durante esta fase essa pesquisa.

Primeiramente, Strauss e Corbin [2008] afirmam que o principal objetivo da GT é a geração de teorias, e não a validação das mesmas. A geração de teorias não é exatamente o que se propõe como objetivo da fase 3 desta pesquisa, no entanto o mesmo processo de codificação da GT é útil para a identificação de conceitos e o relacionamento entre os mesmos. Além disto, a GT é tradicionalmente utilizada para levantar teorias livremente de dados pouco direcionados, tendo em vista os próprios exemplos de codificação indicados por Strauss e Corbin [2008].

Como os temas a serem discutidos já foram pré-planejados e direcionados durante as entrevistas como perguntas, durante a codificação axial estabelecemos estes temas como categorias, afim de que pudéssemos compreender as dimensões desses temas. Urquhart et al. [2009] desaconselham a utilização do processo da GT em casos de ideias pré-concebidas, afirmando que tais ideias poderiam restringir a emergência de conceitos a partir dos dados. Também consideramos este aspecto como uma crítica válida à utilização do processo da GT com dados de entrevistas direcionadas, que é o caso desta fase da pesquisa. Strauss e Corbin [2008] afirmam que na GT o "pesquisador não possui uma teoria preconcebida em mente (a não ser que seu objetivo seja elaborar e estender uma teoria 
existente)" - o que justifica a utilização do método na ampliação de conhecimento a respeito de um assunto preconcebido - tendo em vista que esses temas surgiram da realização da abordagem inspirada em pesquisa-ação, executada na fase 1 da pesquisa, bem como validada durante a fase 2 com o questionário.

Na fase 3, possuímos a intenção de compreender as razões por detrás da utilidade das heurísticas levantadas, o que o que não é um sinônimo de coletar livremente dados de entrevistas de forma não direcionada, nem é sinônimo de uma teoria estabelecida e selecionada. Tendo em vista essas diferenças e restrições, utilizamos apenas as codificações aberta e axial para a análise dos dados.

Utilizando a codificação aberta pudemos extrair significado dos dados em forma de conceitos, agrupando estes conceitos sempre que possível, o que nos permitiu um conhecimento inicial das questões que permeiam a utilidade de cada uma das heurísticas levantadas, bem como outras características de sua utilização.

A análise por meio da codificação axial nos permitiu estabelecer uma relação direta de significado entre estes conceitos, na forma de categorias/subcategorias, explicitando as dimensões da cada categoria levantada. Reconhecemos que a não realização da codificação seletiva pode ser considerada uma crítica ao processo, porém Strauss e Corbin [2008] afirmam que "se o objetivo da pesquisa é chegar a um conjunto de resultados e não ao desenvolvimento da teoria, a integração não é relevante".

Apesar disto, utilizamos um conjunto de sentenças explanatórias para auxiliar na disponibilização das relações atribuídas durante a codificação axial. Este conjunto de sentenças explanatórias é similar às indicadas por Strauss e Corbin [2008] durante a codificação seletiva.

\subsubsection{Resultados}

Como já mencionado, realizamos os procedimentos da codificação aberta e da axial, visando compreender as razões e conceitos relacionados às heurísticas propostas durante a fase 1 da pesquisa e validadas durante a fase 2 .

Por questões de brevidade durante o texto, nessa seção disponibilizamos fundamentalmente o resultado da codificação axial, que permitiu uma identificação das dimensões de cada categoria estabelecida. Além deste resultado, também disponibilizamos um conjunto de sentenças que vinculam e promovem significado dessas relações entre cada uma das categorias e suas subcategorias, característico durante a etapa de codificação seletiva. Consideramos que esta análise poderia ser especialmente útil na aplicação destas heurísticas, visto que é comum na abordagem de métodos ágeis realizar práticas baseando-se em ideias/princípios e não apenas nas ações sem contexto. Não estamos disponibilizando neste texto as propriedades vinculadas a cada característica principal, pois além de não ser o objetivo principal desta fase, não foi constatado um conjunto de conceitos muito significativos dentre estas propriedades.

Apesar da brevidade destes resultados, os dados completos resultantes deste processo de análise como a transcrição das entrevistas, análise na codificação aberta, memorandos da codificação aberta, análise e memorandos da codificação axial são disponibilizados no Apêndice A.

Como já mencionado na seção de codificação, as categorias principais foram pré-selecionadas como os temas tratados em cada uma das perguntas realizadas aos entrevistados. A disposição destes resultados foi estruturada da seguinte forma, para cada item:

- Descrição da categoria principal - vinculada a uma heurística;

- Descrição dos relacionamentos entre conceitos dispostos nos dados, com base nessa categoria principal - representados pelas dimensões na GT, que buscam responder a perguntas como "Por que?", "Como?", "Quando?", etc. [Strauss e Corbin, 2008]. Para cada conceito também indicamos quais são os dados de origem do relacionamento deste conceito no contexto da categoria principal. Lembrando que a transcrição/análise completa pode ser verificada no Apêndice A;

- Conjunto de sentenças promovendo um significado entre os conceitos relacionados e suas dimensões/relacionamentos. 
Segue o resultado da análise de cada uma das heurísticas:

\section{Proximidade de quadros/cartazes no local da reunião diária}

- Por que?

- [direcionamento da equipe] (baile)

- [agrega durante reunião] (mezuro2)

* Como?

· [comunicação durante a reunião] (mezuro1) (cogroo)

- [dinâmica da reunião] (mezuro1)

- [percepção de informações] (baile)(calopsita)(cogroo)

* Por que?

- [impacto das informações] (cogroo)

- [atenção a informações] (archimedes)(calopsita)

- [ferramenta de lembrança] (cogroo)

* Por que?

- [intervalo entre os encontros] (cogroo)

* Sobre?

- [assuntos cotidianos] (cogroo)

- [considerar assuntos] (calopsita)

* Como?

- [considerar informações] (mezuro2)

* Quando?

- [durante o dia] (calopsita)

- [durante a reunião] (calopsita)

- [percepção da situação] (mezuro2)

- Como?

- [atualização durante a reunião diária] (archimedes)

* Por que?

- [percepção de informações] (archimedes)

- [restrições do espaço de trabalho] (mezuro1) (mezuro2)

* Como?

- [adaptabilidade] (mezuro1)

- [mudança do layout físico] (mezuro2)

Primeiramente, a proximidade de quadros e cartazes mais importantes no local da reunião diária pode ser importante pois agrega durante a reunião, auxilia a equipe em alguns aspectos como por exemplo a comunicação durante a reunião, chegando a auxiliar na dinâmica da reunião.

Outro ponto levantado é que possuir estes quadros e cartazes próximos ao local da reunião diária pode ser utilizado como ferramenta de lembrança para a equipe com relação à situação do projeto, inclusive assuntos cotidianos, pois esta disposição amplia a percepção da situação, a percepção de informações e consequentemente o impacto das informações.

Esta disposição também pode ser útil pois auxilia na atenção a informações, incentivando a equipe a considerar assuntos, tanto durante a reunião quanto durante o dia, pois estará a considerar informaçôes dispostas. 
Ao aplicar esta heurística, algumas formas de realização são citadas pelos entrevistados. Uma abordagem que pode ajudar é realizar a atualização durante a reunião diária, que de acordo com o entrevistado do caso gerou um aumento na percepção de informações.

Outro aspecto importante ao aplicar esta heurística é se atentar para as restrições do espaço de trabalho, pois ela pode influenciar o fato de se possuir quadros e cartazes próximos ao local da reunião diária. Essas restrições do espaço de trabalho podem muitas vezes exigir adaptabilidade da equipe e mudança do layout físico local, para acomodar a realização desta heurística.

\section{Coletividade na manipulação de informações no espaço de trabalho}

- Por que?

- [aprendizado do acompanhamento ágil] (baile)

* Por que?

· [iniciantes na metodologia] (baile)

- [atenção a informações] (archimedes)

- [discussão sobre quadros/cartazes] (mezuro1) (cogroo)

- [escolha de informações úteis] (mezuro1)

- [reflexão sobre informações] (calopsita)

- Senão?

- [tracker solo] (archimedes)

- [acompanhamento ágil insatisfatório] (archimedes)

- [reflexão sobre informações] (archimedes)

- Como?

- [rotatividade entre os integrantes] (baile)

* Por que?

- [aprendizado do acompanhamento ágil] (baile)

$*$ Dificuldades?

- [continuidade de ideias] (cogroo)

- [difusão do significado de informações] (cogroo)

- [todos presentes na atualização] (archimedes)

* Por que?

- [compreensão de informações] (archimedes)

- [ausência de necessidade de pareamento] (mezuro1)

* Como?

- [proximidade de quadros e cartazes na reunião diária] (archimedes)

- Quando?

- [interesse coletivo na manipulação] (mezuro1) (cogroo)

Com relação à coletividade, ou boa divisão, de tarefas de acompanhamento ágil por entre os membros da equipe, a análise das entrevistas indicam que este aspecto pode ser importante para o aprendizado do acompanhamento ágil por entre os membros da equipe, em casos de iniciantes na metodologia - o que pode ser bem útil dependendo do contexto.

Além disto, a coletividade auxilia na escolha de informações úteis para serem dispostas no ambiente de trabalho, devido ao fato da tarefa ser coletiva e existir uma maior discussãa sobre quadros/cartazes. 
Aparentemente, a coletividade também pode influenciar positivamente em aspectos já mencionados do acompanhamento ágil, como a atenção a informações e a reflexão sobre informações.

Existem casos de que a predominância de um tracker solo gerou o que foi considerado como acompanhamento ágil insatisfatório, pois os integrantes não estavam prestando atenção a informações neste cenário.

Dentre as maneiras de aplicar esta heurística, existe a possibilidade de realizar a rotatividade entre os integrantes para o acompanhamento, o que também se mostrou útil para o aprendizado do acompanhamento ágil, porém possui algumas limitações quanto à continuidade de ideias e à difusão do significado das informações utilizadas. Também é possível criar um ambiente em que estejam todos presentes na atualizaçãa, o que pode auxiliar na compreensãa de informações, e pode acarretar na ausência de necessidade de pareamento no acompanhamento ágil. Pode ser importante a relação desta última forma com a proximidade de quadros/cartazes no local da reunião diária e suas características pois normalmente neste contexto em que estão todos presentes na atualização, esta é realizada durante a reunião diária.

Outro item levantado é o interesse coletivo na manipulação, que apesar de não ter sido apontado como obrigatório é importante para que a coletividade gere mais benefícios.

\section{Acompanhamento ágil no tratamento de problemas específicos}

- Por que?

- [evidenciação de problemas] (baile)

- [interesse na atualização de informações] (baile)

- [percepção de informações x trabalho realizado] (baile)

- [trabalho direcionado] (baile) (calopsita)

- [atenção a informações](calopsita)

- [lembrar dos problemas] (calopsita)

- [incômodo pela presença de informações] (mezuro2)

- [controle visual de problemas] (cogroo)

- Como?

- [informações mensuráveis] (mezuro1)

* Por que?

$$
\text { · [acompanhamento de informações] (mezuro1) }
$$

- Senão?

- [continuidade dos problemas](cogroo)

- Quando?

- [desejo de ação imediata] (archimedes)

- [redução da utilidade após resolução do problema] (calopsita)

Com relação utilizar o acompanhamento ágil para o tratamento de problemas específicos, a análise das entrevistas mostra que esta utilização pode ser útil pois auxilia na evidenciação de problemas da equipe de desenvolvimento. Dispor informações referentes a problema no ambiente de trabalho pode auxiliar no trabalho direcionado em relação a esses problemas devido à atenção a informações gerada por esta prática.

Manter essas informações dispostas também pode gerar interesse na atualização das informações pelos membros da equipe, fazendo este tipo de abordagem ser utilizada para lembrar dos problemas.

A utilização deste tipo de abordagem pode gerar impacto a ponto de causar algo comparado a um incômodo pela presença de informações, e pode ser utilizada como um controle visual de problemas para serem acompanhados e tratados. 
Houve entrevistados indicando que a utilização de informações mensuráveis pode auxiliar no acompanhamento destas informações.

Em alguns casos, a não utilização deste tipo de abordagem gerou problemas que foram levantados e foram continuados continuidade de problemas.

Este tipo de abordagem pode ser mais efetiva em contextos que se possui um desejo de açã o imediata, enquanto dispor informações baseadas em problemas no ambiente de trabalho possuem redução da utilidade após resolução do problema.

\section{Facilidade de assimilação das informações disponibilizadas}

- Por que?

- [compreensão de informações] (mezuro1) (calopsita)

* Como?

· [atenção a informações] (baile)

· [percepção de informações] (calopsita)

- [separação cognitiva de informações] (baile) (mezuro2) > Quando? > [poluição visual] (baile)

* Por que?

- [informação continuamente útil] (mezuro1)

· [interesse em informações] (baile)

- [leitura rápida] (baile) (calopsita)

- [compreensão externa] (cogroo)

- Como?

- [clareza das informações] (mezuro1)

- [significado de informações] (mezuro1)

- [forma de representação de informações] (mezuro1) (cogroo)

* Como?

· [representação simples] (cogroo)

- [disponibilização informal] (cogroo)

A análise dos dados das entrevistas aponta que pensar facilidade na assimilação das informações dispostas para a equipe de desenvolvimento pode ser um item importante na administração do acompanhamento ágil. Este aspecto pode ser útil pois busca diretamente a compreensãa das informações pelos membros da equipe. Este auxílio se dá pois os integrantes prestam mais atenção a informações bem como melhoram sua percepção das informações, para que haja interesse nas informações e que cada informação disposta possa ser uma informação continuamente útil. Um dos resultados mais interessantes deste aspecto é que promove a separação cognitiva de informações dispostas no ambiente de trabalho, o que pode ser um problema dependendo do contexto e se tornar ainda necessário em casos de poluição visual do ambiente.

Outro benefício desta utilização é que promove a leitura rápida das informações dispostas, e ainda melhora a compreensãa externa destas informações por outros indivíduos envolvidos, não diretamente presentes no cotidiano da equipe de desenvolvimento.

Com relação à sua aplicação, deve-se buscar a clareza das informações, repensando para cada uma o significado de informações. Para as informações dispostas no ambiente, deve-se pensar a forma de representação de informações, que podem ser diversas (gráficos, imagens, palavras, post-its, etc), buscando sempre uma representação simples e que tudo isto esteja em um contexto de disponibilização informal. 


\section{Pareamento na manipulação de quadros/cartazes}

- Por que?

- [segurança no acompanhamento ágil] (archimedes)

- [direcionamento do acompanhamento ágil] (archimedes)

* Quando?

- [iniciantes na metodologia] (archimedes)

- [velocidade na manipulação] (baile) (calopsita)

- Quando?

- [programação em par] (baile)

* Por que?

- [alinhamento de forma de trabalho](baile)

* Senão?

- [programador solo]

- [aprendizado do acompanhamento ágil] (cogroo)

- Como?

- [rotatividade entre os integrantes] (cogroo)

* Problemas?

- [continuidade de ideias] (cogroo)

Ao se tratar da realização de tarefas de manipulação e atualização de quadros/cartazes em duplas, a análise dos dados mostrou algumas informações relevantes.

Realizar a manipulação de quadros e cartazes em duplas também pode promover velocidade na manipulação, reduzindo o tempo e esforço gastos com esta tarefa.

Parear neste tipo de tarefa pode ser útil ao promover segurança no acompanhamento ágil pelos membros da equipe. Parear também pode auxiliar no direcionamento do acompanhamento ágil, em como agir neste item para escolher e melhor utilizar recursos visuais no auxílio da equipe de desenvolvimento como um todo. Esse direcionamento do acompanhamento ágil pode ser bem valioso também em casos da existência de iniciantes na metodologia.

A realização deste tipo de manipulação em duplas pode se mostrar especialmente útil em contextos onde se pratica a programação $\mathbf{e m}$ par, pois pode resultar na existência do programador solo enquanto um integrante realiza as manipulações necessárias no ambiente de trabalho - o que indica a importância do alinhamento de forma de trabalho nesta questão. Também se demonstra útil se utilizar do pareamento nesta tarefa para promover aprendizado do acompanhamento ágil.

Dentre as formas de realizar o pareamento, existe a possibilidade de se basear na rotatividade entre os integrantes da equipe, o que se demonstra de forma geral como algo positivo de acordo com a análise da heurística vinculada à coletividade em tarefas de acompanhamento ágil. Porém, um problema demonstrado é a questão de continuidade de ideias, que pode ser impactada pela abordagem de rotatividade.

\section{Praticidade na manipulação do espaço de trabalho informativo}

- Por que?

- [velocidade na manipulação] (baile) (calopsita) (cogroo)

- [coletividade da manipulação] (mezuro2)

- [atualização de informações] (mezuro1)

* Por que? 
- [utilidade de informações] (mezuro1)

* Como?

· [atualização corrente] (mezuro1)

- Senão?

- [negação > informações atualizadas] (baile)

* Por que?

· [peso na manipulação] (baile)

- [desperdício de tempo] (cogroo)

* Por que?

- [utilidade da informação] (cogroo)

· [incômodo] (cogroo) > Por que? > [ajudar e não atrapalhar] (cogroo)

- Como?

- [relação custo/benefício] (archimedes)

- [escolha de informações simples] (archimedes)

- [restrições do espaço de trabalho] (mezuro1)

- [meio de disponibilização] (calopsita)

* Por que?

- [clareza das informações] (calopsita) > Quando? > [necessidade de adaptação de quadros] (calopsita)

* Como?

- [remoção de informações] (baile)

- [rascunho de informação] (baile)

* Por que?

- [utilidade de informações] (baile)

- [administração do espaço] (baile)

Com relação à praticidade na realização de tarefas de manipulação do espaço de trabalho informativo e referentes ao acompanhamento ágil, a análise das entrevistas indica que este item pode ser útil pois entre outros aspectos aumenta a velocidade na manipulaçãoo. Além disto, manter informações práticas de se atualizar pode incentivar a utilização dos quadros por todos os membros da equipe, resultando em uma maior coletividade da manipulação destas informações. Esta prática de forma geral incentiva e auxilia na atualização de informações, um de seus maiores benefícios. Possuir praticidade na manipulação de quadros/cartazes incentiva inclusive a atualização corrente, que é a atualização durante o dia de trabalho, no momento em que alguma informação se torna desatualizada - ao invés de atualizá-la em momentos específicos (como a reunião diária).

Manter informações atualizadas, neste contexto, pode influenciar em assuntos sérios como a discutir a própria utilidade da informação, e a desatualização pode ocorrer em contextos onde existe baixa praticidade na manipulação (negação -> informações atualizadas), devido ao peso na manipulação que existe neste contexto.

Caso não exista praticidade, existe um risco da manutenção do espaço de trabalho informativo resultar em desperdício de tempo, o que se torna um incômodo para equipe, pois as informações são para ajudar e não atrapalhar. Este desperdício de tempo, bem como o incômodo podem levar a consideração da própria utilidade das informações presentes no ambiente de trabalho.

Com relação à maneira de se manter o ambiente prático de ser atualizado, deve-se sempre pensar na relação custo/benefício de uma informação, valorizando a escolha de informações simples. 
Ainda sobre a praticidade da manipulação, deve-se levar em consideração as restrições do espaço de trabalho da equipe, pois esta pode influenciar significativamente para o esforço desta manipulação.

Outra característica interessante é o meio de disponibilização de uma informação, pois o meio de disponibilização (cartaz/quadro branco/página de internet, etc) pode influenciar na praticidade da manipulação desta informação - principalmente em casos que existe a necessidade de adaptação de quadros, pois dependendo do meio de disponibilização isto pode afetar a clareza das informações.

Em alguns casos a praticidade da manipulação é melhorada simplesmente ao promover a remoção de informações desnecessárias do ambiente de trabalho. Também pode ser útil a utilização de um rascunho de informação para novas métricas, dispondo informações com baixa qualidade de uma forma simples porém prática de ser atualizada. Após isto pode-se verificar a utilidade da informação sugerida e posteriormente aumentar a qualidade de sua disponibilização, melhorando também a administração do espaço.

\section{Remoção de quadros/cartazes/informações com baixo valor no espaço de trabalho}

- Por que?

- [percepção restrita de informações](baile) (calopsita)

- [incômodo pela presença de informações] (mezuro1)

- [remoção de preocupações] (mezuro1)

- [substituição de informações] (mezuro2)

- [foco em assuntos importantes] (baile) (calopsita)

- Senão?

- [negação > percepção de informações] (baile)

- [desperdício de tempo] (archimedes)

- Como?

- [coletividade no acompanhamento ágil](baile)

* Por que?

- [escolha de informações úteis](baile)

- [interesse na atualização das informações] (baile)

- [histórico] (cogroo)

* Por que?

- [aprendizado do acompanhamento ágil] (cogroo)

- Quando?

- [utilidade de informações] (baile) (archimedes) (mezuro1) (mezuro2)

* Quando?

- [bom o suficiente] (baile)

- [informações estáveis] (baile)

- [informações fora do contexto] (archimedes)

- [excesso de informação] (calopsita) (cogroo)

Pela análise realizada nas entrevistas já mencionadas, a remoção de informações consideradas com pouco valor no ambiente de trabalho pode ser importante porque os indivíduos da equipe possuem uma percepção restrita de informações. Além disto, manter este tipo de informação no ambiente de trabalho pode gerar um certo incômodo pela presença de informaçóes, $\mathrm{e}$ 
remover este tipo de informações pode ser considerado como a remoção de preocupações, favorecer a utilização do espaço cognitivo utilizado pela informação removida, e com isso promover a substituição de informações por outras mais relevantes ao contexto corrente. De forma geral, remover informações menos relevantes auxilia para que a equipe mantenha seu foco em assuntos importantes.

Caso a remoção de informações com baixa relevância não esteja em vigor no ambiente informativo, a presença deste tipo de informação pode influenciar negativamente na percepção das informações relevantes pela equipe de desenvolvimento, além de se mostrar um desperdício de tempo no momento de atualização dos quadros/cartazes.

Uma das formas para tratar esse assunto é promovendo a coletividade no acompanhamento ágil, pois auxilia na escolha de informações úteis bem como promove o interesse na atualização das informações pela equipe. Pode ser relevante a criação de um histórico de quadros/representações/informações já utilizadas no passado, principalmente em contextos de aprendizado do acompanhamento ágil.

A decisão de quando remover ou não remover informações deve estar associada com a percepção da utilidade das informações dispostas no ambiente. Pode não ser necessário manter uma informação no ambiente se existe a impressão que o assunto que ela se refere está bom o suficiente no contexto da equipe, ou se ela se mostra como uma informação estável. Também devem ser removidas informações fora do contexto, que não estão representando o contexto atual de preocupações da equipe. Devem ser removidas informações no caso de excesso de informação disposta no ambiente de trabalho.

\subsection{Fase 4}

\subsubsection{Aplicação do questionário}

$\mathrm{Na}$ fase 4 , o mesmo questionário aplicado na fase 2 foi reaplicado no contexto da turma de 2011.

O objetivo do questionário elaborado na fase 2 foi de avaliar o quão útil/importante cada uma das características associadas às heurísticas se mostrou durante as experiências das equipes. Um detalhe importante neste contexto é que o pesquisador não possuiu papel algum durante a realização da disciplina no ano de 2011. Portanto, a reaplicação do questionário de validação deveria ser analisada levando em consideração que nenhum tipo de intervenção foi realizada.

Possuir a opinião dos integrantes da turma de 2011 em relação aos aspectos vinculados às heurísticas levantadas seria vantajoso pois permitiria a triangulação com os resultados obtidos na turma de 2010. Estes dados seriam relevantes pois uma série de sugestões específicas foram realizadas na fase 1 para as equipes de desenvolvimento da turma de 2010 durante o decorrer de seus projetos na turma de 2010, o que não ocorreu na turma de 2011.

Devido ao conjunto de sugestões aplicadas na turma de 2010, não podemos descartar a possibilidade de que respostas indicadas na fase 2 possuam influência do papel do pesquisador nos integrantes das equipes. Apesar disto, as heurísticas não haviam sido agrupadas no período em que o pesquisador realizou intervenções nas equipes, e portanto não foram explicitamente divulgadas para os membros da equipe neste período. Além disto, as heurísticas também não haviam sido divulgadas no momento em que os integrantes responderam ao questionário.

Apesar de não podermos ignorar o papel do pesquisador, as sugestões realizadas na fase 1 possuíram um papel importante na turma de 2010 incentivando as equipes a utilizarem técnicas de acompanhamento ágil para auxiliar em seu processo de desenvolvimento. Este aspecto também deve ser considerado na triangulação, pois existe a possibilidade de que este conjunto de sugestões tenha auxiliado as equipes de $2010 \mathrm{em}$ como melhor utilizar este conjunto de técnicas - tornando-as mais úteis em no dia-a-dia das equipes de 2010 em relação às equipes da turma de 2011. Caso esta possibilidade seja verdadeira, os integrantes da equipe de 2010 poderiam considerar os diversos aspectos relacionados às heurísticas como mais úteis/importantes em seu ambiente de desenvolvimento, justificando que este aspectos fossem melhor avaliados em 2010 em relação a 2011. 
O questionário foi aplicado e disponibilizado via internet, e a participação dos integrantes das equipes era anônima e opcional, da mesma forma que na fase 2 da pesquisa. Para auxiliar na comparação de resultados, a estrutura do questionário reaplicado para a turma de 2011 foi idêntica ao questionário preparado na fase 2 e aplicado na turma de 2011. A única alteração nesta estrutura foi a atualização da lista de possíveis equipes na pergunta "A qual equipe você pertence?" para valores significativos na turma de 2011. Mais detalhes sobre esta estrutura podem ser observados na seção 5.8.2.

\subsubsection{Resultados}

A turma de 2011 era composta no total por 37 integrantes, considerando coaches e não coaches. Nesta turma, recebemos um total de 20 respondentes à aplicação do questionário, cerca de $54,05 \%$ dos integrantes.

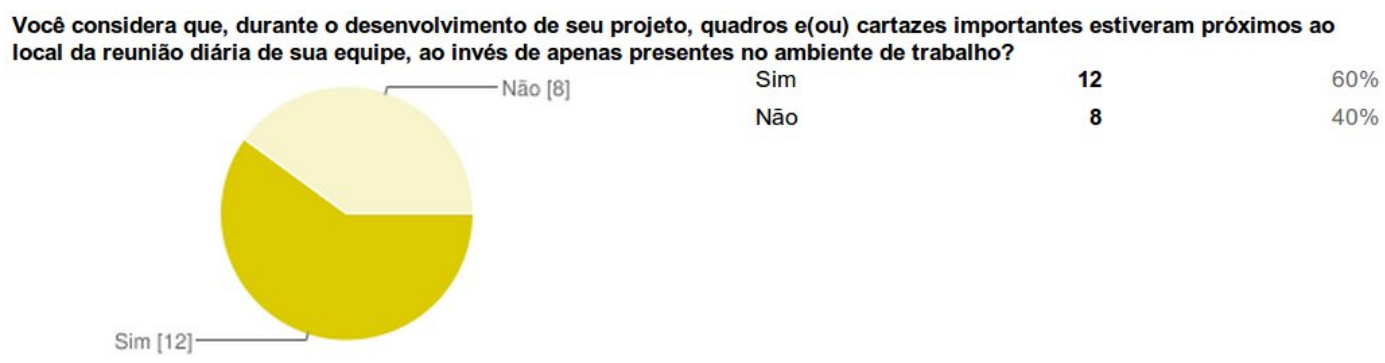

Figura 5.18: Filtro: Proximidade da reunião diária - 2011.

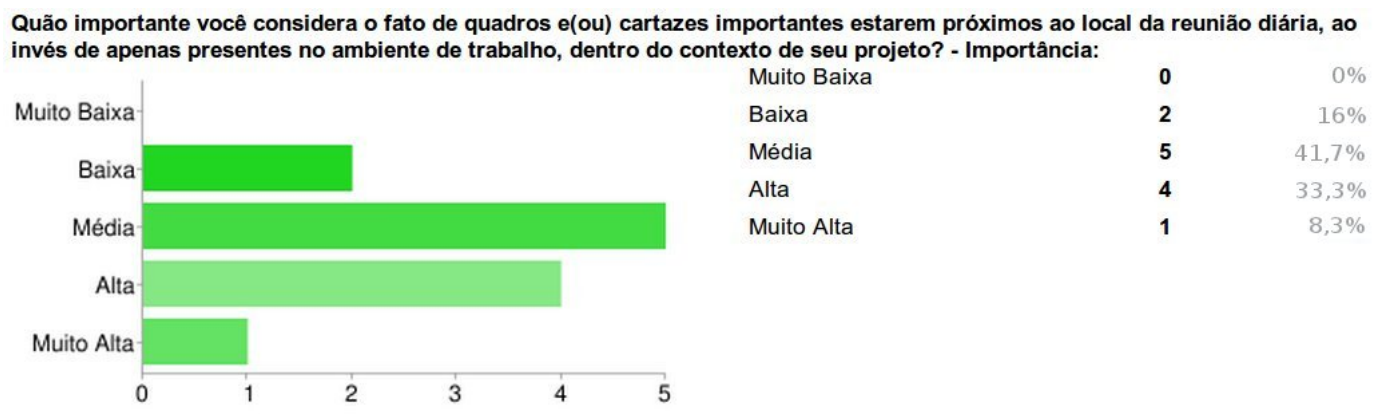

Figura 5.19: Proximidade da reunião diária - 2011.

Quanto ao primeiro aspecto avaliado, a importância de quadros e(ou) cartazes próximos ao local da reunião diária, as respostas tendem para utilidade entre média e alta, possuindo $41,7 \%$ e $33,3 \%$ das respostas respectivamente. Apesar disto, observamos que apenas $60 \%$ dos participantes responderam possuir quadros e(ou) cartazes próximos ao seu local de reunião diária, número significativamente inferior à turma de 2010 em que 100\% dos integrantes responderam desta forma. Mais detalhes podem ser observados nas figuras 5.18 e 5.19 .

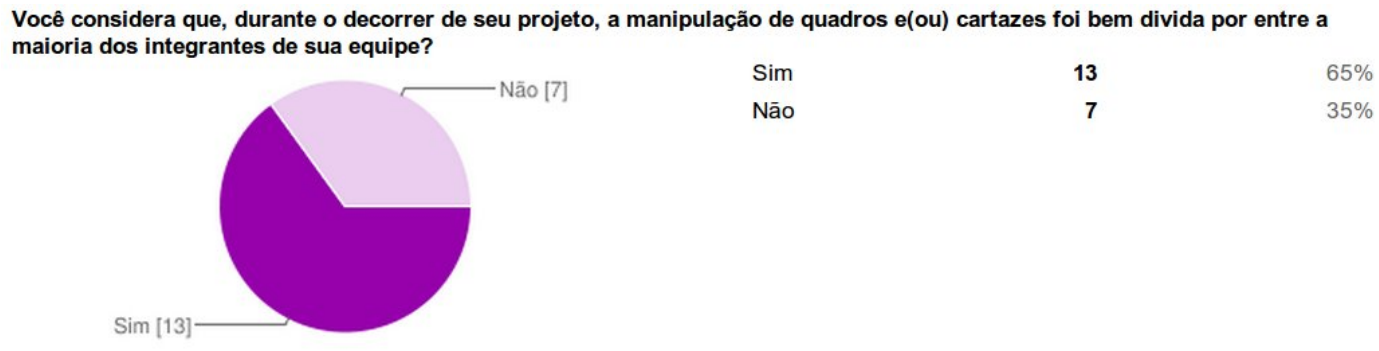

Figura 5.20: Filtro: Acompanhamento coletivo - 2011. 


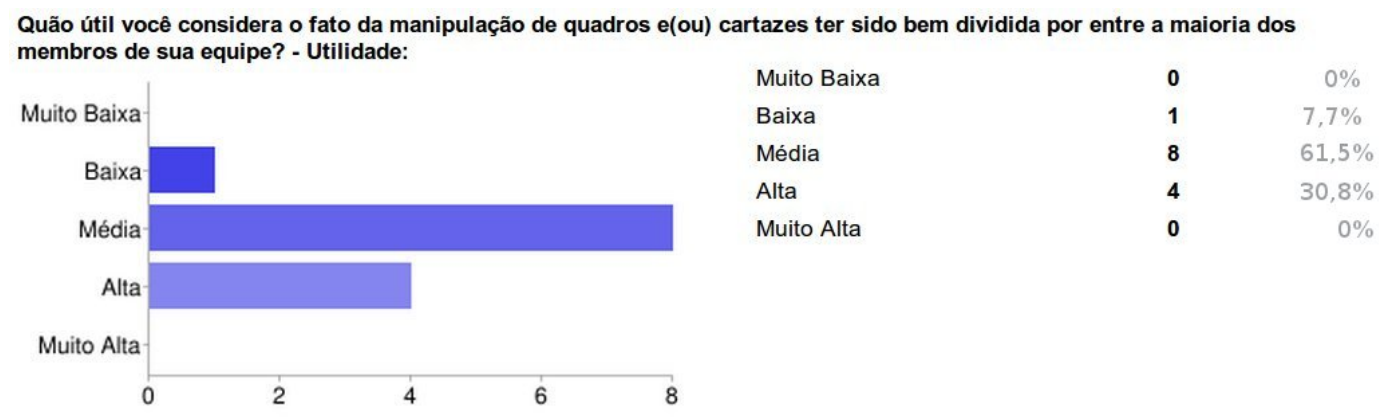

Figura 5.21: Acompanhamento coletivo - 2011.

O aspecto relacionado a se possuir uma boa divisão também possuiu uma tendência por entre média e alta, possuindo $61,5 \%$ e 30,8\% das respostas da questão correspondente na turma de 2011 . O porcentagem de participantes que afirmaram possuir uma boa divisão das tarefas de manipulação de quadros e(ou) cartazes em suas equipes foi de $65 \%$, número também inferior ao coletado na aplicação de 2010. Estas e outras informações indicadas pelos participantes sobre a boa divisão neste tipo de tarefa podem ser observadas nas figuras 5.20 e 5.21 .

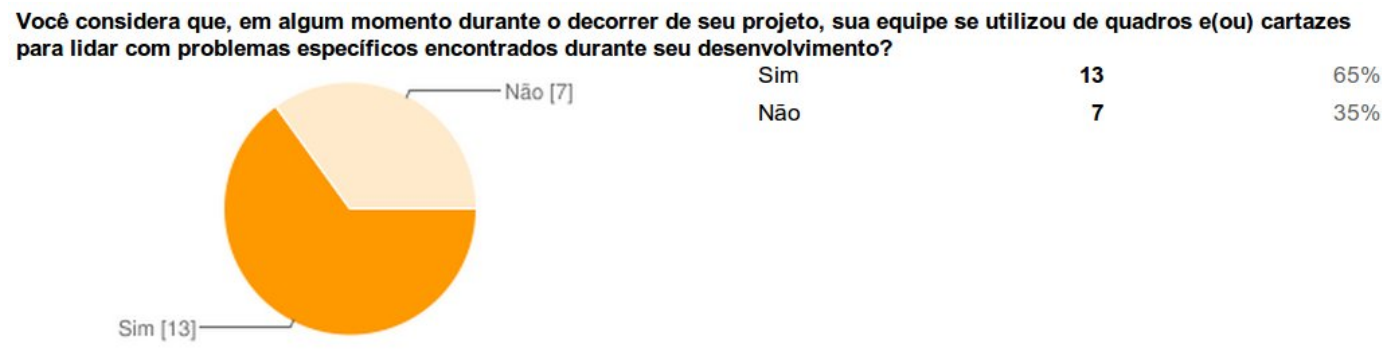

Figura 5.22: Filtro: Tratamento de problemas especificos - 2011.

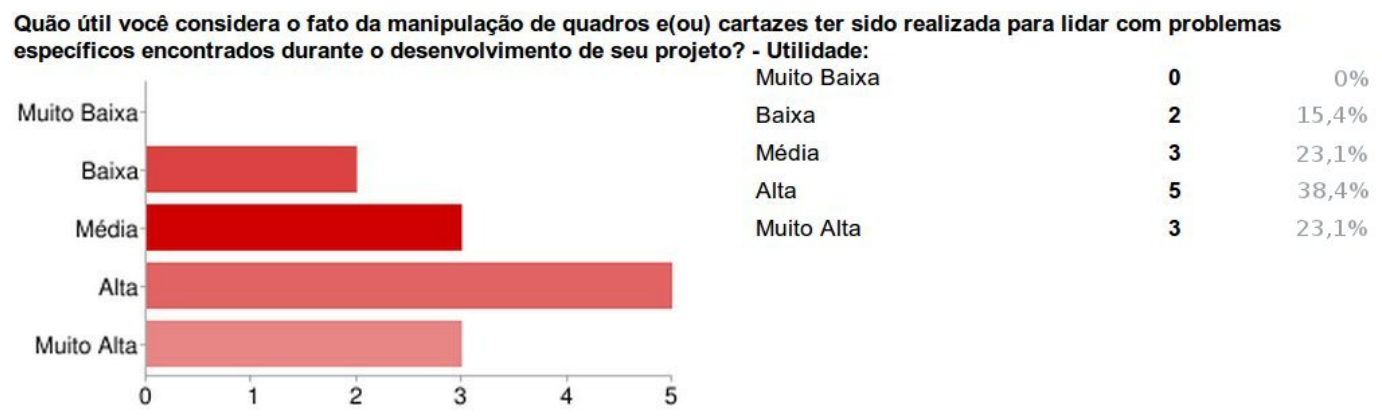

Figura 5.23: Tratamento de problemas especificos - 2011.

A avaliação da utilidade de se manipular quadros e(ou) cartazes para tratar de problemas específicos possuiu uma divergência maior de resultados por entre participantes, comparado aos dois aspectos anteriores. Os resultados divergem por entre baixa e muito alta, porém possui tendência para alta, com aproximadamente $38,4 \%$ das respostas. O valor de integrantes que possuíram quadros em suas equipes para lidar com problemas específicos foi de $65 \%$. Mais detalhes estão disponibilizados nas figuras 5.22 e 5.23 .

O aspecto vinculado a disponibilizar informações de maneira fácil de ser assimiliada foi avaliado tendenciando uma importância por entre média e alta, possuindo respostas $47 \%$ e $35,3 \%$ respectivamente. Dentre os participantes do questionário, $85 \%$ afirmam que houve informações em quadros e(ou) cartazes disponibilizadas de forma fácil de serem assimiladas. Estes e outros dados relacionados a este aspecto podem ser visualizados nas figuras 5.24 e 5.25. 


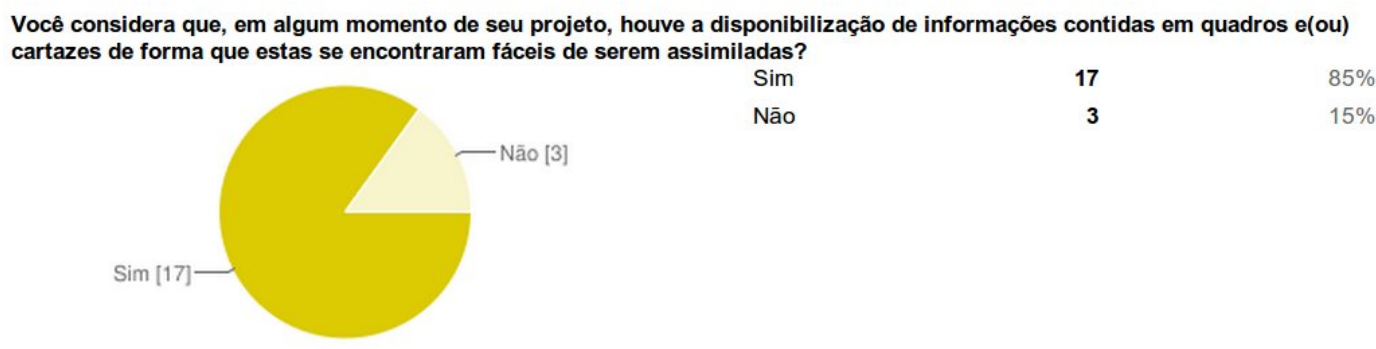

Figura 5.24: Filtro: Facilidade de assimilação - 2011.

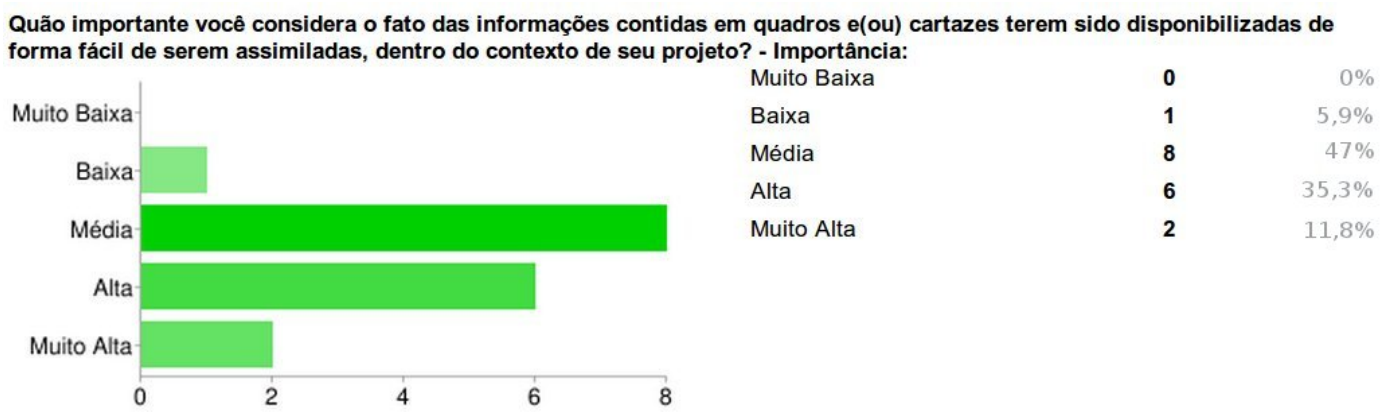

Figura 5.25: Facilidade de assimilação - 2011.

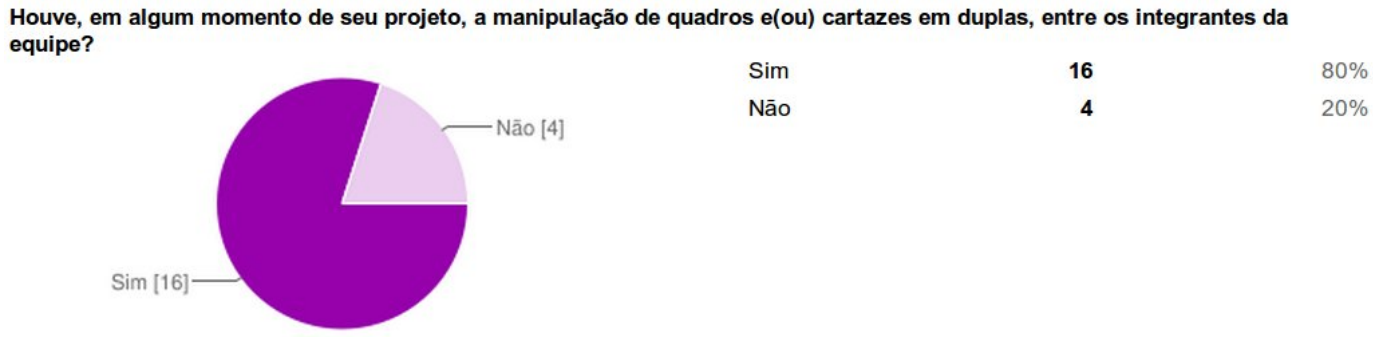

Figura 5.26: Filtro: Pareamento no acompanhamento - 2011.

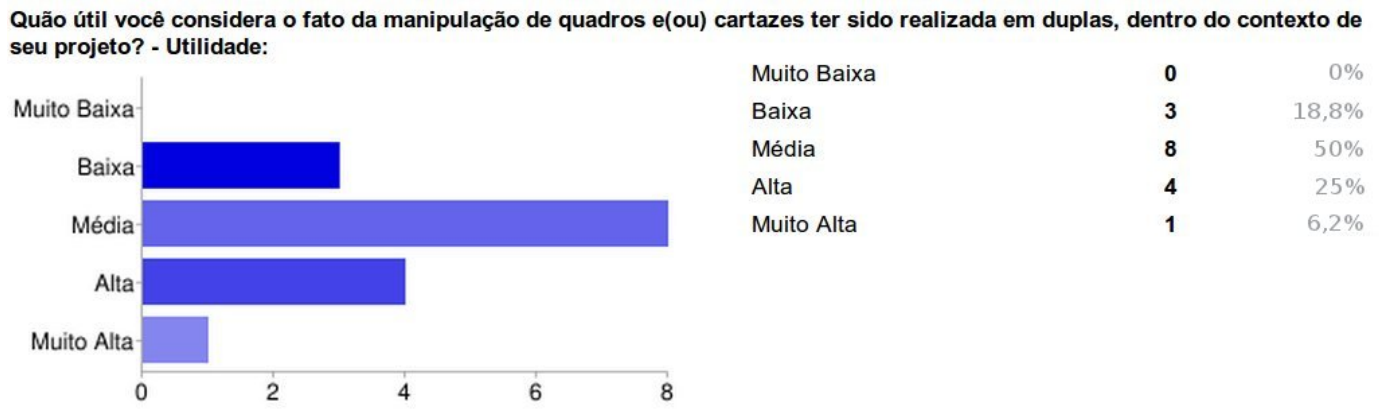

Figura 5.27: Pareamento no acompanhamento - 2011.

Realizar a manipulação de quadros e(ou) cartazes em duplas de integrantes foi avaliado com tendência entre média e alta, com $50 \%$ e $25 \%$ dos resultados respectivamente. Além disto, $80 \%$ dos participantes afirmam ter realizado esta prática ao menos uma vez em seus projetos. Mais informações podem ser observadas nas figuras 5.26 e 5.27 .

O aspecto relacionado à importância da praticidade na manipulação de quadros e cartazes foi avaliada com tendência entre média e alta, com $30 \%$ e $55 \%$ respectivamente. Este aspecto não possuiu nenhum tipo de pergunta filtro, pois trata de uma característica dos quadros e cartazes disponibilizados no ambiente. Esta característica faz parte da estrutura do questionário, definida na 5.8.2. Mais detalhes sobre as respostas de sua pergunta avaliativa estão disponíveis na Figura 


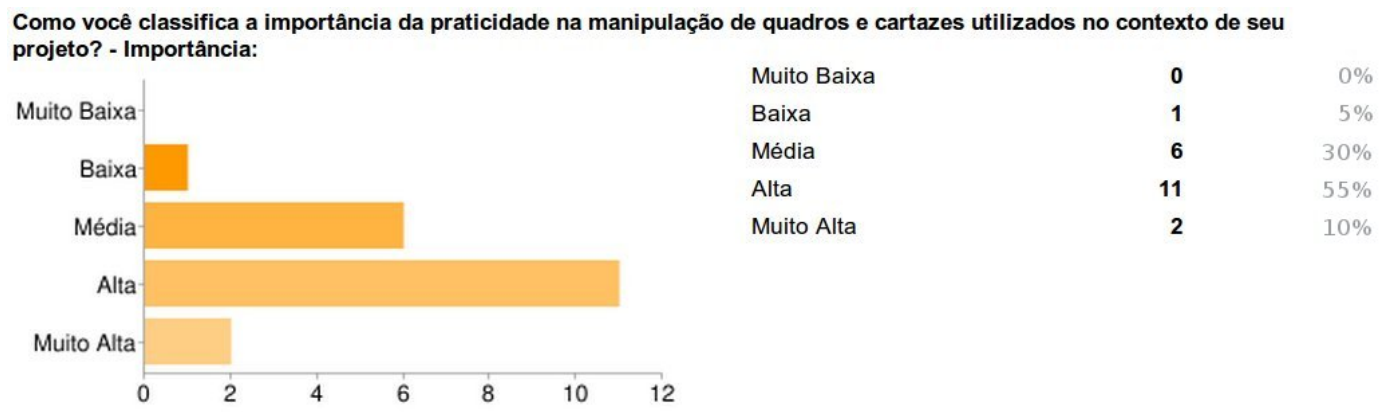

Figura 5.28: Praticidade na manipulação - 2011.

5.28 .

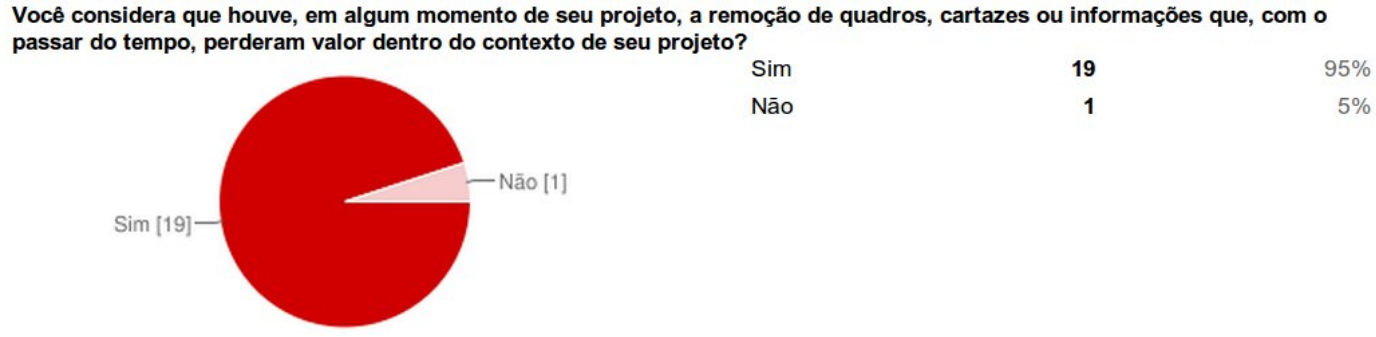

Figura 5.29: Filtro: Remoção de informações de menor valor - 2011.

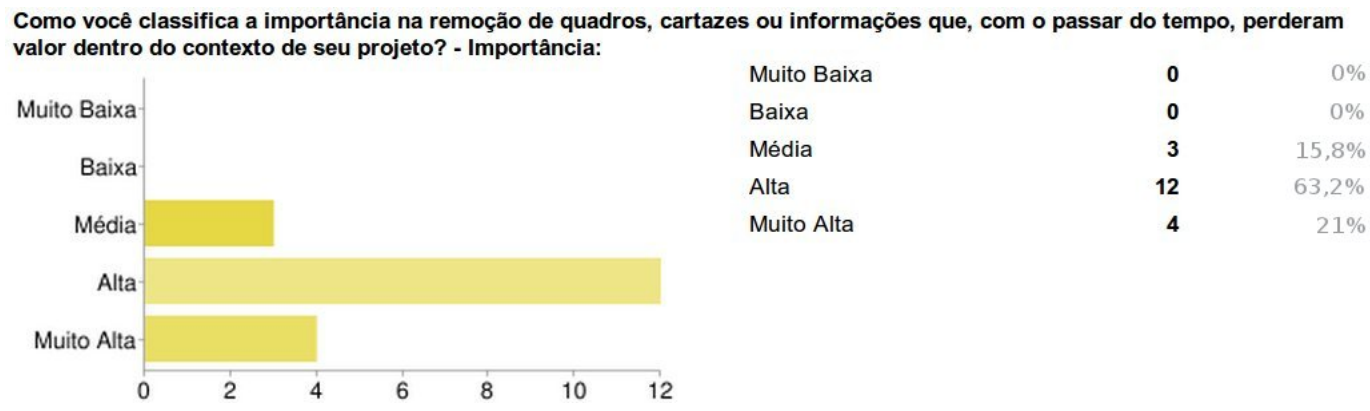

Figura 5.30: Remoção de informações de menor valor - 2011.

A remoção de quadros e cartazes, que, com o passar do tempo, perderam o valor dentro do contexto, foi avaliada com tendência entre alta e muito alta quanto à sua importancia, possuindo porcentagens de $63,2 \%$ e $21 \%$ em suas respostas respectivamente. Outro aspecto interessante é que $95 \%$ dos integrantes afirmam ter vivenciado a remoção de quadros e(ou) cartazes com esta característica em seu projeto - o maior índice de participação dentre os aspectos avaliados da turma de 2011. Outros detalhes da avaliação deste aspecto podem ser observados nas figuras 5.30 e 5.29.

\subsection{Discussão}

A pesquisa experimental realizada coletou dados significativos para auxiliar a atingir os objetivos deste trabalho. Nesta seção realizamos uma discussão sobre cada um dos pontos resultantes desta pesquisa experimental, como o levantamento, a avaliação e os conceitos relacionados às heurísticas propostas para o acompanhamento ágil.

\subsubsection{Heurísticas levantadas}

Diversas heurísticas foram propostas com base nos dados da fase 1 da pesquisa experimental. Durante esta fase, realizamos diversas sugestões para as equipes de desenvolvimento no intuito de 
auxiliá-las com relação a suas tarefas de acompanhamento ágil.

Primeiramente, consideramos que levantar um conjunto de heurísticas a serem propostas, ao invés de simplesmente mapear quadros/informações utilizados, condiz com a abordagem de se realizar práticas com base em guidelines, muito utilizada em métodos ágeis como tratado por Poppendieck e Poppendieck [2007] e de acordo com o princípio de adaptabilidade.

Muitas vezes, as sugestões realizadas para as equipes foram baseadas na literatura disponível em métodos ágeis e outras áreas dentro do desenvolvimento de software. Por esta causa, a maioria das heurísticas que se mostraram valiosas já possuíam alguma referência direta ou indireta na literatura.

A utilização do acompanhamento ágil para tratar problemas específicos da equipe pode ser relacionada à afirmação de Beck e Andres [2006] de "se você possui uma questão que requer progresso constante, crie um gráfico para acompanhá-lo". Este aspecto também pode ser relacionado a algumas técnicas de gerenciamento de métricas, como o Goal Question Metric [Basili et al., 1994], que define métricas baseadas em objetivos organizacionais - em uma abordagem top-down.

A importância da praticidade na manipulação de quadros/cartazes está relacionada a uma característica desejada dos radiadores de informação apontada por Cockburn [2005] "É facilmente atualizado", e pode ser associada à responsabilidade atribuída ao papel do tracker do Extreme Programming de Beck [1999] pela medição de acompanhamento de métricas importantes sem a um grande overhead.

O valor da facilidade de assimilação das informações dispostas em quadros/cartazes ou outros dispositivos pode ser relacionada com o atributo "É compreendido em um relance", associado por Cockburn [2005] como atributo desejado de um radiador de informação indicado. Blandford e Furniss [2005] também consideram diversos aspectos relacionados com a cognição humana, o que inclui questões de assimilação das informações dispostas no espaço de trabalho informativo.

A importância em remover informações que se tornaram de menor valor pode ser denotada pela sugestão de Beck e Andres [2006] "se um gráfico parar de ser atualizado, remova-o".

O valor de se manter quadros/cartazes importantes próximos ao local da reunião diária não foi diretamente encontrado em trabalhos da comunidade ágil, apesar de Sharp et al. [2009] descrever casos reais em que equipes possuem o "Quadro" como ponto focal em sua reunião diária. Apesar disto, a utilização desta heurística pode ser indiretamente associada ao princípio de Hartmann e Dymond [2006] na escolha de métricas/diagnósticos apropriados em uma equipe ágil: "Promove combustível para conversas significativas". Isto se dá levando em consideração o objetivo intrínseco da reunião diária de se fomentar comunicação por entre os integrantes. O valor deste aspecto também pode ser indiretamente relacionado com a afirmação de Poppendieck e Poppendieck [2007] sobre a necessidade de se basear em um recurso visual (como o kanban) para auto-direcionar o trabalho internamente na equipe, o que também influencia na proximidade deste tipo de quadro ao local da reunião diária - tendo em vista o propósito de planejamento da reunião diária.

Apesar de termos encontrado diversas referências para relacionar as heurísticas propostas à afirmações na literatura, nem todas puderam ser relacionadas. Não encontramos referências na literatura que suportassem os aspectos de pareamento no acompanhamento ágil e a boa divisão de tarefas relacionadas ao acompanhamento ágil. Logo, consideramos que estes dois aspectos, juntamente com a utilidade de se manter quadros/cartazes relevantes ao local da reunião diária, devem ser melhor estudados em oportunidades de pesquisa futuras, pois deveriam ser melhor compreendidos dentro do contexto de métodos ágeis.

\subsubsection{Avaliação das heurísticas}

Cada um dos aspectos relacionados às heurísticas foi avaliado quanto a sua utilidade/importância nos dois ambientes trabalhados, as equipes de desenvolvimento de software das turmas de Laboratório de Programação Extrema de 2010 e 2011. Esta avaliação foi realizada por meio de um questionário, disponibilizado para todos os integrantes das equipes. A Tabela 5.12 demostra um resumo comparativo dos resultados coletados pela aplicação do questionário nestes dois ambientes, associando cada heurística aos resultados indicados a seu aspecto relacionado no questionário. Além disto, nesta mesma tabela está disponível a porcentagem de integrantes que tiveram experiência 
com o aspecto relacionado para cada heurística. Destacamos em cinza escuro e claro a primeira e segunda opção com maior porcentagem de respostas para cada heurística na aplicação do questionário em ambas as turmas.

Tabela 5.12: Questionários - Dados de 2010 e 2011

\begin{tabular}{|c|c|c|c|c|c|c|c|}
\hline Heurística & Ano & Experiência & Muito baixa & Baixa & Média & Alta & Muito Alta \\
\hline \multirow{2}{*}{$\begin{array}{l}\text { \# 1. Mantenha quadros mais } \\
\text { importantes próximos ao local } \\
\text { da reunião diária }\end{array}$} & 2010 & $100 \%$ & $0 \%$ & $6,6 \%$ & $6,6 \%$ & $53, \%$ & $33,3 \%$ \\
\hline & 2011 & $60 \%$ & $0 \%$ & $16.7 \%$ & $41.7 \%$ & $33,3 \%$ & $8,3 \%$ \\
\hline \multirow{2}{*}{$\begin{array}{l}\# \text { 2. Promova a alteração dos } \\
\text { radiadores de informação por } \\
\text { todos os integrantes da equipe }\end{array}$} & 2010 & $80 \%$ & $0 \%$ & $3,7 \%$ & $8,8 \%$ & $58,8 \%$ & $28,7 \%$ \\
\hline & 2011 & $65 \%$ & $0 \%$ & $7,7 \%$ & $61,5 \%$ & $30,8 \%$ & $0 \%$ \\
\hline \multirow{2}{*}{$\begin{array}{l}\# 3 . \text { Foque-se em necessidades } \\
\text { específicas do momento }\end{array}$} & 2010 & $90 \%$ & $0 \%$ & $0 \%$ & $22,2 \%$ & $59,3 \%$ & $18,5 \%$ \\
\hline & 2011 & $65 \%$ & $0 \%$ & $15,4 \%$ & $23,1 \%$ & $38,4 \%$ & $23,1 \%$ \\
\hline \multirow{2}{*}{$\begin{array}{l}\text { \# 4. Disponibilize a informação } \\
\text { de forma a ser facilmente } \\
\text { assimilada pelo cérebro }\end{array}$} & 2010 & $100 \%$ & $0 \%$ & $0 \%$ & $20 \%$ & $37 \%$ & $43 \%$ \\
\hline & 2011 & $85 \%$ & $0 \%$ & $5,9 \%$ & $47 \%$ & $35,3 \%$ & $11,8 \%$ \\
\hline \multirow{2}{*}{$\begin{array}{l}\# 5 . \text { Realize preenchimento } \\
\text { e(ou) alterações em duplas }\end{array}$} & 2010 & $90 \%$ & $0 \%$ & $18,5 \%$ & $33,3 \%$ & $40,8 \%$ & $7,4 \%$ \\
\hline & 2011 & $80 \%$ & $0 \%$ & $18,8 \%$ & $50 \%$ & $25 \%$ & $6,2 \%$ \\
\hline \multirow{2}{*}{$\begin{array}{l}\text { \# 6. Promova praticidade } \\
\text { e facilidade de manutenção }\end{array}$} & 2010 & $100 \%$ & $0 \%$ & $3 \%$ & $10 \%$ & $50 \%$ & $37 \%$ \\
\hline & 2011 & $100 \%$ & $0 \%$ & $5 \%$ & $30 \%$ & $55 \%$ & $10 \%$ \\
\hline \multirow{2}{*}{$\begin{array}{l}\# \text { 7. Remova quadros com } \\
\text { pouco valor }\end{array}$} & 2010 & $87 \%$ & $0 \%$ & $0 \%$ & $26,9 \%$ & $38,5 \%$ & $34,6 \%$ \\
\hline & 2011 & $95 \%$ & $0 \%$ & $0 \%$ & $15,8 \%$ & $63,2 \%$ & $21 \%$ \\
\hline
\end{tabular}

Um dos aspectos que mais de destacam na Tabela 5.12 é a divergência entre a porcentagem de integrantes com experiência nos aspectos vinculados às heurísticas em cada uma das turmas. Na turma de 2010 claramente a grande maioria dos respondentes afirmaram ter experiências com os aspectos relacionados às heurísticas, enquanto na turma de 2011 esta porcentagem é significativamente menor, apesar de ainda representar a maioria dos participantes em todos os casos.

Consideramos que que o trabalho realizado na fase 1 na turma de 2010, em que o pesquisador realizava sugestões às equipes de desenvolvimento auxiliando-os a utilizar técnicas de acompanhamento ágil e seu espaço de trabalho informativo para auxiliar em seu contexto, pode ter sido uma das fontes desta divergência. Por um lado, não podemos descartar a possível influência do pesquisador na turma de 2010, o que poderia ter afetado o valor indicado por cada respondente quanto aos aspectos vinculados às heurísticas no questionário. Apesar disto, o pesquisador não informou diretamente estas heurísticas para as equipes de desenvolvimento, pois estas foram justamente agrupadas com base nos resultados da fase 1, o que limitaria esta influência nas respostas do questionário. O papel do pesquisador, como Meta-tracker da turma de 2010, se limitou na grande maioria dos casos a sugestões específicas orientadas a problemas pontuais em cada equipe de desenvolvimento, em um nível de abstração bem menor do que o exposto no questionário. Isto pode ser facilmente observado na comparação da elaboração do questionário na seção e nos dados coletados da fase 1, expostos na seção .

Apesar desta limitação, consideramos que a divergência entre os dados de 2010 e 2011 sugerem que a aplicação de alguns aspectos vinculados ao acompanhamento ágil podem ter impactos positivos significativos quando assistidos por um indivíduo mais experiente (neste caso, o pesquisador interagindo com um modelo baseado em action-research). Outro argumento que apoia isto são as afirmações e justificativas dispostas pelos integrantes na fase 3, dados que estão diretamente dispo- 
nibilizados no Apêndice A, que demonstram as razões por detrás do valor encontrado em cada um dos aspectos associados às heurísticas e como cada uma foi útil no seu contexto de desenvolvimento.

Um dado bem relevante quanto a esta divergência é que apenas $65 \%$ dos respondentes afirmaram ter utilizado quadros e(ou) cartazes para lidar com problemas específicos durante o desenvolvimento de sua equipe. Este aspecto é um dos mais sugeridos pela literatura, e o fato de apenas $65 \%$ dos integrantes terem afirmado tê-lo utilizado é um forte indício de uma necessidade de direcionamento quanto ao acompanhamento ágil e suas possibilidades no auxílio de equipes ágeis de desenvolvimento.

Quanto a comparação da avaliação de cada um dos aspectos vinculados às heurísticas, destacamos os relacionados às heurísticas "Promova praticidade e facilidade de manutenção", "Remova quadros com pouco valor" e "Foque-se em necessidades específicas do momento" pois são avaliados como Alta ou Muito Alta por pelo menos $50 \%$ dos respondentes no caso de ambas as aplicações do questionário, tanto na turma de 2010 quanto na turma de 2011.

Com uma maior divergência nos resultados, consideramos que as heurísticas "Mantenha quadros mais importantes próximos ao local da reunião diária", "Promova a alteração dos radiadores de informação por todos os integrantes da equipe" e "Disponibilize a informação de forma a ser facilmente assimilada pelo cérebro" devem ser utilizadas na maioria dos casos pois seus aspectos relacionados são avaliados com utilidade/importância Alta ou Muito Alta por pelo menos $80 \%$ dos respondentes da turma de 2010 - em que houve uma maior experiência dos integrantes quanto a estes aspectos.

$\mathrm{O}$ aspecto relacionado à heurística "Realize preenchimento e(ou) alterações em duplas" possuiu alguns resultados mais divergentes na turma de 2010, com apenas 48,2\% dos respondentes avaliando-o como utilidade Alta ou Muito Alta e portanto consideramos que este aspecto deve ser melhor estudado quanto à sua importância em equipes de desenvolvimento ágil. Apesar disto, seus resultados, tanto na turma de 2010 quanto na de 2011, apresentam ao menos avaliação média quanto a sua importância para a maioria dos respondentes.

\subsubsection{Conceitos relacionados às heurísticas}

$\mathrm{Na}$ fase 3 da pesquisa, realizamos uma série de entrevistas com alguns integrantes da equipe de 2010 para compreender o "por que?" da aparente utilidade das heurísticas levantadas na fase 1. Além disto, relacionamos também um conjunto de aspectos associados às heurísticas, incluindo características contextuais sobre sua aplicação. Estas relações podem ser relevantes para equipes ágeis que se utilizem destas heurísticas. O resultado final desta fase foi um conjunto de conceitos associados às heurísticas, mapeados utilizando as técnicas de codificação aberta e codificação axial da Grounded Theory.

Dentre o conjunto de conceitos e seus relacionamentos, muitos deles demonstram ideias já presentes na literatura, enquanto outros apresentam direcionamentos não diretamente explorados. Muitas das ideias já presentes na literatura podem ser expandidas pelo mapeamento de conceitos e relacionamentos realizado na fase 3. Esta expansão se dá ora por meio de um relacionamento mais claro entre conceitos que justificam uma ideia, ora descrevendo de forma mais clara as diferentes abordagens de aplicação das heurísticas e os detalhes de cada uma delas. Alguns destaques destes resultados são discutidos nos parágrafos abaixo.

Cockburn [2005] menciona que um radiador de informação ideal deve ser facilmente atualizado. Nossos dados apontam que pode ser útil uma análise custo/benefício das informações a disponibilizar para a equipe, rebatendo seu valor ao custo de se manter esta informação atualizada. Este autor também cita casos em que um radiador de informação foi removido devido ao feedback negativo constante deste radiador. Os relacionamentos resultantes da fase 3 apontam que a presença de informações relacionadas a um problema atual pode gerar incômodo nos membros da equipe, e houveram casos em que a remoção destas informações representaram a remoção deste incômodo o que justifica o caso citado por Cockburn.

Sharp et al. [2009] descrevem casos em que equipes ágeis utilizavam o "Quadro" como ponto focal de sua reunião diária. Nossos dados apontam que a proximidade de quadros importantes 
no local da reunião diária pode auxiliar na dinâmica da reunião, pois auxilia na percepção de informações e consequentemente no impacto destas informações nos membros da equipe. Além disto, a proximidade destes quadros pode auxiliar em que a equipe considere os assuntos relacionados a estas informações tanto durante o tempo da reunião quanto durante o dia inteiro.

Autores como Beck [1999] sugerem a utilização de métricas na equipe para comunicar a necessidade de mudança, porém nossos dados apontam que este tipo de abordagem pode ser mais efetiva quando se possui o desejo de ação imediata por meio da equipe quanto a esta mudança.

Um dos relacionamentos que não puderam ser diretamente vinculados a afirmações na literatura é quanto ao acompanhamento coletivo. Além da heurística em si não poder ter sido diretamente vinculada à bibliografia, nossos dados apontam que é importante que os integrantes da equipe como um todo possuam interesse na manipulação dos quadros e(ou) cartazes, para que uma boa divisão desta tarefa ocorra em uma equipe ágil de maneira saudável. Além disto, a coletividade no acompanhamento ágil pode auxiliar na reflexão de informações por entre os membros da equipe, além de permitir uma melhor escolha de informações úteis a serem disponibilizadas no ambiente de trabalho informativo.

Outro ponto interessante, não diretamente tratado na literatura, é quanto a presença de restrições no espaço de trabalho da equipe de desenvolvimento. Nossos dados apontam casos em que restrições no espaço de trabalho da equipe gerou a necessidade de mudanças no layout físico dos membros da equipe, bem como exigiu alterações significativas da forma em que os quadros eram disponibilizados, e como a equipe lidava com quadros e informações. Lidar com restrições de espaço de trabalho é um item importante a se observar no tocante a manutenção de um espaço de trabalho informativo em equipes ágeis de desenvolvimento.

Nossos dados apontam também uma diferença interessante em níveis de interação por entre os membros de algumas equipes de desenvolvimento e informações dispostas em quadros e(ou) cartazes no espaço de trabalho. Os dados das entrevistas sugerem a diferenciação de alguns conceitos relacionados a interação entre indivíduos e informações, de forma que podem ser representados em diferentes níveis - um membro da equipe pode:

1. Prestar atenção a informações [atenção à informações];

2. Compreender informações disponibilizadas [compreensão de informações];

3. Refletir a respeito de informações [reflexão de informações];

4. Informações impactarem ações do indivíduo [impacto de informações].

Compreender a diferença entre estes níveis de influência de informações dispostas para com os integrantes de equipes de desenvolvimento pode ser útil na administração de um espaço de trabalho informativo e não encontramos esta diferenciação de forma clara na literatura de métodos ágeis.

\subsubsection{Limitações e ameaças a validade}

A pesquisa experimental foi proposta utilizando um método misto sequencial de pesquisa, possuindo duas fases com caráter qualitativo (fases 1 e 3) e duas fases com caráter quantitativo (fases 2 e 4). A pesquisa em si, considerando cada uma de suas fases e abordagens utilizadas possui limitações e ameaças a validade que não podem ser desconsideradas.

Primeiramente, cada um dos os dois ambientes estudados representavam um conjunto de projetos de desenvolvimento de software realizados por alunos na disciplina de Laboratório de Programação Extrema no IME-USP. Devido a este fato, uma série de limitações se dá à pesquisa realizada.

Apesar dos projetos estudados possuírem, de forma geral, ao menos um indivíduo na figura de coach e outro na figura de cliente, os projetos open-source foram desenvolvidos em um contexto acadêmico. Por isto, não podemos garantir que equipes ágeis de desenvolvimento de software comercial se comportem da mesma forma em diversos aspectos, o que representa uma limitação desta pesquisa. Apesar disto, não pudemos identificar aspectos desta diferença que pudesse impactar significativamente na manipulação de quadros e(ou) cartazes em um ambiente de trabalho informativo, 
que cremos se realizar de maneira similar tanto na indústria quanto na academia. Esta observação pode não ser válida para outros aspectos relacionados a métodos ágeis de desenvolvimento de software, como a interação da equipe com o cliente, negociação contratual, etc.

Outra limitação da pesquisa é que a maioria dos integrantes da equipe não possuíam experiência anterior em desenvolvimento de software utilizando métodos ágeis, e não temos como garantir que o comportamento observado ocorreria em equipes experientes no desenvolvimento utilizando estes métodos. Além disto, os ambientes estudados possuíam características similares, o que apesar de ter contribuído para um mecanismo de comparação entre os questionários da fase 2 e 4, pouco colaborou para restringir a limitação de não se analisar equipes já experientes.

Esta pesquisa foi realizada sob orientação do Prof. Dr. Alfredo Goldman, que também possuiu papel de professor da disciplina em ambas as turmas estudadas. Apesar deste papel ter auxiliado na oportunidade de estudo de ambas as turmas, os integrantes da disciplina possuíam o conhecimento desta orientação, e não podemos descartar que este conhecimento possa ter afetado a interação entre os integrantes das equipes e o pesquisador. Apesar disto, utilizamos o mecanismo de questionário quantitativo para uma melhor avaliação das heurísticas, e este questionário foi disponibilizado para preenchimento anônimo.

Como já mencionado, uma das limitações desta pesquisa é o papel do pesquisador como Metatracker da disciplina, auxiliando os membros das equipes utilizarem de técnicas de acompanhamento ágil para auxiliar em seu desenvolvimento por meio de uma abordagem baseada em action-research, o que caracterizou a fase 1 da pesquisa. Apesar disto, realizamos uma comparação com os dados do questionário da fase 4, aplicado na turma de 2011, em que o pesquisador não possuiu nenhum papel ou influência - o que consideramos possuir utilidade para triangulação de dados.

Destacamos também que na primeira semana de aula na turma de 2011 foi realizada uma aula sobre acompanhamento ágil para os alunos da disciplina, e não possuímos controle da influência gerada por esta aula inicial. Apesar disto, os questionários eram explicitamente baseados na percepção de valor que cada integrante possuiu com base em suas experiências, o que consideramos suficiente para tratar desta limitação.

Outra limitação da pesquisa é a ausência de observação sobre o acompanhamento ágil realizado na turma de 2011. Não acompanhamos a forma com que as equipes desta turma realizaram este tipo de tarefa, o que poderia impactar na relevância dos dados demonstrados pelas respostas dos questionários na fase 4. Apesar disto, o fato do pesquisador não estar envolvido na disciplina evitou influências indesejadas, de forma que possibilitou a fase 4 e tornou seus dados relevantes para a pesquisa. 


\section{Capítulo 6}

\section{Conclusões}

Este trabalho buscou contribuir para a comunidade científica e a indústria de métodos ágeis ao pesquisar a respeito de uma característica encontrada neste tema, a manipulação e disponibilização de informações relevantes para a equipe de desenvolvimento. Abordamos este tema a partir do conceito que denominamos acompanhamento ágil, com base no conceito de tracking definido por Beck [1999].

Primeiramente, realizamos uma análise da bibliografia de métodos ágeis, buscando características nestes métodos que pudessem ser atribuídas no tema estudado. Consideramos em boa parte destes métodos o conceito de manipulação e disponibilização de informações relevantes para a equipe de desenvolvimento, normalmente utilizado como ferramenta de feedback e comunicação. Apesar disto, este tema é tratado por meio de diversos conceitos com algumas leves diferenças entre si, como por exemplo tracking [Beck, 1999], espaço de trabalho informativo [Beck e Andres, 2006], radiadores de informação [Cockburn, 2005, Poppendieck e Poppendieck, 2007], dispositivos de feedback extremo [Hunt e Hume, 2007].

Percebemos que, ao analisar princípios ágeis, muitos deles podem afetar significativamente como que a manipulação e disponibilização de informações pode ocorrer com um melhor aproveitamento, observando aspectos como a humanidade, foco e fluxo de trabalho, a interação com o cliente, a adaptabilidade de o feedback. Também observamos o auxílio que a reflexão dos princípios ágeis podem promover para o acompanhamento ágil em equipes ágeis de desenvolvimento, principalmente na indústria.

Com relação à pesquisa experimental, esta foi dividida em quatro fases, seguindo uma abordagem de métodos mistos de pesquisa [Creswell, 2009], que consideramos ter resultado em contribuições relevantes para a comunidade de métodos ágeis.

A fase 1 resultou no levantamento de um conjunto de sete heurísticas para o acompanhamento ágil. Apesar dos dados desta fase mostrarem indícios da utilidade/importância de cada uma das heurísticas levantadas, não pudemos considerar estes aspectos como os mais importantes nas equipes analisadas, devido a restrições no método avaliativo utilizado para as sugestões realizadas por meio da abordagem baseada em pesquisa-ação.

$\mathrm{Na}$ fase 2, elaboramos um questionário possuindo perguntas fechadas referentes à utilidade/importância de cada um dos aspectos, afim de reforçar a utilidade/importância das heurísticas levantadas pela fase 1 . Seis das sete heurísticas foram avaliadas com utilidade/importância alta ou muito alta por ao menos $73.1 \%$ dos respondentes do questionário aplicado na fase 2, com exceção do aspecto "Pareamento no acompanhamento ágil", em que este número decai para 48,2\%, porém demonstra apenas $18,5 \%$ de utilidade baixa/muito baixa. Consideramos que estes dados reforçam a utilidade dos aspectos levantados na fase 1.

Também realizamos seis entrevistas semi-direcionadas durante a fase 3 , buscando compreender o "por quê" de cada uma das heurísticas, sendo cinco dos seis integrantes coaches das equipes. Analisamos estas entrevistas com a codificação aberta e axial da teoria fundamentada em dados [Strauss e Corbin, 2008]. Além de contribuir para responder o "por quê" da utilidade das heurísticas, as entrevistas mostraram outras informações relevantes para a aplicação destas heurísticas, como 
as restrições à sua utilização, em que contexto que estas se tornam mais úteis e como estas devem ser aplicadas. Esta análise permitiu expandir diversas ideias relacionadas ao acompanhamento ágil já definidas na literatura, bem como sugerir novos conceitos relacionados a este tipo de tarefa, tanto para justificativa de algumas das heurísticas levantadas, quanto para a vinculação de outros conceitos como diferentes abordagens e suas características.

$\mathrm{Na}$ fase 4 reaplicamos o questionário aplicado na fase $2 \mathrm{em}$ outro ambiente, o da turma de 2011, o que apesar de ter demonstrado uma avaliação inferior para maior parte dos aspectos relacionados às heurísticas, proveu dados para triangulação em um ambiente sem influência alguma do pesquisador. Por meio da comparação da avaliação das heurísticas dentre os dois ambientes, viemos a discriminar: Três heurísticas (Praticidade e facilidade de manutenção, Remoção de quadros com pouco valor e se focar em necessidades específicas) possuíram avaliação alta ou muito alta por $50 \%$ dos respondentes em ambas as turmas; Três heurísticas (Proximidade de quadros importantes à reunião diária, coletividade na manipulação de quadros e cartazes, e facilidade de assimilação) possuíram avaliação alta ou muito alta por ao menos $80 \%$ dos respondentes da turma de 2010; E uma heurística (Pareamento no acompanhamento ágil) que apesar de ter avaliações ao menos média por mais de $50 \%$ dos respondentes possuiu resultados significativamente divergentes comparada às outras heurísticas.

Dentre as sete heurísticas levantadas, quatro puderam ser diretamente relacionadas com afirmações encontradas na bibliografia de métodos ágeis, uma pode ser indiretamente relacionada, porém duas não encontramos referencial para relacioná-las.

Consideramos que o trabalho realizado contribuiu para a academia tanto pela discussão sobre princípios ágeis no acompanhamento, bem como os resultados da pesquisa experimental: 1. Levantamento das heurísticas para o acompanhamento ágil; 2. Definição das razões por detrás da utilidade das heurísticas; 3 . Avaliação da utilidade dos aspectos relacionados às heurísticas; 4. Discussões sobre as heurísticas e suas relações com referências bibliográficas. Por fim, concluímos que estas contribuições auxiliam a responder a pergunta de pesquisa "Como melhor usar as técnicas de acompanhamento ágil para auxiliar equipes ágeis de desenvolvimento de software?" bem como atingem os objetivos propostos no estudo, definidos na seção 1.2.

\subsection{Considerações Finais}

Primeiramente, observamos que a utilização do espaço de trabalho da equipe pode envolver questões significativas vinculadas ao princípio ágil "humanidade", como por exemplo a cognição humana. Consideramos que a área de pesquisa de Cognição Distribuída é central para a compreensão do fluxo de informação neste tipo de ambiente e trabalhos como o de Sharp et al. [2006] se tornam essenciais para a evolução desta área.

Ao utilizarmos uma abordagem de métodos mistos sequenciais de pesquisa, observamos que esta abordagem nos permitiu dados mais completos para tirar conclusões a respeito do tema estudado. Sem uma abordagem qualitativa não possuiríamos capacidade de levantar adequadamente um conjunto de heurísticas com base no cotidiano das equipes de desenvolvimento, além de não conseguirmos compreender as razões por detrás da utilidade destas heurísticas. Sem o questionário com perguntas fechadas e sua análise quantitativa, consideramos que não teríamos dados suficientes para justificar e solidificar a utilidade das heurísticas levantadas. Consideramos que a utilização de métodos mistos de fato "se aproveita de suas forças e minimiza suas fraquezas" [Johnson e Onwuegbuzie, 2004] em relação às abordagens simplesmente quantitativas ou qualitativas.

Dentro do contexto da fase 1, a utilização de uma abordagem baseada em pesquisa-ação se mostrou muito importante, pois uma característica intrínseca deste método é a resolução de problemas de maneira colaborativa. Agir colaborativamente com as equipes de desenvolvimento, buscando resolver seus problemas, permitiu uma maior pré-disposição dos membros das equipes em colaborar com a pesquisa em andamento, inclusive nas fases 2 e 3, que não foram baseadas neste método. Observamos que este tipo de abordagem pode ser útil para promover parcerias com a indústria e permitiria outras oportunidades de pesquisa em ambientes comerciais. 


\subsection{Sugestões para Pesquisas Futuras}

As heurísticas levantadas e estudadas durante as fases da pesquisa experimental foram avaliadas em um contexto de equipes ágeis de desenvolvimento de software, porém baseadas em ambientes acadêmicos, a verificação e estudo de tais heurísticas em um ambiente desenvolvimento comercial contribuiria para a comunidade de métodos ágeis. A taxa de participantes no questionário aplicado foi de $62,5 \%$ e $54,04 \%$ para as fases 2 e 4 respectivamente, sendo que o valor da maioria das heurísticas foi consideravelmente bem avaliada, o que reforçaria o interesse da aplicação destas heurística na indústria.

O estudo da manipulação e disponibilização de informações na indústria também permitiria o surgimento de outras heurísticas, que poderiam ser unidas às já dispostas neste trabalho e formar um arcabouço de conhecimento nesta área de métodos ágeis. Isto também seria útil para enriquecer a diferenciação de estratégias diferentes a serem tomadas a respeito do acompanhamento ágil de acordo com o contexto encontrado.

Por último, a disposição e manutenção de informações no ambiente de trabalho possui uma característica cognitiva, e sua compreensão é essencial para o direcionamento desta tarefa. Como já mencionado, Sharp et al. [2006] realiza um trabalho neste sentido, e consideramos que outras iniciativas com este propósito seriam de grande valor. 
CONCLUSÕES 


\section{Apêndice A}

\section{Transcrição e análise das entrevistas da fase 3 da pesquisa}

Os dados das entrevistas referentes à fase 3 da pesquisa são disponibilizadas da seguinte forma:

- P: Perguntas

- R: Respostas

- M1: Memorandos da codificação aberta

- M2: Memorandos da codificação axial

\section{A.1 Coach - Equipe: Archimedes}

Proximidade de quadros e cartazes no local da reunião diária

P: Você considera que foi útil a proximidade de quadros ou cartazes importantes no local da reunião diária?

R: Com certeza, porque a gente já faz a atualização de todas as métricas na reunião diária [atualização na reunião diária]. Isso força com que o grupo inteiro preste atenção no que está sendo feito nas métricas e tudo mais [percepção de informações]. Se ficasse longe [negação - > proximidade de quadros na reunião diária] acredito que iria ficar batido e o pessoal não iria nem olhar essas métricas [negação -> atenção a informações].

M2: Aqui o entrevistado indica a experiência de sua equipe na [atualização durante a reunião diária], e a vincula à [percepção de informações], após isto indica que caso informações ficassem longe as pessoas não dariam [atenção à informações].

\section{Coletividade no acompanhamento ágil}

P: Você considera que foi útil uma manipulação de quadros/cartazes de uma forma bem distribuída na sua equipe?

R: Sim, tanto que na primeira iteração a gente fez o tracking e ele estava bem ruim [acompanhamento ágil instatisfatório]. Na retrospectiva a gente levantou como um grande problema porque o tracker atualizava a métrica sozinho [tracker solo], e o restante do grupo nem olhava essas métricas [negação -> atenção à informações]. Esse foi o nosso maior problema na primeira iteração [problema da equipe].

M2: Vejo que o entrevistado relaciona uma situação na equipe dele, que se encontrava com um [acompanhamento ágil insatisfatório], com o fato de existir uma única pessoa responsável pelo acompanhamento ágil [tracker solo], resultando em outros integrantes não prestassem [atenção à informações]. Apesar disto, [tracker solo] pode ser visto como uma negação ao conceito [coletividade 
no acompanhamento ágil], podendo-se associar seus relacionamentos em uma dimensão de "Senão"da categoria [coletividade no acompanhamento ágil]. Não vejo a relação do conceito [problema de equipe] à categoria, visto que o entrevistado está falando pontualmente do cenário ocorrido em sua equipe. $\mathrm{P}$ : $\mathrm{O}$ que você acha que gerou uma melhoria nesse aspecto, se ela de fato ocorreu?

R: Acho que a aliada com a proximidade [proximidade de quadros e cartazes na reunião diária]. A gente obrigou que o grupo inteiro estivesse presente na hora da atualização das métricas [todos presentes na atualização]. Isto melhorou muito a qualidade do entendimento do grupo quanto às métricas [compreensão de informações].

M2: Apesar das sentenças estarem claras, creio que [proximidade de quadros e cartazes na reunião diária] neste contexto esteja associado à experiência da equipe na coletividade, mais precisamente com o fato de estarem [todos presentes na atualização]. P: Com relação à coletividade, no sentido da divisão (da equipe) das tarefas de alteração, do tracking, sendo esta realizada um dia cada indivíduo, ou uma iteração cada um. Você acha que isto foi útil no contexto da sua equipe?

R: Sim, a gente rotacionou os trackers por iteração [rotatividade entre os integrantes]. E se a gente não rotacionasse provavelmente no fim do semestre só um iria saber o que realmente era o tracking, o pessoal iria entender as métricas coletadas, mas não iriam entender o espírito do tracking [aprendizado do acompanhamento ágil].

M2: Vejo que o entrevistado realiza uma relação entre a [rotatividade entre os integrantes] e o [aprendizado do acompanhamento ágil]. P: Você acha que o fato de vocês terem rotacionado o tracker contribuiu em melhorias na relação de quadros e informações?

R: Sim, eu acho que ajudou bastante. Porque.. eu não sei.

\section{Acompanhamento ágil para tratamento de problemas específicos}

P: Você acha que a manipulação de quadros/cartazes/informações/métricas são úteis se utilizadas como ferramentas para se tratar de problemas específicos encontrados durante o desenvolvimento?

R: Ai eu já sou um pouco mais "terrorista"quanto a esse lado [posição radical]. Eu acho que as métricas são para o tratamento de problemas específicos [finalidade do acompanhamento ágil]. Eu posso até estar errado, mas minha opinião é essa [reforço - $>$ finalidade do tracking]. Eu acho que as métricas são criadas quando um problema surge na retrospectiva [informações baseadas em problemas] e você tem que resolver para a próxima iteração [desejo de ação imediata], ai você cria uma métrica. Eu acho que é esse o objetivo da métrica [finalidade da disponibilização de informações]. Posso estar errado, mas é minha opinião [reforço - > finalidade da disponibilização de informações].

M2: Vejo que o entrevistado tem uma [posição radical] ao realizar uma forte correção desta categoria com a própria [finalidade do acompanhamento ágil]. Pois a criação de [informações baseadas em problemas] está relacionada com a [finalidade da disponibilização de informações]. Vejo também que o entrevistado relaciona o "e você tem que resolver para a próxima interação"com a criação de métricas, o que interpreto como uma condição temporal - o [desejo de ação imediata].

\section{Facilidade de assimilação dos quadros e(ou) cartazes}

P: Você considera que é importante que as informações contidas em quadros/cartazes sejam disponibilizadas de uma forma fácil de serem assimiladas? Isso pode incluir a manipulação de cores, desenhos, imagens, post-its com cores diferentes, simbolos, etc.

R: No caso do archimedes em específico a gente explorou muito pouco isso, porque o grupo não tinha disposição para fazer os cartazes coloridos e tudo mais [interesse da equipe]. Então, a gente acabou não explorando esse lado, de fazer a métricas de uma forma bem criativa [criatividade]. A gente fez de uma forma bem objetiva mesmo [tracking objetivo]. Então nesse aspecto eu acho que o archimedes não explorou tanto não [ausência de experiência].

M2: O entrevistado aponta que seu grupo não teve muita experiência com isso. Estamos desconsiderando esses comentários na codificação axial. 


\section{Pareamento nas tarefas de acompanhamento ágil}

P: Vocês realizaram a manipulação de quadros/cartazes em duplas?

R: Sim, a partir da metade do semestre a gente passou a parear, porque devida à falta de experiência do grupo, o tracker ficava muito inseguro [insegurança] com o que ele estava fazendo na iteração [tracker solo]. Então a gente resolveu parear para passar mais segurança para a dupla [segurança no acompanhamento ágil]. Porque eles estavam se sentindo meio perdidos [direcionamento do acompanhametno ágil], nunca haviam trabalhado com métricas e tudo. Parear foi perfeito, foi a solução ótima para a gente [aprovação - > pareamento no tracking].

M2: Vejo que o entrevistado relaciona o [pareamento no acompanhamento ágil] com a [segurança no acompanhamento ágil], bem como a melhoria no [direcionamento do acompanhamento ágil]. P: Que bom, então você acha que interferiu/foi útil por falta de experiência?

R: Sim [iniciantes na metodologia].

M2: Vejo a influência por existirem [iniciantes na metodologia] no [direcionamento do acompanhamento ágil] que a equipe precisava - no contexto de pareamento. P: E também pela questão do aprendizado das pessoas?

R: Bem, o aprendizado eu acredito que não [sem influência no aprendizado]. O aprendizado eu acredito que, como todos foram trackers acredito que ao menos duas vezes este semestre, o aprendizado eles teriam aprendido de qualquer maneira [aprendizado garantido]. Foi mais por insegurança [falta -> segurança no acompanhamento ágil] e falta de experiência que a gente resolveu parear [iniciantes na metodologia]. P: Você acha que o pareamento teria impactos na qualidade dos quadros ou disposição dos quadros?

$\mathrm{R}$ : Eu acredito que sim, mas por uma falha da disciplina [caso específico]. Porque como aqui não é um trabalho, é uma disciplina, o pessoal tem preguiça de ser tracker. Então o pareamento faz com que um cobre o tracking do outro e se desenvolva um pouco mais as métricas [desenvolvimento das informações]. Senão elas ficam bem simples e na lei do mínimo esforço - o que funciona na faculdade.

M2: Pelo fato do integrante considerar como um caso específico da disciplina em que os trabalhos foram feitos, desconsideramos as associações referentes à essa resposta.

\section{Praticidade de manipulação de quadros e(ou) cartazes}

P: Como você considera a importância que esses quadros/cartazes/informações sejam práticos de serem manipulados?

R: Então, eu acho que funciona na base do custo-benefício [relação custo/benefício - "in vivo"]. Se você tem uma métrica que você considera que seja muito importante, mas ela vai dar um pouquinho de trabalho, você tem que medir se compensa ou não fazer essa métrica [relação custo/benefício]. Mas no caso do archimedes para este semestre a gente só fez métricas bem simples então era coisa de três/quatro minutinhos depois da nossa stand-up a gente tomava para atualizar as métricas [informações práticas de se atualizar]. Então a praticidade ficou máxima para a gente [aprovação -> praticidade na manipulação].

M2: Vejo a importância da [relação custo/benefício] em escolhas referentes ao espaço de trabalho informativo. Vejo também uma escolha de sucesso, saber como escolher e aplicar [informações práticas de se atualizar].

\section{Remoção de quadros e(ou) cartazes com pouco valor}

P: Você considera que é importante a remoção de quadros/cartazes/informações que com o passar do tempo se tornaram de menor valor dentro do contexto da sua equipe?

$\mathrm{R}$ : Bastante, mas a gente só teve um exemplo para remoção de informação que foi na primeira iteração. A gente pegou um tracker que não sabia nem o que era metodologia ágil e muito menos o que era tracking [iniciante em métodos ágeis]. Então esse foi o maior problema, a gente pegou as métricas do ano passado e tomou como parâmetro, então acabou que a gente fez muita métrica para a primeira iteração e não precisava [utilidade de informações]. Então só foi nesse caso que a gente 
removeu, porque provavelmente a turma do ano passado tinha várias métricas devido aos problemas que eles foram enfrentando durante o semestre [contexto diferente]. E a gente sem problema nenhum, estimando as primeiras histórias, não conhecendo nem a arquitetura do projeto, já estava com 5,6 métricas na parede [informações fora do contexto]. Então foi totalmente desnecessário e a gente acabou retirando [utilidade de informações], mas durante o semestre a gente não teve caso de remoção de métricas não.

M2: Vejo que o entrevistado afirma que a [utilidade de informações] pode estar relacionada com a existência de [informações fora do contexto]. P: E você tem alguma consideração à respeito porque a remoção desses quadros pode ser útil?

R: Ah, eu acho que a remoção serve para você não perder tempo [desperdício de tempo]. É basicamente isso. Se essa métrica não serve para você para que você vai perder 5 minutos de cada dia, ainda mais na disciplina de XP que era duas vezes por semana, atualizando este quadro [desperdício de tempo]. Então é mais por não ter sentido ter a métrica - exatamente isso [utilidade de informações]. Bastante, mas só tivemos um exemplo no entanto. Acabou que fizemos muitas métricas para a primeira iteração, porém não era necessário [utilidade de informações]. Acho que a remoção serve para não perder tempo [desperdício de tempo].

M2: Vejo basicamente a questão do [desperdício de tempo] associado à [remoção de informações] e conseqüentemente a discussão da própria [utilidade de informações] nesse contexto.

\section{A.2 Coach - Equipe: Baile}

\section{Proximidade de quadros e cartazes no local da reunião diária}

P: Você considera que é útil a proximidade de quadros e cartazes e no local da reunião diária?

R: Sim, eu considero muito importante. Isto porque na hora do stand-up a gente começa a discutir como é que foi o dia [discussão sobre o dia] e ai olhando para um quadro próximo [proximidade de quadros] a gente já lembra o que é importante a gente melhorar, o que é importante a gente manter [direcionamento da equipe]. Se este fica em um local longe, dificilmente a gente desvia o rosto das pessoas que estão falando para olhar para esse lugar [falta de atenção às informações]. No começo a gente tinha esse cartaz do lado oposto, mas o time decidiu que ali era um lugar ruim que ninguém olhava, ninguém lembrava [não -> percepção de informações]. Então a gente mudou isso para o quadro branco e ficou bem melhor, a gente presta mais atenção [mudança do local das informações].

M2: Vejo que com relação à categoria "proximidade de quadros/cartazes na reunião diária", o entrevistado afirma que o "por quê"da [proximidade de quadros] é que auxilia no [direcionamento da equipe]. Observo também que o entrevistado está realizando um vínculo em um cenário que um quadro importante não estava próximo [proximidade de quadros], ao fato de ter gerado uma falta de [percepção das informações].

\section{Coletividade no acompanhamento ágil}

P: Você acha que é importante dividir as tarefas de tracking por entre os membros da equipe?

$\mathrm{R}$ : Eu achei bem importante [importante] desde o começo. Na verdade, a gente fazia uma rotatividade [rotatividade entre os integrantes]. Eu acho interessante porque cada um aprende o que é o tracking [aprendizado de tracking], especialmente nesta disciplina que muita gente é nova nessa metodologia [iniciantes na metodologia], e também as pessoas ficam mais atentas sobre como melhorar as métricas e começam a dar sugestões [melhoria do acompanhamento ágil].

M2: Percebo que o entrevistado considera [coletividade no acompanhamento ágil] como [importante], incluindo a possibilidade de realizar uma [rotatividade entre os integrantes]. Vejo que o entrevistado está relacionando o assunto tratado, [coletividade no acompanhamento ágil], com o [aprendizado do acompanhamento ágil], devido a integrantes serem [iniciantes na metodologia], e que isso influência na [melhoria do acompanhamento ágil]. 


\section{Acompanhamento ágil para tratamento de problemas específicos}

P: Você considera que a manipulação de quadros ou cartazes pode ser útil como ferramenta para se tratar de problemas específicos que foram encontrados em seu desenvolvimento?

R: Sim, eu acho muito útil [útil]. A gente procura fazer uma métrica diante de um problema que gente tem [informações baseadas em problemas], então ela fica ali o tempo inteiro chamando atenção para um problema [evidenciação de problemas]. Sempre o time fica interessado em ver qual é a próxima atualização da métrica, pra ver se a gente melhorou ou não [interesse na atualização de informações].

M2: Vejo que o entrevistado relaciona de ter sido realizada a escolha de [informações baseadas em problemas], que isso está relacionado à [evidenciação de problemas], e que neste caso a equipe possui [interesse na atualização de informações]. P: Existe algum aspecto que você considera que esteja relacionado com essa utilidade? Por exemplo adaptabilidade?

$\mathrm{R}$ : É, eu acho que realmente a equipe se interessa e começa a ver a métrica no código [percepção de informações x trabalho realizado]. Ela começa a programar pensando em melhorar aquela métrica [trabalho direcionado], e o tipo de problema que a gente está passando fica mais evidenciado [evidenciação de problemas].

M2: O que mais se destaca na minha opinião é como a [utilização do acompanhamento ágil para tratamento de problemas específicos] leva a equipe a realizar um [trabalho direcionado].

\section{Facilidade de assimilação dos quadros e(ou) cartazes}

P: Você considera que é importante que informações contidas em quadros ou cartazes estejam disponibilizadas de uma forma de serem assimiladas? Isso inclui manipulação de cores, desenhos, imagens, cores diferentes de post-its, etc.

R: Eu acho importante sim [importante], não é simplesmente um aspecto decorativo, supérfulo [disponibilização não supérfula]. Eu acho que a métrica tem que chamar a atenção [atenção à informações]. Se você não destacar cada uma vai correr o risco de olhar para o quadro e achar que é tudo uma coisa só, uma coisa muito grande, muito jogada [poluição visual], e você não vai ter interesse de ver [negação -> interesse em informações]. Então se for um quadro mais organizado, que usa cores [facilidade de assimilação], isso facilita você à leitura rápida [leitura rápida] e identificar a separação das métricas: aqui é uma métrica, ali é outra [separação cognitiva de informações], e ler isso melhor [percepção de informações].

M2: Vejo principalmente a correlação entre [facilidade de assimilação] com a [leitura rápida], bem como a [separação cognitiva de informações] e a influência no [interesse em informações], [atenção à informações], e é possível gerar um ambiente com [poluição visual].

\section{Pareamento nas tarefas de acompanhamento ágil}

P: Você considera util a manipulação de quadros e cartazes seja realizada em duplas?

R: Primeiro porque a dupla atualiza mais rápido [velocidade na manipulação], não é só uma métrica, então você pode paralelizar. Outro aspecto é que como a gente programa pareado [programação em par], então os trackers param já minutos antes sem ter que ficar uma pessoa escrevendo o código sozinha [programador solo]. Então a dupla pára e atualiza as métricas [alinhamento de forma de trabalho].

M2: Vejo a clara associação entre o pareamento e a [velocidade na manipulação], bem como a influência que a [programação em par] possui nesta forma de trabalho, pois não parear na manipulação de quadros/cartazes neste tipo de contexto pode influenciar na existência de um [programador solo] - o que se resume ao [alinhamento de forma de trabalho].

\section{Praticidade de manipulação de quadros e(ou) cartazes}

P: Você considera que é importante que os quadros e cartazes sejam fáceis de serem manipulados? Isto inclui tanto o preenchimento cotidiano quanto a substituição dos quadros. 
R: Sim, eu acho que deve ser fácil de preencher, mas não chegamos em nenhum ponto que dificultasse o preenchimento [sem experiência]. Porque assim, a gente tem que atualizar, e não pode bater o olho e falar "esse gráfico a gente não consegue atualizar [velocidade na manipulação], vamo deixar pra depois, amanhã a gente atualiza isso melhor, agora não vai dar tempo, estou com pressa". Tem que ser realmente algo fácil, que você vai lá e atualiza rapidamente para mantê-lo atualizado [facilidade na atualização]. Não deixá-lo defasado, para que mostre logo algum problema, rápido [defasado - "in vivo"]. E também é importante você poder trocar alguma métrica, que não está ajudando a resolver nenhum problema [remoção de informações]. Você apaga do quadro, remove o cartaz, troca por outro. Nesse ponto o quadro é mais prático né [comparação entre facilidade].

M2: Percebo que o entrevistado está falando sobre a [velocidade na manipulação], mas indica que a praticidade na manipulação dos quadros é importante para que a equipe não possua [informações atualizadas] devido ao espaço de trabalho informativo possuir muito [peso na manipulação].

\section{Remoção de quadros e(ou) cartazes com pouco valor}

P: Você considera que é importante a remoção de quadros, cartazes ou informações que com o passar do tempo se tornaram de pouco valor no contexto da sua equipe?

R: Sim, deixa eu só comentar um pouquinho sobre o outro assunto, que as vezes a gente não sabia se ia dar certo uma métrica, a gente fazia ela no quadro meio que um rascunho [rascunho de informação]. Se a gente visse que realmente aquilo estava ajudando [utilidade de informações], a gente passava para um cartaz, porque a gente tinha certeza que iria usar mesmo [qualidade do quadro]. Movendo-a para um cartaz sobraria espaço no quadro para podermos experimentar uma outra, ou alguma coisa mais importante ali [administração do espaço].

M2: Vejo que o entrevistado ainda está se referindo à [praticidade na manipulação], informando uma possibilidade de [rascunho de informação], e após a verificação da [utilidade de informações] pode-se melhorar a [qualidade do quadro], pensando também na [administração do espaço].

R: A gente teve um caso para acompanhar testes, fez uma métrica, e o que ocorreu foi que ela ficou meio estável [informações estáveis]. A gente tinha dúvida se a gente estava escrevendo testes o suficiente ou não [dúvida em qualidade]. Mas a métrica mostrou uma certa constância, oscilou muito pouco [informações estáveis]. Então na próxima iteração a gente resolveu tirá-la, porque a gente olhava para aquilo mas era perda de tempo porque não trazia nenhuma informação, pois a gente via que estava bom já [bom o suficiente]. Então a gente mantinha o nosso foco em um menor número de coisas importantes [foco em assuntos importantes].

M2: Vejo a importância de se remover métricas em momentos em que estas estejam em um um contexto de [informações estáveis], juntamente com a sensação de que o assunto tratado por esta métrica é considerado pela equipe como [bom o suficiente]. Também vejo a necessidade do [foco em assuntos importantes]. P: Você acha que esse foco e a disponibilização de um número menor de coisas, como você mesmo disse, contribui para o bom andamento da equipe?

R: Sim, eu acho porque quando você começa aumentar muito o número de métricas [quantidade de informações], fica difícil lembrar de todas elas [percepção de informações]. As vezes você lembra de uma menos importante, esquece de uma outra [percepção de métricas]. Então é importante primeiro discutir com a equipe, ver quais são os problemas mesmo [coletividade no acompanhamento ágil], quais métricas usar para estes problemas [escolha de informações úteis]. Esses problemas que a equipe sente, ela estará interessada em olhar essas métricas, qualquer outra que você adicionar não vai receber tanta atenção [interesse na atualização das informações], você só vai gastar tempo atualizando, não será importante [desperdício de tempo]. Sim, ocorreu uma métrica que ficou constante [informações estáveis], então ela foi removida, não trazia informação nenhuma [remoção de informações]. Foco em menor número de coisas importantes [foco em assuntos importantes]. Quando começa a se aumentar o número de métricas, fica difícil lembrar de todas, pode-se esquecer de algumas [percepção de informações].

M2: Vejo basicamente a mesma questão, a influência que possuir "poluição"no ambiente pode causar para a [percepção de informações] importantes, e como é importante manter o [foco em 
assuntos importantes]. Considero como conceito novo a [coletividade no acompanhamento ágil] para a [escolha de informações úteis] e para promover o [interesse na atualização das informações].

\section{A.3 Integrante - Equipe: Calopsita}

\section{Proximidade de quadros e cartazes no local da reunião diária}

P: Você considera que é útil que quadros/cartazes importantes estejam próximos ao local da reunião diária?

R: Acho que sim [útil]. Acho que deu para perceber bem, porque no começo a gente tinha alguns quadros que estavam mais longe [negação - $>$ proximidade de quadros na reunião diária] e a gente costumava a esquecer bastante de prestar atenção neles [negação -> atenção à informações]. Então acho que quando a gente os colocou mais perto do local da reunião diária [proximidade de quadros na reunião diária] ajudou bastante a lembrar que eles estavam lá [percepção de informações].

M1: Creio que quando este entrevistado está se refeindo a quadros, e sua proximidade à reunião diária, e como isso influencia na sua percepção deles, ele está se referindo às informações contidas nestes quadros.

M2: Primeiramente, o entrevistado cita uma situação vivida em sua equipe, em que existiam que não estavam [proximos à reunião diária] e a ausência de [atenção à informações], bem como aproximá-los trouxe uma maior [percepção de informações]. P: Você achou que este aspecto teve alguma influência na informação que eles representavam dentro da equipe de desenvolvimento?

R: Como assim? P: Você acha que a informação contida nesses quadros, associado ao fato de estarem próximos na reunião diária, auxiliou a equipe a melhorar?

R: Isso sim. Tanto que nas reuniões a gente quando ia pensar o que ia fazer no dia, antes a gente esquecia [negação -> atentar à informações], quando a gente começou a ver que ele estava mais perto, a gente começou a considerá-lo [considerar assuntos] na reunião [durante a reunião] e no dia [durante o dia] a gente lembrava sei lá.. do pareamento, para escolher os pares e tal. Acho que isso fez diferença [fazer diferença - "in vivo"].

M2: O que me chama atenção neste trecho é que além de vincular a proximidade dos quadros na reunião diária com a [atenção à informações], como outros entrevistados também realizaram, este indica também que [quadros próximos à reunião diária] auxiliam a [considerar assuntos] [durante a reunião] e [durante o dia].

\section{Coletividade no acompanhamento ágil}

P: Você considera que a manipulação de quadros foi consideravelmente bem dividida por entre os membros da sua equipe?

R: Acho que sim. Acho que no começo era uma iteração um tracker [tracker solo], mas ai como a gente decidiu fazer cada dia um par diferente [rotatividade entre os integrantes] acho que isso melhorou bastante - ficou bem dividido depois.

M2: Entrevistadmenciona interação do conceito com a [rotatividade entre os integrantes]. P: Então você considera que é útil que a manipulação de quadros/cartazes seja bem divida por entre os membros da sua equipe?

R: Acho que sim. Acho que também acaba prestando mais atenção [atenção à informações]. Porque no começo como era só uma pessoa que fazia, só mais ela que prestava atenção, os outros não davam tanta importância [atenção à informações]. Então quando você coloca a mão na massa meio que você dá mais valor para o que está lá eu acho [valorização de informações].

M2: Entrevistado relaciona a coletividade à [atenção à informações] da equipe, bem como a [valorização de informações]. P: Então você acha que o fato de alguém atualizar os quadros influencia na compreensão que essa pessoa possui sobre esses quadros?

R: Acho que bastante, porque as vezes quando está só o quadro lá a pessoa não pára muito para pensar o que aquilo significa [falta -> atenção à informações], então quando o cara tem que pensar para preencher ele acaba sendo forçado a refletir um pouco [reflexão sobre informações]. 
M2: O que mais me chama atenção nessa resposta é a correlação entre "mexer"e a [reflexão sobre informações].

\section{Acompanhamento ágil para tratamento de problemas específicos}

P: Você considera útil a utilização de quadros/cartazes/métricas para o tratamento de problemas específicos encontrados durante o desenvolvimento?

R: Acho que sim. Acho que alguns quadros com o tempo se tornam meio irrelevantes [decréscimo de relevância de informações]. Um exemplo nosso talvez seja o quadro de testes, que no começo ninguém sabia fazer [informações baseadas em problemas]. Uma coisa importante é colocá-lo para meio que forçar todo mundo a fazer testes [trabalho direcionado]. E agora mais para o final, acho que o pessoal está mais acostumado então talvez agora não seja tão importante tê-lo [redução da utilidade após resolução do problema]. Mas acho que no processo foi bem importante tê-lo para o pessoal ser meio forçado a fazer [trabalho direcionado].

M1:Apesar do integrante estar se referindo ao conhecimento técnico de sua equipe, no contexto da pergunta ele está se referindo a um problema que sua equipe enfrentava, que é a falta de conhecimento no desenvolvimento de testes para o auxílio de seu sistema. Vejo que o integrante está se referindo à mudança de cenário positiva em relação à capacidade da equipe de desenvolver testes após a indicação da quantidade de testes escritos disposta em um quadro/cartaz.

M2: Percebo que o entrevistado se refere algumas vezes à remoção de informações no ambiente de trabalho. Porém diversas sentenças são especificamente a respeito da utilização do acompanhamento ágil para problemas específicos. Vejo a utilização já mencionada de [informações baseadas em problemas] com o [trabalho direcionado], porém vejo uma [redução de utilidade após resolução do problema] aqui. P: Refletindo.. você consegue associar por que a utilização de quadros/cartazes/métricas pode ser útil no tratamento de problemas específicos?

R: Eu acho que mais porque como é uma coisa visual, chama atenção [atenção à informações], quando você está lá programando as vezes você vira a cara e tem um papel lá tipo: "Ah.. tem que fazer isso"[trabalho direcionado]. Então por ser visual acaba lembrando as vezes [lembrar dos problemas].

R: Nada de mais, apenas o vínculo da categoria com [atenção à informações], [trabalho direcionado] e [lembrar dos problemas].

\section{Facilidade de assimilação dos quadros e(ou) cartazes}

P: Você considera que é importante que as informações contidas em quadros e cartazes sejam disponibilizadas de uma forma fácil de serem assimiladas? Isso pode incluir a manipulação de cores/desenhos/imagens/post-its ou qualquer outra coisa que auxilie nessa questão?

R: Acho que principalmente pelo fato de não ser uma coisa que todo mundo vai ficar o dia inteiro parando para olhar e pensar [leitura rápida]. Acho importante ser algo que você olha e bate o olho rápido [leitura rápida]. Então, sei lá, uma linha verde subindo você consegue entender rápido [compreensão de informações], se fosse tudo preto eu acho que seria menos notado [percepção de informações]. Acho que faz bastante diferença sim.

M1: Vejo que a expressão "Não ficar o dia inteiro olhando", juntamente pelo fato da pergunta estar se referindo à facilidade na assimilação de quadros/cartazes, se trata da capacidade dos membros da equipe de desenvolvimento compreender rapidamente as informações - explicitada pela parte da expressão "...dia inteiro parando para olhar e pensar."Portanto associo essa característica ao conceito [velocidade na assimilação].

M2: Vejo que basicamente o entrevistado se refere a benefícios como [leitura rápida], [compreensão de informações] e a [percepção de informações].

\section{Pareamento nas tarefas de acompanhamento ágil}

P: Você considera útil que a manipulação de quadros e(ou) cartazes seja realizada em duplas, no contexto da sua equipe? 
R: Acho que o que foi mais útil foi que dava para acabar antes as coisas do tracking, para começar a programar em si mais cedo [velocidade de manipulação]. Porque eu acho que para o cliente é o que vai fazer diferença, e não essa de ficar fazendo tracking [desiteresse do cliente]. Acho que foi interessante nesse sentido mesmo.

M2: Vejo também a relação do pareamento com a [velocidade na manipulação]. Vejo que esta afirmação com relação ao cliente não é algo diretamente ligado ao acompanhamento ágil, e sim à qualquer outra coisa que não seja gerar valor de negócio. P: Então foi mais no sentido da agilidade com que as coisas(quadros/cartazes/etc) são preenchidas?

R: Isso, acho que sim [velocidade na manipulação].

M2: Claramente [velocidade na manipulação].

\section{Praticidade de manipulação de quadros e(ou) cartazes}

P: Você considera que é importante que os quadros/cartazes sejam práticos, o que pode incluir aspectos como o preenchimento cotidiano, bem como a alteração desses quadros, redesenho, substituição?

R: Acho que sim [importante]. Principalmente do que eu falei antes que não é algo que traz valor para o cliente [desinteresse do cliente]. Então como nosso principal foco é trazer valor para o cliente, então se não for uma coisa prática a gente vai estar gastando tempo à toa [desperdício de tempo]. Por isso é importante ser uma coisa bem rápida [velocidade na manipulação].

M2: O entrevistado aponta a respeito do [desinteresse do cliente], mas não vejo que ele se refere que isso está diretamente associado ao acompanhamento ágil, e sim ao tempo gasto em tarefas não correspondentes à geração de valor para o cliente, tempo gasto no acompanhamento ágil pode ser apenas um exemplo. Porém vejo a questão do [desperdício de tempo] associada à praticidade. P: Você acha que a ausência de praticidade na manipulação pode levar aos quadros serem menos atualizados ou serem descontinuados?

R: Acho que de certa forma sim. No nosso caso a gente teve um problema que a escala no meio do caminho mudou [situação inesperada] e como era feito na cartolina a gente fez uma gambiarra para fazer funcionar [necessidade de adaptação de quadros]. Mas o que eu pensei agora, se estivesse no quadro branco [meio de disponibilização] seria mais fácil [facilidade na adaptação], então talvez ficasse mais claro/mais apresentável [clareza das informações].

M1: Quando o integrante está realizando a relação cartolina x quadro branco, vejo que o mesmo está se referindo à capacidade de você apagar o quadro branco com facilidade. Vejo que o integrante se refere que esta característica permitiria uma mais fácil adaptação de quadros, deixando-os mais claros para a equipe, comparado a fazer essa adaptação inadequadamente em uma cartolina (representado pelo termo "gambiarra"), que também resultou em uma apresentação desagradável das informações.

M2: Vejo que o entrevistado está relacionando um caso real de sua equipe, em que uma [situação inesperada] de mudança de escala em um gráfico, associado com o [meio de disponibilização] deste quadro e como isto pode a afetar a [clareza das informações] devido à [necessidade de adaptação de quadros].

\section{Remoção de quadros e(ou) cartazes com pouco valor}

P: Você considera que é importante a remoção de quadros/cartazes que com o passar o tempo se tornaram de menor valor no contexto da sua equipe?

$\mathrm{R}$ : Eu acho que bastante. No nosso caso também, a gente enfrentou isso no quadro branco. No começo a gente colocou tanta coisa que não dava muito para localizar as coisas importantes [excesso de informação] - ai eu acho que no final ninguém prestava muita atenção no quadro [foco em assuntos importantes]. Quando a gente apagou as coisas menos relevantes [remoção de informações menos relevantes], facilitou bastante encontrar as informações importantes [percepção restrita de informações]. Acho que ajudou sim. 
M2: Vejo a utilidade em se remover quadros em caso de [excesso de informação], e como isso tem a ver com o [foco em assuntos importantes] da equipe com relação à informações, e como isso tem a ver com o a [percepção restrita de informações]. P: Então você considera que a remoção de informações que com o passar o tempo tiveram menor valor auxiliou na assimilação de informações mais importantes das removidas?

R: Sim, sim. Porque eu acho que quando tem muita coisa [excesso de informação] você acaba não conseguindo selecionar muito [percepção restrita de informações]. Então tem tanta coisa que você não pega nada assim [percepção restrita de informações]. Então acho que foi bem relevante isso.

M1: Vejo que o integrante, o termo "selecionar muito", está se referindo à capacidade de cada integrante da equipe de "escolher"informações para se atentar. Para mim esta idéia está vinculada à percepção limitada que seres humanos possuem com relação à informações dispostas em um ambiente, normalmente tratada por temas em psicologia como a Cognição Distribuída.

M2: Vejo claramente a influência da [percepção restrita de informações] ao [excesso de informação].

\section{A.4 Coach - Equipe: CoGrOO}

\section{Proximidade de quadros e cartazes no local da reunião diária}

P: Você considera que é útil a proximidade de quadros e cartazes e no local da reunião diária?

R: Não só útil, como essencial [essencial], pois com os quadros por perto o pessoal tem mais idéia do que falar [comunicação durante a reunião], considerando que por exemplo, eles por exemplo não terminaram ontem de programar as $18 \mathrm{~h}$ e estão começando a fazer as coisas hoje as $8 \mathrm{~h}$ novamente. Se não fosse assim talvez não precisasse necessariamente do quadro próximo à reunião, o que não é o caso [intervalo entre os encontros]. A gente tem uma diferença de alguns dias entre um programa e outro. Então, com o quadro próximo, refresca a memória para que possamos falar coisas mais corretas, por exemplo o que foi feito desde a última reunião [assuntos do dia]. Hoje é sexta, a última reunião foi terça, e ai? Se tiver o quadro perto a gente lembra o que foi feito na terça, então acho que o quadro próximo é útil por causa disso [ferramenta de lembrança].

M1: Ao meu ver, o coach está se referindo à vantagem de se ter os quadros pertos da reunião diária tendo em vista uma dificuldade em comum entre as equipes de desenvolvimento analisadas, que é a diferença de tempo entre os encontros das equipes. Visto que as equipes de encontravam nomalmente terças-feiras e sextas-feiras, muitos consideravam esta distância como uma ameaça à continuidade e fluidez do trabalho.

M2: Com relação à análise axial deste trecho em relação à categoria, pode-se observar a relação que o entrevistado realiza entre a [comunicação durante a reunião] e a [proximidade de quadros na reunião diária], bem como o valor desta proximidade como [ferramenta de recordação] de [assuntos cotidianos] devido à [intervalo entre os encontros]. P: Isto você está falando comparado com quadros que estão distantes do local da reunião diária, apesar de presentes no local, certo?

R: Sim. Inclusive eu vi uma coisa engraçada esses dias, ouvi fala R: "Longe dos olhos, baixa prioridade". Colocando perto, o que está mais próximo, mais fácil de lembrar, o pessoal comenta mais[percepção de informações]. Então, se os quadros que mostram os problemas estiverem próximos isso tem impacto [impacto das informações].

M2: Vejo que o entrevistado associa a [percepção de informações] ao [impacto das informações], e a [percepção de informações] à proximidade de quadros/cartazes ao local da reunião diária. P: Então você acha que os quadros que estão mais próximos da reunião diária são os mais comentados?

R: Eu imagino que sim. São os mais lembrados [atenção à informações]. Porque para comentar em reuniões, o pessoal lembra geralmente de coisas que ele gostaram muito de fazer - que deram certo - ou então de problemas que estão "enchendo muito o saco", ou do que eles estão lendo logo em cima, ou alguém próximo que quer falar de todos os outros problemas, se não tiver esse alguém muitos deles vão passar batido [ferramenta de lembrança]. 
M2: Nada de novo aqui, apenas relacionando [atenção à informações] com a proximidade, bem como essa característica e a utilização do acompanhamento como [ferramenta de lembrança].

\section{Coletividade no acompanhamento ágil}

R: A maioria dos integrantes meteu a mão na massa com relação à tracking [coletividade no acompanhamento ágil]. Inclusive no inicio do semestre eu tentei convencê-los que todos fizessemos, e não apenas um pegasse para fazer [negação - > tracker solo]. Claro, tivemos problemas com isso, questões de continuidade de idéias [continuidade de idéias - "in vivo"], coisas do tipo, e eu tentava ver com alguns entender o que eles fizeram e quando ficava difícil demais eu pedia para eles explicarem [difusão do significado de informações]. Então, aquela questão do quadro não estar muito claro, precisar que alguém explique, ai a gente acabava comentando ou tentava fazer alguma facilitação [difusão do significado de informações].

M2: O que me chama atenção aqui é o conceito de [continuidade de idéias], ainda não mencionado vinculado à continuidade, bem como a [difusão do significado de informações]. Apesar destas características estarem vinculadas à coletividade (devido à pergunta), vejo que nesta equipe, conforme dados da fase 1, houve uma [rotatividade no acompanhamento] e considero que estas características negativas estejam vinculadas à [rotatividade no acompanhamento] e não à [coletividade no acompanhamento] em si. - Você acha que é útil essa manipulação ter sido bem dividida por entre os membros da sua equipe?

R: Bem dividida acho que não se faz necessário, acho que é uma questão de demanda né. É necessário, faz, então se todos da equipe tiverem isso em mente, então o negócio vai fluir bem melhor, desde que o quadro represente o que está sendo realmente feito [interesse coletivo na manipulação]. O ruim é deixar o quadro lá parado, a esmo, com uma ou duas semanas de atraso e nada, não reflita o que a gente está fazendo [desatualização de informações]. Ou então deixar de fazer quadros que reflita por exemplo o caso do estudo, tipo estamos estudando, mas nenhum lugar do mundo estava escrito que estamos estudando, internamente na equipe nós sabíamos que estávamos estudando, mas fora da equipe ninguém sabia [visão externa da equipe]. Então, a equipe ficou parada, né, em questões de tracking, ninguém sabia nada e ninguém via nada, e nada acontecia. E quadros fora do momento, por exemplo, colocaram um quadro de commits, por pressão de Meta-coach, mas como colocar um quadro de commit se o pessoal ainda nem começou a programar de verdade [pressão externa]. E outra coisa, além disso, sobre o mesmo quadro de commit, começaram a programar, mas como cobrar que a equipe faça vários commits se a equipe ainda estão escrevendo linhas com bastante esforço [informação em contexto errado]. Então, imagina se o cara está lá à 2 horas e conseguiu escreveu uma funcionalidade, e mal. E quando ele conseguiu escrever o cara vai lá e fala poxa, você não fez nenhum commit, mas como você vai fazer um commit se ainda não saiu nada? Então tem que ter um certo bom senso [bom senso] nessa situação.

M1: Vejo que o coach está se referindo ao fato de como era uma disciplina, questões de quadros/cartazes utilizados também eram observados pelos responsáveis da disciplina.

M2: Vejo a declaração da característica [interesse coletivo na manipulação] presente, porém após isto diversas sentenças me parecem relacionadas ao acompanhamento ágil como um todo, e não ao tema da coletividade. - Então você acha que alguns quadros foram colocados em um contexto que ainda não existia necessidade deles?

R: Isso, eu acho.

M2: Não trata da coletividade.

\section{Acompanhamento ágil para tratamento de problemas específicos}

R: Claro que sim, se você não expõe o problema, já falar é expor né, mas, se não existe um lugar que você pode ter controle se aquele problema está evoluindo [controle visual de problemas] ou está do mesmo jeito a muito tempo. Teve caso que a gente teve que criar cartão pra resolver o problema, que todos sabiam que tinha um problema desde o início, e passando o tempo falaram de novo do problema, e o problema estava lá e com o passar do tempo o problema continuava [continuidade 
dos problemas]. E o pessoal só falado, e ai, quando a gente vai resolver esse problema? Até que se criou um cartão indicando que o problema existe [evidenciação de problemas]. Depois que foi criado o cartão em poucos dias o problema foi sanado [resolução de problemas].

M2: Vejo que o foco aqui é a relação entre a [resolução de problemas] através do [controle visual de problemas], e como o acompanhamento ágil pode favorecer nesta questão - dispondo informações de problemas. Vejo também que o entrevistado afirma a respeito da [continuidade dos problemas] em casos que esse problema não era evidenciado no espaço de trabalho.

\section{Facilidade de assimilação dos quadros e(ou) cartazes}

R: Está bem perto da coletividade/entendimento. Acho que quanto mais fácil, mais coragem você tem para alterar, para sei lá, também para que os de fora vejam e entendam sem precisar de ninguém para explicar [compreensão externa]. Se um bate o olho e entende é bom, acho isso ótimo [leitura rápida]. Se outro entendeu mas não gostou de tal coisa, apaga e altera pra uma coisa mais fácil [busca por maneiras mais fáceis de assimilação]. Eu acho bem bacana uma coisa ser fácil, e ai pra facilidade, a questão do dinamismo para alterar os quadros é bom, por exemplo, eu vi alguns quadros muito bonitos de algumas equipes - são realmente belos - mas e na hora de alterar aquilo lá, eles vão fazer o que? Vão chorar pra jogar fora? Vão ficar com resistência para alterar [praticidade na manipulação]? Acho que mesmo que seja rabisco, mas se der pra entender, acho que é válido [disponibilização informal].

M1: Para mim, ao falar "bater o olho e entende", o coach está se referindo a compreensão das informações dispostas imediatamente, ao olhar de relance para o quadro/cartaz. - Você acha disponibilizar uma informação de uma forma fácil de ser entendida - claramente entendida - rapidamente entendida? Você acha que a utilidade disso é bem consideravel?

M2: Vejo uma preocupação deste entrevistado na [compreensão externa] das pessoas a respeito do projeto. Também vejo que para o entrevistado, gerar quadros pensando na [facilidade de assimilação] pode impactar na [praticidade da manipulação]. Também vejo a recomendação de uma [disponibilização informal].

R: Ah sim, eu creio que sim. Agora se é fácil representar.. ai é outra história.. porque representar algumas coisas não é simples não [forma de representação de informações], por mais simples que o problema pareça ser, mas a representação dele nem sempre é tão óbvia, eu acho. - Você consegue refletir em alguma questão que possa ser impactada pelo fato de algumas informações estarem fácil de algumas informações estarem fáceis de serem assimiladas?

R: Sim, eu vou citar até um caso meio bobinho, que não sei se se encaixa. Por exemplo, imagina que eu tenho na equipe um pessoal que está com dificuldade de entender a arquitetura que alguns fizeram alguns dias atrás [informação passada]. E o outro precisa ficar lendo testes/código para entender a arquitetura para dar seguimento naquilo [necessidade atual]. Acho que uma pequena representação, não precisa ser a UML toda elaborada, mas desde que tenha uma representação das classes e das suas dependências, acho que isso ai já é de grande ajuda pra quem vai programar [representação simples]. O cara acertou, bateu o olho, é bem mais fácil de assimilar [representação fácil]. Se ele vai conseguir ou não é outra história. Mas eu acho que é bastante válido isso.

M2: Considero que boa parte do fato citado - a respeito da UML de um sistema - não diz muito a respeito da [facilidade de assimilação] de uma informação, e sim a respeito da utilidade da informação em si sendo disponibilizada. Porém, vejo a questão da [representação simples] relacionada com a facilidade de assimilação, com a expressão "O cara acertou, bateu o olho, é bem mais fácil de assimilar".

\section{Pareamento nas tarefas de acompanhamento ágil}

P: Vocês usaram pareamento no tracking? R: Sim, usamos P:Você acha que a manipulação dos quadros e cartazes em duplas foi útil no caso da sua equipe? R: Bem, acho que vai mais aquela história que falamos. Bom quando todos souberem manipular, que não tenha a responsabilidade desse ou daquele fulano fazer [reprovação -> tracking solo]. Todos juntos façam [coletividade no 
tracking]. Mas por enquanto por questões de aprendizado [aprendizado do acompanhamento ágil] e de continuidade de idéias [continuidade de idéias], nós adotamos assim: A dupla começa, na próxima dupla que for parear, fica um da dupla antiga, e o outro fica [rotatividade entre os integrantes]. Dessa forma as idéias da dupla anterior continuam e o próximo que entrou consegue entender [continuidade de idéias]. Agora, se isso é tão bom, não sei, pareceu ser bom. Não sei necessariamente o que que faltou ali.

M2: Vejo que o entrevistado prefere uma maior [coletividade no tracking] ao invés do pareamento, porém entra em questões de [aprendizado do acompanhamento ágil] e da [continuidade de idéias] associada ao fato de ter sido rotativo com pareamento.

\section{Praticidade de manipulação de quadros e(ou) cartazes}

P: Você considera que é importante que os quadros e cartazes sejam fáceis de serem manipulados? Isto inclui tanto o preenchimento cotidiano quanto a substituição dos quadros.

$\mathrm{R}$ : Acho que sim, tem que ser fácil. Tanto para preencher, para representar o estado atual do projeto, tem que ser muito fácil, eu não tenho que perder tempo com isso [desperdício de tempo] - se eu quiser levantar da minha cadeira pra ir no quadro, fazer alguma coisa, eu não quero perder mais que $1 / 2$ minutos [velocidade na manipulação]. Se eu tiver que perder mais tempo com isso, acho que o quadro não está ajudando tanto assim [utilidade da informação]. Talvez ajude informativamente mas está me atrapalhando um pouco [incômodo]. O quadro está lá para me auxiliar e não para pra ficar me tomando tempo [desperdício de tempo] - eu penso nisso. Se eu tiver que pensar em arrumar o quadro de uma maneira mais bonitinha - sei lá, posso pensar quando estou no transito e depois chegar lá e fazer [reflexão fora ambiente de trabalho]. Mas eu acho que não tem que perder tanto tempo com isso [desperdício de tempo]. Inclusive eu posso criticar essa situação, perder muito tempo com tracker não sei se vale, vale a pena vale - as vezes você investiu o dia inteiro para fazer um monte de tracking lá, bonitinho, depois você vai eliminando no meio do caminho o que não foi legal [remoção de informações]. Pode ser que valha a pena [relação custo/benefício]. Mas tem que tomar cuidado com isso, o tracking está lá para te auxiliar e não para te atrapalhar [ajudar e não atrapalhar].

M2: Vejo a importância na [velocidade na manipulação], que o entrevistado afirma não querer um [desperdício de tempo] manipulando quadros - que quando isso ocorre os quadros estão [incômodo]. Muitas vezes uma abordagem que pode ajudar é a [remoção de informações]. Que o objetivo do acompanhamento é [ajudar e não atrapalhar].

\section{Remoção de quadros e(ou) cartazes com pouco valor}

P: Você considera que é importante a remoção de quadros, cartazes ou informações que com o passar do tempo se tornaram de pouco valor no contexto da sua equipe?

R: Pro projeto sim, inclusive é importante. Senão você fica com sujeira [excesso de informação]. Se você não precisa daquilo mais pode jogar fora [utilidade de informações]. Agora se você quer como questão de histórico para experiências, sei lá, tira uma foto, guarda aquilo lá [histórico]. Ai certo dia consulta seu acervo de tracking, por exemplo se você estiver sem idéia do que fazer, ver o que foi bom e o que não foi [histórico -> idéias futuras]. Ai é uma questão de aprendizado [aprendizado do acompanhamento ágil]. Então, seja o que foi bom ou foi ruim, se não estiver legal tira, antes de tirar tira foto e, de repente o que pode ser interessante anota embaixo: "eu fiz assim, dessa forma", pra da próxima vez não ocorrer mais neste erro [aprendizado do acompanhamento ágil].

M2: Vejo a mesma relação de [excesso de informação] ao entrevistado falar "sujeira". Também vejo que ele afirma existir uma importância em manter um [histórico] com a finalidade de [aprendizado do acompanhamento ágil] nesse contexto. P: Você consegue refletir em porque pode ser importante a remoção desses quadros?

R: Eu posso fala R: "leia o tópico anterior?". Acho importante porque se o tracker está para te ajudar, você tem que perder tempo [desperdício de tempo], se tem coisa que está lá e não está te ajudando, não tem porque estar lá [utilidade de informações], então diz "tchau"pra ele. 


\section{A.5 Coach 1 - Equipe: Mezuro}

\section{Proximidade de quadros e cartazes no local da reunião diária}

P: Você acha que é útil manter quadros considerados mais importantes próximos da reunião diária?

R: Eu acho que é útil sim [útil]. No começo a gente não estava fazendo isso, a gente estava deixando o kanban, que é o nosso quadro principal, no ambiente de desenvolvimento enquanto a gente ia para outro lugar com mais espaço para fazer nossa reunião diária [negação - > proximidade de quadros na reunião diária]. A gente mudou para levar o kanban junto, o que ajudou bastante porque fica mais dinâmico porque você vai lá e coloca: "Hoje eu vou trabalhar nessa tarefa, tarefa tal a gente fez semana passada, foi isso, isso e isso"[comunicação na reunião]. O que a gente fez semana passada? "Ah, a gente fez isso, isso e isso". Ficou alguma coisa pendente? "Ah, no TODO aqui tem isso aqui, quem fez isso?"[comunicação durante a reunião]. Dinamiza bastante a reunião, ela fica mais rápida - que era um dos problemas que a gente tinha [dinâmica da reunião - "in vivo"]. Então eu acho que ajuda sim [útil] e é importante [importante].

M2: A primeira coisa que observo é a relação que o entrevistado faz entre um quadro relevante para sua equipe, o kanban, e sua [proximidade na reunião diária], e como isto auxiliou sua equipe em relação à [comunicação durante a reunião], que auxilia na [dinâmica da reunião], e que é [útil] e [importante]. P: Então você acha que ajuda no sentido da velocidade da reunião?

R: Na dinâmica inteira, eu acho que ajuda bastante [dinâmica da reunião]. E no nosso caso, a gente tem um monte de quadros que ficam presos na parede de verdade [restrições de espaço de trabalho]. Então, a gente não conseguia levar por exemplo o quadro de pareamento [restrições de espaço de trabalho]. E essa parte "enchia o saco"[incômodo] porque alguém tinha que ficar no meio do caminho, que era 5 passos de distância, mas tinha que ficar alguém 2 passos e meio falando: "Ah, fulano pareou tantas vezes com ciclano", então agora vamos parear com beltrano [atualização durante a reunião diária]. Então, se todos os quadros pudessem ser levados juntos seria melhor, ou o contrário, se a reunião pudesse ser do lado dos quadros [aprovação - > proximidade de informações na reunião]. No caso não dava, mas a gente fez o que pode [adaptabilidade].

M1: Uma coisa que me chama a atenção é que o entrevistado muitas vezes se refere à quadros presos da parede vinculados ao tema de proximidade de quadros e cartazes durante a reunião diária. Isto ocorre pois em sua equipe as reuniões ocorriam em um local cerca de 5 metros de distância do local de sua reunião diária, logo, esta ausência de mobilidade dos quadros está sendo considerada, no caso desta equipe, como referente à distância dos quadros durante a reunião diária.

M2: O entrevistado reforça o auxílio que essa categoria traz para a [dinâmica da reunião], também informa sobre algumas [restrições de espaço de trabalho] que pode gerar [incômodo] ao se realizar a [atualização durante a reunião diária], e que isso pode exigir uma certa [adaptabilidade].

\section{Coletividade no acompanhamento ágil}

P: Você acha que a manipulação de quadros ou cartazes foi bem dividida pela maioria dos integrantes da sua equipe?

R: Então, eu estava pensando aqui, esse aspecto aqui é a coletividade no tracking, e também tem esse de pareamento no tracking. Eu vou falar os dois juntos, tudo bem? No nosso grupo foi assim, o pareamento no tracking não aconteceu. No começo a gente tinha estipulado que uma pessoa era "dona"do tracking pela semana [tracker solo], só que não funcionava, porque todo mundo queria mexer, todo mundo queria "brincar"[interesse coletivo na manipulação] e o tracking era de todo mundo [coletividade no acompanhamento ágil]. A equipe sentia que era uma coisa para a equipe, e não para a pessoa que deveria controlar aquilo [coletividade no acompanhamento ágil]. Desde o começo a gente tinha essa coletividade no tracking presente, a equipe inteira cuidou do tracking, deu opiniões o tempo todo: "Ah.. esse quadro de carinhas não está legal, não ta servindo pra nada". "Ah mas vamos fazer tal"[discussão sobre quadros/cartazes]. E a gente discutia sobre os quadros e.. é do grupo, então achei bem legal e não precisamos fazer o pareamento no tracking [ausência de 
necessidade de pareamento].

M2: O entrevistado inicia sua resposta indicando que falaria sobre ambos os conceitos, [coletividade no acompanhamento ágil] e [pareamento no acompanhamento ágil], porém logo após ele indica que o [pareamento no acompanhamento ágil] não ocorreu em sua equipe, portanto as afirmações subseqüêntes são referentes apenas primeiro conceito. O que primeiramente me chama a atenção é relação entre a afirmação do [tracker solo] não funcionar com o [interesse coletivo na manipulação], afirmando a [coletividade no acompanhamento ágil]. Vejo que o entrevistado relaciona essa coletividade à [discussão sobre quadros/cartazes], bem como à [ausência de necessidade de pareamento]. P: Tudo bem, então vamos comentar só sobre essa questão que você já começou a comentar - a coletividade. Você acha que a coletividade foi útil então?

R: Sim, foi bem útil. Porque.. é ai que faz sentido o tracking eu achei. Porque as pessoas precisam de alguma coisa, usam uma informação, ai elas sentem que isso é importante para elas [necessidade de informação], então elas mantém essa informação [escolha de informações úteis]. O tracking ser "do grupo"[coletividade no acompanhamento ágil] fez com que o tracking ficasse "vivo"até agora [utilidade do acompanhamento ágil].

M2: Apesar de não estar claro, algo que me chama a atenção no que o estrevistado é que ele menciona algo relacionado à [necessidade de informação] que as pessoas precisam, e o fato do acompanhamento ser "do grupo", e a [utilidade de uma informação]. O que me parece é que o entrevistado está se dizendo que a equipe consegue uma melhor [escolha de informações úteis] pelo fato do tracking ser coletivo, o que já resume esse vinculo à [utilidade do acompanhamento ágil]. P: Então você acha que a utilidade da coletividade no tracking tem a ver com a relação à utilização do quadro pelas pessoas?

R: Sim, sem sobra de dúvida.

M2: A pergunta realizada não foi muito clara, não sei muito o que "tirar"disso. P: E você acha a utilização dos quadros melhora a compreensão das pessoas sobre os aspectos demonstrados nos quadros?

R: Sim, também [compreensão de informações]. Por exemplo, nosso grupo teve dificuldade com o papo-em-pé longo, então a gente criou - seguindo sua sugestão - um gráfico de "Quanto tempo demorava cada papo-em-pé"e ai quando a gente fazia um risquinho a mais porque estava demorando as pessoas já começavam a se mexer e tal [mudança de atitude]. Então quando a gente precisa do quadro e ele pode ajudar a gente, a gente consegue mantê-lo [continuidade de informações]. É um ciclo, não tem como separar as coisas, eu acho [correlação de aspectos no tracking]. É fundamental que o quadro tenha utilidade [utilidade de informações - "in vivo"]. Se ele não tiver utilidade, ele não será mantido, eu acho [continuidade de informações].

M2: Apesar da pergunta ter sido direcionada, nesta resposta vejo que o entrevistado realiza diversos comentários sobre um cenário - explicitado na fase 1 da pesquisa - em que a equipe utilizava um "contador"manual no quadro branco para explicitar o quanto tempo havia passado da reunião diária, visando agilisá-la. Porém, os comentários subsequêntes me parecem estar associados ao feedback causado por este dispositivo, e não do fato dos quadros/cartazes terem sido administrados de forma coletiva. Por isso estamos desconsiderando a análise desta resposta para a definição de dimensões e propriedades na categoria [coletividade do acompanhamento ágil].

\section{Acompanhamento ágil para tratamento de problemas específicos}

P: Você acha que é util você utilizar cartazes/quadros/métricas/infomações como ferramenta para se tratar problemas específicos encontrados durante seu desenvolvimento?

R: Eu acho que sim [útil], porque quando o problema é da equipe, e a equipe faz um cartaz [informações baseadas em problemas], ela começa a tomar noção de qual é o motivo, por que está demorando, o que pode ser feito para melhorar [compreensão sobre o problema]. Talvez seja difícil generalizar, mas se seu problema tem algum tipo de métrica, como é o caso do stand-up, você pode medir o tempo e colocar em um gráfico [informações mensuráveis], funciona muito bem. Se é uma coisa um pouco mais subjetiva como uma "carinha"[negação -> informações mensuráveis], não sei 
qual é a utilidade que ele vai ter, vai depender do caso [acompanhamento de informações]. Mas se for algo mensurável terá bastante efeito na equipe, e ajuda bastante.

M2: Vejo que o entrevistado associa a escolha de [informações baseadas em problemas] e a [compreensão sobre o problema]. Ele também aborda que [informações mensuráveis], relacionando a utilidade das mesmas - essa utilidade estou agrupando como [acompanhamento de informações] por ser algo intimamente ligado à utilidade do acompanhamento ágil, bem como faz sentido essa discriminação entre informações mensuráveis e não mensuráveis neste contexto. Não consegui compreender o que o entrevistado quer dizer exatamente com "efeito na equipe".

\section{Facilidade de assimilação dos quadros e(ou) cartazes}

P: Com relação à facilidade de assimilação, isso inclui a manipulação de cores/desenhos/imagens/postits com cores diferentes, e outras formas de você representar informação de uma forma fácil de ser assimilada. Você acha que esse aspecto é importante dentro do contexto da sua equipe?

R: Sim, é bem importante porque se as pessoas não entenderem elas não irão usar a informação [compreensão de informações]. Então para elas usarem, elas tem que entender e tem que estar de uma forma clara [clareza das informações]. Então não adianta você colocar um número sendo que a pessoa não vai saber o que significa esse número, por exemplo: "Satisfação é 3", e daí sabe [significado de informações]? Então a facilidade de assimilação está relacionada com isso [facilidade de assimilação], se é um gráfico de tempo, então o número faz sentido, mas se é um gráfico de humor, um número não vai fazer sentido - ai faz sentido uma "carinha"[forma de representação de informações]. Acho que quanto mais fácil é de você assimilar informação, mais fácil você vai processar [compreensão de informações] e mais fácil você vai querer manter essa informação [informação contínuamente útil]. Então de novo, juntando tudo, se você não assimila, você não vai manter aquele gráfico [informação contínuamente útil].

M2: Vejo a relação entre a [facilidade de assimilação] e a [compreensão de informações], e deve ser realizada visando a [clareza das informações], o [significado de informações] e o [forma de representação de informações], o que facilita para uma [informação contínuamente útil].

\section{Pareamento nas tarefas de acompanhamento ágil}

Não realizado na equipe...

\section{Praticidade de manipulação de quadros e(ou) cartazes}

P: Você considera que é importante que seja prática essa manipulação de quadros/cartazes dentro do contexto da sua equipe?

R: É bem importante sim, porque quando tem um computador na frente do seu gráfico, que você tem que ficar se "espremendo", você atualiza esse gráfico uma vez só [restrições no espaço de trabalho]. Se seu gráfico está no kanban (quadro branco) e é só você levantar e mexer você vai atualizá-lo várias vezes durante o dia [atualização constante]. E foi engraçado, porque a gente percebeu exatamente isso. No nosso kanban a gente tinha o nome da dupla que estava em cada tarefa, mas a gente só escrevia o nome com o canetão [forma de praticidade]. Isso era prático no começo, no stand-up, quando a gente definia as tarefas, era bem prático escrever com o canetão não tinha problema [praticidade em momentos específicos]. Mas depois se você trocasse de tarefa para uma outra história que estava acima no kanban, as vezes o nome ficava perdido lá embaixo e a tarefa de cima ficava sem nome [falta de atualização]. Então a gente não se tocava porque era importante essa informação, mas a gente não tinha se tocado até hoje - recentemente [falta de percepção]. Ai você sugeriu a gente colocar um post-it pequeno com o nome de cada um - que ai a pessoa vai lá e coloca e ela pode mexer facilmente com o post-it, é só desgrudar e colar [maneira mais prática]. Eu fiquei hoje o dia fora, e quando eu voltei o pessoal já tinha mudado as tarefas todas, e os nomes estavam do lado de cada tarefa, seguindo a tarefa [atualização corrente]. Então foi bem fácil bater o olho no kanban e descobrir quem está fazendo o que, aonde, quando [informação 
atualizada]. Então é bem importante sim a praticidade na manipulação. Se é mais fácil as pessoas mexem [atualização de informações], e torna-se mais útil [útilidade de informações].

M2: Vejo que o entrevistado relaciona o assunto tratado (praticidade na manipulação) com o contexto de sua equipe, a existência de [restrições do espaço de trabalho]. O entrevistado também trata a respeito do kanban, que no caso intepretamos com o quadro branco que possuía seu kanban (dado tanto ao contexto quanto ao observável em fotos), tendo em vista que seu grupo possuía [restrições no espaço de trabalho]. Tendo isso em vista, percebo que o entrevistado relaciona essas [restrições no espaço de trabalho] com a atualização constante. Vejo que o entrevistado cita uma alteração na forma de representar uma informação, no caso que pessoa estava vinculada a que tarefa, e afirma que com a [maneira mais prática] houve uma [atualização corrente]. Vejo também que o entrevistado relaciona possuir uma [atualização de informações] associada à [útilidade de informações].

\section{Remoção de quadros e(ou) cartazes com pouco valor}

P: Você acha que é importante a remoção de quadros/cartazes que com o passar do tempo a equipe considera que se tornaram de menor valor dentro do contexto da sua equipe?

R: Eu acho que sim, porque se alguma coisa não está tendo valor para você, e você não está usando, você não irá atualizá-la e ela se tornará cada vez mais inútil [utilidade de informações]. Se você a remove, é uma coisa a menos para você ficar lembrando: "Nossa, tem aquele cartaz lá, não quero mexer nele, mas tem aquele cartaz"[incômodo pela presença de informações]. Então fica martelando na sua cabeça, mesmo que não mexa e fale: "Não vou mais mexer", Ele estará lá, te atrapalhando a visão, poluindo a área de tracking [foco restrito]. Então a gente removeu o humorômetro, porque para a gente não fazia muito sentido, e foi bastante legal porque o pessoal parou de se preocupa R: "Ah, tem que encher o quadro lá com a carinha de hoje, po, que saco"[remoção de preocupações]. Então é importante sim remover as informações inúteis.

M2: Vejo que o entrevistado primeiramente discute a existência de informações com a [utilidade de informações]. Também vejo [incômodo pela presença de informações] ao ele indicar o "é uma coisa a menos pra você ficar lembrando". Vejo que essa questão apontada como "fica atrapalhando a visão"pode ser resumida pelo [foco restrito] que as pessoas possuem. Vejo que remover quadros também pode resultar na [remoção de preocupações].

\section{A.6 Coach 2 - Equipe: Mezuro}

\section{Proximidade de quadros e cartazes no local da reunião diária}

P: Você considera que é útil a proximidade de quadros e cartazes no local da reunião diária?

R: Sim, inicialmente a gente estava fazendo nosso stand-up meeting todos emparelhados [restrições do espaço de trabalho]. Foi realizada uma sugestão sua, que a gente aderiu, e trouxe benefícios [mudança de layout físico]. Porque quando a gente levava o quadro lá na frente todo mundo ficava à frente do quadro [proximidade de quadros na reunião diária] todo mundo tinha noção sobre o projeto [percepção da situação]. Então foi interessante ter essa proximidade sim [interessante].

M1: O coach está se referindo a uma sugestão realizada durante a fase 1 da pesquisa que consistia em colocar as informações mais relevantes no quadro branco, pois a equipe possuía um local restrito onde disponibilizava os quadros e a equipe não cabia inteiramente nesse local. Esta sugestão foi avaliada como positiva pois o quadro branco era móvel e a mesma realizava sua reunião diária em um local separado, onde poderia levar este quadro. Vejo que quando o coach se refere a "noção sobre o projeto", ele está se referindo à percepção que os integrantes possuem sobre o projeto.

M2: O que me chama atenção neste trecho é que o entrevistado aponta o mesmo ponto que outro entrevistado da equipe mezuro, que é a questão de [restrições do espaço de trabalho], que pode acarretar em [mudança do layout físico] para a reunião (ver memorando M1), o que também indica que isso pesou bastante nesta equipe com relação à este assunto. Após isto, o entrevistado 
indica que a [proximidade de quadros na reunião diária] pode auxiliar na [percepção da situação] pelos integrantes. P: Como você reflete sobre essa questão da proximidade dos quadros da reunião diária? Que aspectos você acha que estão relacionados com isto, por que você considera que isso é útil? Se quiser complementar...

R: Acho que é isso mesmo, acho que a idéia de você ter o seu quadro próximo durante a reunião [proximidade de quadros na reunião diária], ele agrega durante a reunião [agrega durante reunião "in vivo"]. E quando a gente estava naquela outra disposição que todo mundo ficava emparelhado, um ao lado do outro [restrições do espaço de trabalho], tinha gente que não ouvia ou não olhava para o quadro e acabava desconsiderando informações úteis [negação -> considerar informações].

M2: Considero que o entrevistado está vinculando a idéia de manter quadros próximos à reunião, e o fato deste quadro [agregar durante a reunião]. Apesar do entrevistado relacionar a desconsideração de informações úteis à situação antiga da equipe, conceituada como [restrições do espaço de trabalho] e explicitada no memorando M1 correspondente à pergunta anterior, vejo que ele está se referindo nessa sentença ao fato de que nesta situação os quadros estavam longe do espaço de trabalho, portanto vejo que é um vínculo ao conceito [proximidade de quadros na reunião diária] e não ao conceito [restrições do espaço de trabalho].

\section{Coletividade no acompanhamento ágil}

R: Inicialmente a gente acatou a decisão de cada semana a gente definia quem seria o tracker da semana [tracker solo]. Com o tempo a gente foi vendo que era pró-ativo da equipe [interesse coletivo na manipulação]. Quando chegava no final da semana ou as vezes até na terça mesmo a gente já fazia a atualização e nós como coaches nem sabíamos que isso era feito [acompanhamento auto-gerenciável]. Ficou tão assim.. natural, e já fazia parte do processo, ficou uma coisa natural [naturalidade no processo]. Então já a gente não tinha um esquema mais, eles trouxeram essa responsabilidade para si [interesse coletivo na manipulação] sempre que eles olhavam que não estava atualizado eles iam lá e atualizavam [atualizações instantâneas].

M2: Vejo que aqui também se enquadra o [interesse coletivo na manipulação] da equipe Mezuro, que tornou o [acompanhamento auto-gerenciável] na equipe e que usufruiu de uma [naturalidade no processo]. Também vejo a relação entre [interesse coletivo na manipulação] e [atualizações instantâneas] em uma equipe com essas características. P: Você considera que foi útil essa coletividade dentro do contexto?

R: Com certeza, acho que sim. P: Você consegue pensar em aspectos que justificam ou aspectos que estão relacionados com a utilidade dessa questão?

R: Acho que o que justifica foi o comprometimento da equipe, acho que foi o que mais pesou [interesse coletivo na manipulação], e ai a motivação em realmente estar até o final tentando satisfazer o cliente [satisfação do cliente]. Inicialmente o nosso quadro de tracking a gente realmente ficou meio em dúvida [dúvida no tracking]. Mas quando a gente realmente chegou em um consenso [reflexão coletiva], mais no meio do projeto, a gente chegou à conclusão que do jeito como a gente estava fazendo, se a gente só melhorasse em alguns pontos ele ficava perfeito [melhoria do acompanhamento]. Realmente hoje a gente tem um burn-up que mostra pra gente todo o histórico do projeto, então a gente tem uma noção de como a gente começou, como a gente evoluiu e onde nós estamos hoje [informação contínuamente útil]. Ele conta uma história o nosso burn-up. Acho que isso facilitou.

M2: Apesar do entrevistado se referir explicitamente ao comprometimento da equipe, considero que ela esteja se referindo ao interesse da equipe em realizar o acompanhamento ágil como "grupo". Não entendo a relação da coletividade no acompanhamento com a [satisfação do cliente], começo a duvidar se a pergunta foi bem compreendida. Creio que as afirmações posteriores estão se referindo ao acompanhamento ágil como um todo, e não à coletividade no acompanhamento em si. 


\section{Acompanhamento ágil para tratamento de problemas específicos}

Sim, considero útil. Realmente é muito interessante utilizar [interessante], porque são informações que ficam visíveis para a equipe e a equipe começa a se sentir, por exemplo, quando tem um resultado que não é muito satisfatório [percepção da situação] a equipe tenta correr atrás e tentar resolver aquilo ali [trabalho direcionado]. Enquanto tiver aquela informação lá no quadro, ela fica como se fosse um calo da equipe, ai a equipe vai lá e tenta resolver [incômodo pela presença de informações]. É sempre bom, sempre que a gente tem algo que está com problema a gente tenta mostrar isso de alguma forma, ou no kanban, ou tentar criar um gráfico, ou algum outro cartaz [aprovação -> tratamento de problemas].

M2: Vejo que a categoria pode ser associada à [percepção da situação] pela equipe, e ela gera um [incômodo pela presença de informações] com relação à algum aspecto do desenvolvimento, levando ao [trabalho direcionado].

\section{Facilidade de assimilação dos quadros e(ou) cartazes}

Sim, com certeza, isso realmente faz parte de toda a concepção de XP, de fato isso é muito importante para a equipe fazer distinção [separação cognitiva de informações], visualização, ter uma visibilidade em relação às informações - acho que tranquilo isso ai.

M2: Não vejo muito conteúdo nesta sentença, mas de fato a [separação cognitiva de informações] é uma relação clara com o tema de facilidade de assimilação.

\section{Pareamento nas tarefas de acompanhamento ágil}

(Não aplicado....) Não se aplicou à nós porque a gente iniciou definindo uma pessoa para fazer o tracking e com o passar o tempo isso praticamente já não foi mais feito e ai a própria equipe foi fazendo a atualização. Algumas vezes foi feito em conjunto, mas outras vezes não - o próprio integrante da equipe foi lá e fez a atualização.

M2: Equipe mezuro não aplicou pareamento.

\section{Praticidade de manipulação de quadros e(ou) cartazes}

Eu acredito que o que realmente levou a equipe a ter essa pró-atividade em relação à atualização dos quadros [incentivo à manipulação] é que justamente eles eram muito práticos [informações práticas de se atualizar]. Ele estava muito simples, muito prático, e ai era só chegar e atualizar sem grandes problemas [praticidade na manipulação]. Então, a praticidade foi um ponto chave pra fazer uma atualização mais simplificada e que não dependesse de uma pessoa específica [coletividade na manipulação] - todo mundo conheceu aquela informação, todo mundo conseguia tocar.

M2:Vejo que o entrevistado basicamente se referiu a duas relações, uma enfocando o [incentivo à manipulação] gerado por [informações práticas de se atualizar], e outra indicando que a [praticidade na manipulação] influenciou na [coletividade na manipulação].

\section{Remoção de quadros e(ou) cartazes com pouco valor}

$\mathrm{R}$ : A gente chegou a praticar isso em alguns quadros, a gente inicialmente tinha feito alguns quadros de motivação da equipe e ai com o tempo a gente foi vendo que tava todo mundo muito integrado, não precisava mais daquele quadro [informações fora do contexto]. Quando alguém tinha algum aborrecimento em relação ao projeto, a própria pessoa já se expressava na equipe, não tinha porque a gente colocar lá (quadro), pois quando a gente colocava essa informação ao final da aula, e ai a pessoa só ia saber na outra semana ou na próxima aula e ia perguntar porque a pessoa tinha se sentido triste/desmotivada com alguma coisa [utilidade de informações]. Então que a gente acabou por tomar uma postura de todo mundo estar integrado tipo, no stand-up meeting, todo mundo trabalhar essa questão de repassar para a equipe informações referentes ao projeto [comunicação fluida]. ai a gente removeu este quadro. Ai a gente colocou um outro quadro no lugar desse, que 
seria uma visão da retrospectiva, o que a gente teve de top do que foi bom, de ponto positivo e o que foi top, de ponto negativo que a gente realmente tem que correr atrás para resolver [substituição de informações]. Esse último quadro valia muito mais a pena a gente manter ele do que o outro de motivação já que a equipe já estava bem integrada e conseguia ter essa informação da motivação [utilidade de informações].

M2: Vejo a tradicional relação entre [utilidade de informações], [informações fora de contexto] e a [remoção de informações]. Vejo que uma informação disposta pode ser desnecessária em cenários de [comunicação fluida], e que remoção pode promover uma [substituição de informações]. 


\section{Referências Bibliográficas}

Basili et al.(1994) Victor Basili, Gianluigi Caldiera e H Dieter Rombach. The goal question metric approach. Em Encyclopedia of Software Engineering. John Wiley and Sons Inc. Citado na pág. 11, $13,14,67$

Beck(1999) Kent Beck. Extreme Programming Explained - Embrace Change. Addison-Wesley. Citado na pág. iii, v, 1, 2, 7, 8, 11, 12, 18, 19, 24, 31, 33, 67, 70, 73

Beck e Andres(2006) Kent Beck e Cyntia Andres. Extreme Programming Explained 2 ed. Addison-Wesley. Citado na pág. iii, v, 1, 7, 8, 17, 18, 19, 20, 21, 23, 24, 31, 67, 73

Beck et al.(2001a) Kent Beck, Mike Beedle, Arie van Bennekum, Alistair Cockburn, Ward Cunningham, Martin Fowler, James Grenning, Jim Highsmith, Andrew Hunt, Ron Jeffries, Jon Kern, Brian Marick, Robert C. Martin, Steve Mellor, Ken Schwaber, Jeff Sutherland e Dave Thomas. Manifesto for agile software development, 2001a. URL http://www.agilemanifesto.org/. Citado na pág. $1,6,19$

Beck et al.(2001b) Kent Beck, Mike Beedle, Arie van Bennekum, Alistair Cockburn, Ward Cunningham, Martin Fowler, James Grenning, Jim Highsmith, Andrew Hunt, Ron Jeffries, Jon Kern, Brian Marick, Robert C. Martin, Steve Mellor, Ken Schwaber, Jeff Sutherland e Dave Thomas. Principles behind the agile manifesto, 2001b. URL http://agilemanifesto.org/principles.html. Citado na pág. 5, 6, 15, 24

Beedle et al.(2000) Mike Beedle, Martine Devos, Yonat Sharon, Ken Schwaber e Jeff Sutherland. Scrum: An extension pattern language for hyperproductive software development. Pattern Languages of Software Design 4. Citado na pág. 5, 10, 17, 19, 21, 22

Blandford e Furniss(2005) Ann Blandford e Dominic Furniss. Dicot: A methodology for applying distributed, cognition to the design of teamworking systems. 12th International Workshop, DSVIS 2005. Citado na pág. 20, 21, 23, 67

Cockburn(2002) Alistair Cockburn. Agile Software Development. Addison-Wesley. Citado na pág. 5,12

Cockburn(2005) Alistair Cockburn. Crystal Clear A Human-Powered Methodology for Small Teams. Addison-Wesley. Citado na pág. iii, v, 1, 2, 7, 8, 11, 18, 20, 23, 31, 67, 69, 73

Creswell(2009) J.W. Creswell. Research design: qualitative, quantitative, and mixed methods approaches. Sage Publications. ISBN 9781412965576. URL http://books.google.com.br/books? id=bttwENORfhgC. Citado na pág. iii, v, 29, 30, 35, 73

de Oliveira Netto(2005) Alvim Antônio de Oliveira Netto. Metodologia da Pesquisa Científica. Visual Books. Citado na pág. 25

Gauch(2003) Hugh Gauch. Scientific Method in Practice. Cambridge University Press. URL http://catdir.loc.gov/catdir/samples/cam033/2002022271.pdf. Citado na pág. 25 
Hartmann e Dymond(2006) Deborah Hartmann e Robin Dymond. Appropriate agile measurement: Using metrics and diagnostics to deliver business value. Agile 2006. Citado na pág. iii, v, 11, $12,14,15,16,23,24,31,67$

Highsmith(1999) James Highsmith. Adaptative Software Development. Dorset House Publishing. Citado na pág. 19, 22, 23

Hollan et al.(2000) James Hollan, Edwin Hutchins e David Kirsh. Distributed cognition: Toward a new foundation for human-computer interaction research. ACM Transactions on ComputerHuman Interaction (TOCHI). Citado na pág. 22

Hunt e Hume(2007) Johanna Hunt e Tom Hume. On rabbits, space and cards: Moving towards an informative workspace. Agile 200\%. Citado na pág. 18, 73

Johnson e Onwuegbuzie(2004) R. Burke Johnson e Anthony J. Onwuegbuzie. Mixed Methods Research: A Research Paradigm Whose Time Has Come. Educational Researcher, 33(7):1426. ISSN 0013-189X. doi: 10.3102/0013189X033007014. URL http://dx.doi.org/10.3102/ 0013189X033007014. Citado na pág. 74

Kua(2007) Patrick Kua. Reface your team space. http://www.thekua.com/atwork/ presentations-and-papers/reface-your-team-space/, 2007. Citado na pág. ix, 23

Mateos-Garcia e Sapsed(2008) Juan Mateos-Garcia e Jonathan Sapsed. Adopting agile and scrum practices as organisational becoming: Cases from the uk video games industry. British Academy of Management Annual Conference. Citado na pág. 21

O'Brien(2001) Rory O'Brien. An overview of the methodological approach of action research. Theory and Practice of Action Research. Citado na pág. ix, 26, 27, 37, 38

Poppendieck e Poppendieck(2007) Mary Poppendieck e Tom Poppendieck. Lean Software Development. Addison-Wesley. Citado na pág. iii, v, 1, 2, 7, 8, 9, 10, 11, 12, 14, 15, 17, 18, 19, 21, $22,31,67,73$

Sato(2007) Danilo Sato. Uso eficaz de métricas em métodos ágeis de desenvolvimento de software. Dissertação de Mestrado, Universidade de São Paulo. Citado na pág. 11, 20

Schwaber(2008) Ken Schwaber. What is scrum?, 2008. URL http://pages.cpsc.ucalgary.ca/ sillito/seng-301/lecture-notes/what-is-scrum.pdf. Citado na pág. iii, v, 1, 7, 10, 12, 20, 22, 23, 31

Scott(2009) Helen Scott. What is grounded theory?, 2009. URL http://www. groundedtheoryonline.com/what-is-grounded-theory. Citado na pág. 25, 26

Sharp et al.(2006) Helen Sharp, Hugh Robinson, Judith Segal e Dominic Furniss. The Role of Story Cards and the Wall in XP teams: A Distributed Cognition Perspective. AGILE Conference, 0:65-75. URL http://dx.doi.org/10.1109/AGILE.2006.56. Citado na pág. 2, 74, 75

Sharp et al.(2009) Helen Sharp, Hugh Robinson e Marian Petre. The role of physical artefacts in agile software development: Two complementary perspectives. Interacting with Computers, 21 (1-2):108 - 116. ISSN 0953-5438. doi: 10.1016/j.intcom.2008.10.006. Citado na pág. 67, 69

Shore e Warden(2008) J. Shore e S. Warden. The art of agile development. Theory in practice. O'Reilly. ISBN 9780596527679. URL http://books.google.com/books?id=g_ji7cRb--UC. Citado na pág. 1

Silva e Menezes(2001) Edna Silva e Estera Menezes. Metotologia da pesquisa e elaboração de dissertação, 2001. URL http://www.portaldeconhecimentos.org.br/index.php/eng/content/ download/12566/125574/file/024_Metodologia\%20de\%20pesquisa\%20e\%20elaboracao\%20de\% 20teses\%20e\%20dissertacoes.pdf. Citado na pág. 25, 26, 37 
Straub(2009) Pablo Straub. Sample burndown chart. http://en.wikipedia.org/wiki/File: SampleBurndownChart.png, 2009. Citado na pág. ix, 10

Strauss e Corbin(2008) A.L. Strauss e J.M. Corbin. Pesquisa Qualitativa: Técnicas e procedimentos para o desenvolvimento da teoria fundamentada. Sage Publications. ISBN 9780803959392. Citado na pág. iii, v, 3, 27, 28, 53, 54, 73

Swaine(2008) Michael Swaine. Is your workspace informative? what does your workspace says about you? Dr. Dobb's Journal, January ed. Citado na pág. 8, 18

Thiollent(2004) M. Thiollent. Metodologia da Pesquisa-Ação. CORTEZ. ISBN 8524900296. Citado na pág. iii, v, $3,26,27,36,38$

Urquhart et al.(2009) Cathy Urquhart, Hans Lehmann e Michael D Myers. Putting the 'theory' back into grounded theory: guidelines for grounded theory studies in information systems. Information Systems Journal, 20(4):357-381. URL http://blackwell-synergy.com/doi/abs/10.1111/j. 1365-2575.2009.00328.x. Citado na pág. 27, 28, 53

Williams e Cockburn(2003) L. Williams e A. Cockburn. Agile software development: it's about feedback and change. Computer, 36(6):39-43. URL http://dx.doi.org/10.1109/MC.2003.1204373. Citado na pág. 5 